$$
\begin{gathered}
\text { UNIVERSIDADE DE SÃO PAULO } \\
\text { ESCOLA DE COMUNICAÇÕES E ARTES } \\
\text { PROGRAMA DE PÓS-GRADUAÇÃO EM MÚSICA }
\end{gathered}
$$

\author{
DISSERTAÇÃO DE MESTRADO
}

MICAEL ANTUNES DA SILVA

\begin{abstract}
REDUÇÃO DA DISSONÂNCIA SENSORIAL EM UMA ESCALA TEMPERADA UTILIZANDO TIMBRES INARMÔNICOS: UMA ABORDAGEM EXPERIMENTAL E APLICAÇÕES ARTÍSTICAS
\end{abstract}




\author{
UNIVERSIDADE DE SÃO PAULO \\ ESCOLA DE COMUNICAÇÕES E ARTES \\ PROGRAMA DE PÓS-GRADUAÇÃO EM MÚSICA
}

DISSERTAÇÃO DE MESTRADO

MICAEL ANTUNES DA SILVA

\title{
REDUÇÃO DA DISSONÂNCIA SENSORIAL EM UMA ESCALA TEMPERADA UTILIZANDO TIMBRES INARMÔNICOS: UMA ABORDAGEM EXPERIMENTAL E APLICAÇÕES ARTÍSTICAS
}

\author{
Dissertação apresentada ao Programa de \\ Pós-Graduação em Música da Escola de \\ Comunicações e Artes da Universidade de \\ São Paulo para obtenção do título de Mestre \\ em Música. \\ Área de Concentração: Processos de Criação \\ Musical \\ Orientador: Prof. Dr. Regis Rossi Alves Faria
}


Autorizo a reprodução e divulgação total ou parcial deste trabalho, por qualquer meio convencional ou eletrônico, para fins de estudo e pesquisa, desde que citada a fonte.

Catalogação na Publicação

Serviço de Biblioteca e Documentação

Escola de Comunicações e Artes da Universidade de São Paulo Dados inseridos pelo(a) autor(a)

Silva, Micael Antunes da

Redução da Dissonância Sensorial em uma Escala Temperada com Timbres Inarmônicos: Uma Abordagem Experimental e Aplicaçōes Artísticas / Micael Antunes da Silva ; orientador, Regis Rossi Alves Faria. -- São Paulo, 2018.

97 p.: il.

Dissertação (Mestrado) - Programa de Pós-Graduação em Música

- Escola de Comunicaçōes e Artes / Universidade de São Paulo. Bibliografia

Versão original

1. psicoacústica 2 . dissonância sensorial 3. temperamento musical 4. timbre inarmônico 5. afinaçāo de instrumentos musicais I. Faria, Regis Rossi Alves II. Título.

CDD 21.ed. - 780

Elaborado por Sarah Lorenzon Ferreira - CRB-8/6888 


\section{Dedicatória}

Aos meus pais.

A todos os periféricos que ousam fazer Arte e Ciência, mesmo não sendo convidados. 


\section{AGRADECIMENTOS}

Gostaria de estender os meus agradecimentos a todos os que participaram desse processo importante de nossa carreira acadêmica, que é a escrita de um trabalho de mestrado. Primeiramente à minha mãe, Mara Aparecida, cujo apoio foi sempre fundamental em minha formação, à minha irmã, Priscila Antunes, que sempre acompanhou com entusiasmo todo o processo, e minha namorada, Ana Carolina Pascott, companheira contínua das alegrias e agonias de um mestrado. Ao Prof. Régis Rossi, cuja orientação criteriosa e acompanhamento contínuo foram fundamentais para o sucesso deste trabalho. À professora Adriana Lopes, minha supervisora do estágio PAE, cuja organização, seriedade e talento servirão de

exemplo para toda a minha carreira. À Rebeca Bayeh pelas ajudas em grupos de estudos e sua colaboração em duas publicações durante a pesquisa, além de seus incentivos durante as fases difíceis da pós-graduação. Ao Guilherme Feulo pelas reuniões semanais de computação e matemática, imprescindíveis para que eu pudesse dar conta do caráter interdisciplinar desta pesquisa. A Paulo Assis por sempre emprestar os ouvidos de engenheiro de áudio e os comentários pertinentes. Ao Fabrizio Veloso Rodrigues, do ICB-USP e Pedro Paulo da ECA-USP que ajudaram com suas experiências nos primeiros desenhos do teste subjetivo, e aos companheiros João Monazzi, Augusto Ruy e Matheus Mafra, que foram os voluntários no teste piloto e ajudaram com seus apontamentos. Aos professores Jônatas Manzolli e Silvio Ferraz pela leitura atenta e generosidade na banca de qualificação.

Aos laboratórios e núcleos cuja infraestrutura e pessoal deram suporte à nossa pesquisa, sendo eles: Núcleo de Engenharia de Áudio (NEAC-LSI-USP); Laboratório de Acústica e Acústica Musical (LATM-FFCHLRP); Ao Laboratório de Acústica Musical e Informática (LAMI-ECA-USP). Estes três laboratórios forneceram o espaço físico necessário para a realização dos testes subjetivos. Ao Núcleo de Sonologia da USP (NuSom) e Grupo de Computação Musical (IME-USP), cujos membros foram companhias contínuas durante o mestrado.

Agradeço ao apoio financeiro, fundamental para a realização desta pesquisa, concedido no processo n.. 2016/09525-7, pela Fundação de Amparo à Pesquisa do Estado de São Paulo (FAPESP) e Coordenação de Aperfeiçoamento de Pessoal de Nível Superior (CAPES). 


\section{RESUMO}

A dissonância sensorial é um conceito que restringe a noção da dissonância à sua dimensão psicofísica, por meio do fenômeno psicoacústico conhecido como rugosidade. Esse conceito foi explorado neste trabalho experimentalmente tendo como foco o teste da hipótese de que é possível modelar a dissonância sensorial em escalas do temperamento por igual utilizando-se timbres inarmônicos. A dissertação é dividida em 5 partes. No capítulo 2, realiza-se uma revisão bibliográfica compilando os principais modelos de dissonância sensorial baseados em estudos experimentais, e uma revisão do sistema de afinação conhecido como temperamento por igual. No capítulo 3 apresenta-se uma proposta de síntese de espectros inarmônicos que modelam a dissonância para o temperamento por igual. Em seguida, apresenta-se um teste subjetivo realizado que avaliou a dissonância sensorial em espectros construídos com dissonância modelada para uma escala temperada de 8 partes iguais. No capítulo 4, são apresentadas aplicações artísticas realizadas, consequentes do estudo da modelagem da dissonância sensorial em escalas do temperamento por igual, como uma proposta de mapeamento de escalas em um teclado MIDI e dois relatos composicionais. Discussões acerca dos resultados e apontamentos para trabalhos futuros são abordados no capítulo final. Os resultados da pesquisa apontam para o fato de os modelos de dissonância sensorial estudados não serem suficientemente eficazes na tarefa de realizar uma avaliação precisa do fenômeno da dissonância sensorial em sons inarmônicos. Além disso, como resultado, abriram-se novas perspectivas para práticas artísticas com dissonância modelada, onde discutimos o impacto do uso dos modelos de dissonância na prática composicional e no contexto da música atual.

Palavras chaves: psicoacústica; dissonância sensorial; modelos de dissonância; temperamento por igual; sistemas de afinação; escalas musicais; 


\begin{abstract}
Sensory dissonance is a concept that restricts the dissonance to their psychophysical dimension, through the psychoacoustics phenomenon known as roughness. This concept was explored in this work experimentally, based on the assumption that it is possible to model the sensory dissonance in equal tempered scales, using inharmonic spectra. Our dissertation is divided into five parts. Firstly, on chapter 2, a literature review exposing the main models of sensory dissonance that are based on experimental studies is presented, as well as a revision of the equal tempered scale system. Secondly, the first part of Chapter 3 presents a method and an algorithm to synthetize inharmonic spectra that models the dissonance for equal tempered scales. Then, in the second part of chapter 3, we expose an experimental test that aims to evaluate the sensory dissonance on a spectrum generated to model the dissonance in a scale that divides the octave into 8 equal parts. On chapter 4, we propose artistic applications using the dissonance studies developed in this work, as well as a prototype of equal tempered scales controller using a MIDI keyboard and two compositional reports. Finally, the results of this research are shown in chapter 5 , that highlights the fact that the models of sensory dissonance approached in this dissertation are not effective to calculate a precise estimation of sensory dissonance in inharmonic spectra. Besides that, as a result, new perspectives for artistic practices using dissonance modeling are presented, as we discuss the impact of dissonance models in the context of composition and contemporary music.
\end{abstract}

Key words: psychoacoustics; sensorial dissonance; dissonance models; equal temperament; tuning systems; music scales; 


\section{LISTA DE FIGURAS}

Figura 1- Percepção de dissonância para um par de tons puros, nos 12 graus da escala temperada, com frequência inicial de 523,25 (Do4), segundo o modelo de Plomp e Levelt (1965). Plotada com Jupyter (2017).

Figura 2- Curva derivada dos testes subjetivos de Plomp e Levelt, fornecendo uma medida de consonância em função da banda crítica para dois tons puros. (PLOMP e LEVELT, 1965)

Figura 3- Díades executadas no experimento de Geary. Figura adaptada de GEARY (1980).

Figura 4- Resultado da escolha dos participantes para cada díade. Figura adaptada de

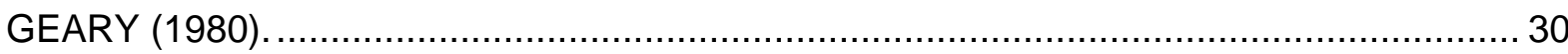

Figura 5- Disposição de uma escala maior em uma escala 17-tet..................................... 36

Figura 6- Fluxograma do algoritmo minimizador de dissonância em escalas do temperamento por igual. Os blocos retangulares correspondem a processos do algoritmo. Os trapezoidais correspondem a seleções devidas ao usuário. ......................................... 38

Figura 7- Exemplo da tela de Apresentação (primeira parte) do teste subjetivo. ................. 44

Figura 8- Exemplo da tela de Instrução sobre a fase de treino para o teste subjetivo. ........ 45

Figura 9- Pergunta do treino e do teste.................................................................. 46

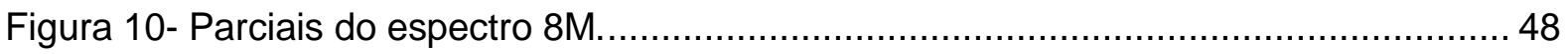

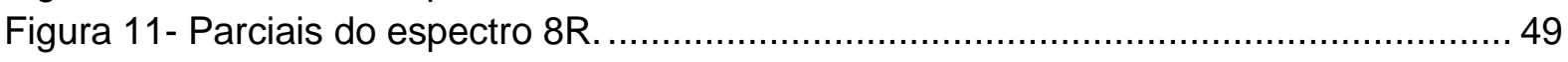

Figura 12- Comparação das curvas de dissonância esperadas segundo o modelo de Vassilakis com o espectro 8M (abaixo) e com o espectro 8R (acima) para uma escala 8-tet, com frequência inicial em $500 \mathrm{~Hz}$

Figura 13- Curva da diferença de dissonância esperada entre os timbres 8R e 8M na escala

8-tet, segundo o modelo de Vassilakis................................................................... 55

Figura 14- Tarefas para o cálculo de escalas n-tet para adaptação em um teclado MIDI... 61

Figura 15-- Tarefas de execução de escalas n-tet para adaptação em um teclado MIDI.... 62

Figura 16- Graus 0 da escala 5-tet marcados em vermelho no teclado. .............................63

Figura 17- Notas em comum (destacadas) das escalas do Grupo A. ................................ 64

Figura 18-Controle dos três módulos de escalas, mapeando-se notas do teclado para notas da escala 17-tet. Para os grupos A e B, 12 notas da escala 17-tet são alcançadas por

oitava. Para o grupo $C$, são mapeadas 11 notas por oitava............................................ 64

Figura 19- Sonograma da peça Kalimba Super Consonante, evidenciando na parte superior

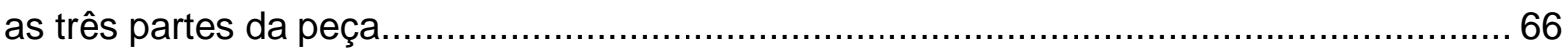

Figura 20- Envelope dinâmico A: Ataque $=118,6 \mathrm{~ms}$ : Sustentação $=2,97 \mathrm{~s}$; Release $=1,64 \mathrm{~s} .67$

Figura 21- Envelope dinâmico B: Ataque $=10 \mathrm{~ms}$ : Sustentação= $2,97 \mathrm{~s}$; Release $=1,64 \mathrm{~s} \ldots .67$

Figura 22- Sonograma da primeira apresentação do timbre com o envelope A, no início da

peça.

Figura 23- Sonograma da primeira apresentação do timbre com o envelope B, no início da

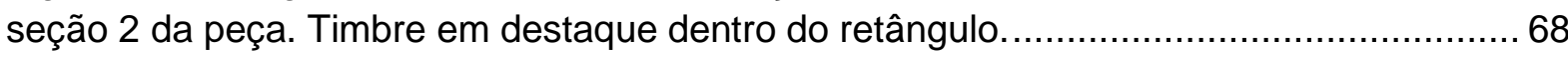

Figura 24- Sonograma apresentando a Introdução da Kalimba Super Consonante, expondo a primeira ideia musical da peça.

Figura 25- Sonograma da Primeira Parte da Kalimba Super Consonante, onde podemos observar o desenvolvimento da ideia apresentada na introdução da peça. .70 
Figura 26- Sonograma da Segunda Parte da Kalimba Super Consonante, onde podemos observar a introdução de uma nova ideia musical em primeiro plano, contrastada com camadas ora mais densas, ora mais rarefeitas em segundo plano.

Figura 27- Curva de dissonância para a escala 16-tet, utilizando o timbre $8 \mathrm{M}$, descrito no

tópico 3.1. As linhas pontilhadas reforçam a posição da máxima consonância.

Figura 28- Esquema da modulação cruzada utilizada na peça Asperezas, onde o oscilador da esquerda modula a fase da direita, e o oscilador da direita modula a frequência do oscilador da esquerda. Os valores de frequência e amplitude dos osciladores são apresentados nas tabelas de 4 a 6 .

Figura 29- Esquema dos processamentos sonoros utilizados na peça Asperezas. 73 Figura 30- Espectrograma da peça Asperezas, dividindo-a em 11 seções, correspondentes às frequências da tabela 4.3. 


\section{LISTA DE GRÁFICOS}

Gráfico 1- Resultados do experimento de Vassilakis comparados com os modelos de

Helmholtz, Hutchinson \& Knopoff e Vassilakis, plotado a partir dos valores da tabela 2. .... 28 Gráfico 2- Resultado do teste 1, em porcentagem, plotando os resultados para ambas as populações. 51

Gráfico 3- Resultado do teste 1, em porcentagem, plotando os resultados para a população músicos. 52

Gráfico 4- Resultado do teste 1, em porcentagem, plotando os resultados para a população de não músicos. 53

Gráfico 5- Diferença, em porcentagem, nos resultados entre Músicos e Não-Músicos para o

Teste 1 . 54

Gráfico 6- Pontuação (score) de dissonância para ambas as populações para o teste 2...56 Gráfico 7- Pontuação de dissonância para a população Músicos para o Teste 2................57 Gráfico 8- Pontuação de dissonância para a população de não-músicos para o Teste 2....58 Gráfico 9- Média das pontuações (scores) de dissonância para o teste 2, comparando ambas as populações, de músicos e não-músicos. ………………………………...... 59

Gráfico 10- Curva de dissonância estimada da peça Asperezas, de 0 a 60.000 ms. .......... 74 Gráfico 11- Curva de dissonância estimada da peça Asperezas, de 60.000 a 120.000 ms. 75 Gráfico 12- Curva de dissonância estimada para a peça Asperezas.

Gráfico 13- Comparação da pontuação de dissonância obtida no teste 2 para ambas as populações, curva experimental acima (em azul) versus a curva estimada segundo 0 modelo de Vassilakis, abaixo (em vermelho).

Gráfico 14- Comparação da pontuação de dissonância obtida no teste 2 para músicos, curva experimental acima (em azul) e curva estimada pelo modelo de Vassilakis, abaixo (em vermelho).

Gráfico 15- Comparação da pontuação de dissonância obtida no teste 2 para não-músicos, curva experimental acima (em azul) e curva do modelo de Vassilakis, abaixo (em vermelho). 


\section{LISTA DE TABELAS}

Tabela 1 - Atribuição de seis graus de consonância/dissonância aos intervalos de uma escala de 12 tons segundo três escolas de pensamento teórico, conforme Tenney (1988). $\mathrm{C}=$ Consonância; $\mathrm{C}-\mathrm{i}=$ Consonância Imperfeita; $\mathrm{C}-\mathrm{m}=$ Consonância média; $\mathrm{D}-\mathrm{m}=$ Dissonância média; D-i= Dissonância Imperfeita; $D=$ Dissonância.

Tabela 2- Resultados do experimento comparado dos modelos de Helmholtz, Hutchinson \& Knopoff e Vassilakis. Valores variam de 0 (máxima consonância) a 42 (máxima dissonância)

Tabela 3- Valores das faixas de frequência da Banda Crítica. (Zwicker, 1961) ................... 32

Tabela 4- Configurações da síntese utilizadas na composição Asperezas, tendo como ferramenta o sintetizador Helm (Tytel, 2016?).

Tabela 5- Configurações dos envelopes utilizadas na composição Asperezas, tendo como ferramenta o sintetizador Helm (Tytel, 2016?)

Tabela 6- Frequências dos osciladores utilizadas na composição Asperezas, tendo como ferramenta o sintetizador Helm.

Tabela 7- Correlação entre as curvas de dissonância obtida experimentalmente e a estimada pelo modelo de Vassilakis avaliadas em 2 segmentos (parte 1 e parte 2).

Tabela 8- Resutados, em porcentagens, para o teste 1, para ambas populações. ............. 89

Tabela 9- Resutados, em porcentagens, para o teste 1, para músicos. .............................90

Tabela 10- Resutados, em porcentagens, para o teste 1, para não-músicos. ..................... 90

Tabela 11- Resultados, em porcentagens, para o teste 2, para ambas populações............92

Tabela 12- Resutados, em porcentagens, para o teste 2, para músicos. ............................. 93

Tabela 13- Resutados, em porcentagens, para o teste 2, para não-músicos. ...................... 94

Tabela 14- Pontuação (Scores) de dissonância do Teste 2 para ambas populações.......... 95

Tabela 15- Pontuação (Scores) de dissonância do Teste 2 para população músicos. ........ 95

Tabela 16- Pontuação (Scores) de dissonância do Teste 2 para população não-músicos. . 95

Tabela 17- Médias das pontuações (scores) para ambas populações, músicos e não-

músicos 


\section{Sumário}

AGRADECIMENTOS

RESUMO $\quad 6$

$\begin{array}{ll}\text { ABSTRACT } & 7\end{array}$

LISTA DE FIGURAS

LISTA DE GRÁFICOS $\quad 10$

LISTA DE TABELAS 11

1. Introdução 14

2. Revisão Bibliográfica 16

2.1. Dissonância Sensorial 16

2.1.1. Concepções da dissonância na história da música segundo Tenney 16

2.1.2. Modelos de dissonância sensorial 19

2.1.2.1. Os alinhamentos harmônicos e a visão de Helmholtz 19

2.1.2.2. O modelo de Plomp e Levelt 20

2.1.2.3. O modelo de Hutchinson e Knopoff 22

2.1.2.4. O modelo de Sethares 22

2.1.2.5. A revisão de Vassilakis do modelo de Sethares 24

2.1.2.6. Avaliando o modelo de Vassilakis 26

2.1.2.7. Percepção da dissonância sensorial em sons inarmônicos 29

2.1.3. Banda Crítica e a formalização matemática de Traunmüller 31

2.2. O temperamento por igual 33

2.2.1. A organização do temperamento por igual na obra de Easley Blackwood

2.2.2. A matemática do temperamento por igual 35

2.2.3. Um exemplo de aproximação diatônica com a escala 17-tet 35

3. Modelagem da dissonância em timbres de espectros inarmônicos 37

3.1. Algoritmo gerador espectros reduzidos em dissonância 37

3.3. Validação da dissonância modelada por meio de teste subjetivo 42

3.3.1. Hipótese experimental 42

3.3.2. Método experimental $\quad 42$

3.3.3. Infra-estrutura experimental 43

3.3.4. Protocolo experimental 43

3.3.5. Estímulos sonoros do teste 47

3.4. Resultado das avaliações dos testes subjetivos 50

3.4.1. Teste 1 - Comparação de díades da escala 8-tet para timbres distintos 50

3.4.2. Teste 2 - Comparação de díades da escala 8-tet de mesmo timbre 56

4. Aplicações artísticas da dissonância modelada 60

4.1. Protótipo instrumental: duas propostas de mapeamento de escalas do temperamento por igual em um teclado MIDI 60

4.1.1 Uma proposta para a escala de 5 a 24 divisões 60

4.1.2. Uma proposta para a escala 17-tet 63 
4.2. Em processos composicionais: Relatos de processos criativos

4.2.1. Kalimba Super Consonante

4.3.2. Asperezas

5. Conclusões

5.1. Avaliação dos resultados dos testes subjetivos

5.2. Ferramentas, instrumentos e práticas criativas realizadas

5.3. Discussões finais e trabalhos futuros

Referências bibliográficas

Apêndice I: Dados dos Testes Subjetivos 


\section{Introdução}

A dissonância é um conceito musical vinculado à percepção do som e tem sido objeto de estudo de disciplinas musicais e de outras áreas do conhecimento (como psicofísica e neurociência) desde trabalhos antigos ligados à teoria pitagórica, passando pelos tratados teóricos de Zarlino e Rameau, e tendo como desdobramentos mais atuais as teorias de percepção contemporâneas, que têm como marco inicial o livro On the sensations of tone de Hermann von Helmholtz, o qual funda o conceito de dissonância sensorial.

O presente trabalho teve como objetivo central avaliar a percepção de dissonância em uma escala do temperamento por igual por meio de testes subjetivos, cujo espectro foi sintetizado com o objetivo de modelar a dissonância sensorial.

No capítulo 2 desta dissertação, realizamos uma revisão bibliográfica do estudo da dissonância sensorial, começando com a contextualização histórica realizada por Tenney (1988) e com os modelos desenvolvidos a partir da perspectiva sensorial, por Helmholtz (1875), Plomp e Levelt (1965), Hutchinson e Knopoff (1978), Sethares (1998) e Vassilakis (2001). Apresentamos também uma breve revisão do temperamento por igual tendo como principal referência o trabalho do compositor Easley Blackwood (1991) sobre esse assunto. Por fim, mostramos o conceito de banda crítica, tendo como referência Zwicker (1961) e a formalização matemática de Traunmüller (1990). Em todo o capítulo também foram explorados os modelos matemáticos relacionados a estes assuntos, e que são aplicados nos capítulos 3 e 4 .

No capítulo 3, apresentamos a contribuição central desta dissertação. Primeiramente, revelamos um algoritmo que modela a dissonância em escalas do temperamento por igual, construído a partir dos modelos de dissonância aqui expostos, e a partir dos trabalhos de Pierce (1966) e Sethares (1998). Para validação desse algoritmo, elaboramos e realizamos um teste subjetivo baseado no teste de comparação pareada em análise sensorial (NBR 13088 e Geary 1980). Os dados compilados dos testes também são apresentados neste capítulo.

No capítulo 4 são apresentadas duas propostas artísticas desenvolvidas durante essa pesquisa: um protótipo de controle para escalas do temperamento por igual a partir de um controlador MIDI e duas propostas composicionais baseadas na modelagem da dissonância sensorial. Essas propostas contribuem para um contexto de criação musical que tem o seu fundamento em modelos psicoacústicos. 
No capítulo 5, encontram-se as análises dos resultados dos testes, as discussões que avaliam o impacto das propostas artísticas aqui desenvolvidas em composição musical, bem como as conclusões e perspectivas abertas para trabalhos futuros. 


\section{Revisão Bibliográfica}

Neste capítulo apresentaremos a revisão bibliográfica. No tópico 2.1, focaremos primeiramente no conceito de Dissonância Sensorial e seus modelos, seguido da apresentação do conceito de banda crítica e sua formalização matemática, e no tópico 2.1 apresentaremos uma breve revisão do Sistema de afinação de Temperamento por Igual.

\subsection{Dissonância Sensorial}

Neste tópico apresentaremos primeiramente a abordagem de Tenney (1988) sobre a dissonância sensorial, com o intuito de contextualizar historicamente a concepção de dissonância sensorial, que será o foco deste trabalho. A partir daí, focaremos nos modelos de dissonância que compõe esta dissertação.

\subsubsection{Concepções da dissonância na história da música segundo Tenney}

O termo dissonância assume diversos significados na história da teoria e prática musical, dependendo do contexto em que se insere. Por isso, tomamos como referência o trabalho de Tenney ${ }^{1}$ (1988) que realiza um levantamento e discussão de possíveis usos do termo dissonância de uma maneira contextualizada na história da música. Para isso, ele se vale do termo Concepção de Consonância-Dissonância $(C C D)^{2}$, composto por 5 subdivisões, da seguinte forma:

- CCD1- Baseado na concepção Pitagórica

- CCD2- Derivado de uma conotação Polifônica

- CCD3- Proveniente de um contexto Contrapontístico

- CCD4- Resultante de uma acepção Harmônica

- CCD5- Originário de um conteúdo Psicofísico

A primeira concepção (CCD1) é melódica, baseada na razão dos intervalos da escala. Ligada à concepção Pitagórica de intervalo musical e ao pensamento teórico grego, essa concepção tem uma noção idealizada do intervalo musical, não levando em conta o fenômeno sonoro resultante dessa organização intervalar. Ilustrada na

\footnotetext{
1 James Tenney (1934-2006) foi um compositor e teórico americano, com significativas contribuições nas áreas de composição algorítmica, música microtonal e sistemas de afinação.

${ }^{2}$ Do termo em Inglês Consonance-Dissonance Concept (CDC), conforme Tenney (1998).
} 
tabela 1 a partir da concepção de dissonância do tratado Musica Enchiriadis ${ }^{3}$ (anônimo, séc IX), esta concepção elege a $4^{\text {a }}$ Justa, $5^{\text {a }}$ Justa e a $8^{\text {a }}$ Justa como intervalos consonantes.

A segunda concepção (CCD2) possui uma conotação polifônica. Para Tenney (1988), o início dessa concepção coincide com a polifonia no século IX e a noção de sonoridade, resultante da simultaneidade das díades. Como consequência de uma maior complexidade na prática da polifonia nos séculos $\mathrm{X}, \mathrm{XI}$ e XII, intervalos de terças e sextas foram admitidos como consonantes. Tenney cita como exemplo o teórico John of Garland (séc. XIII), autor de De Mensurabili Musica ${ }^{4}$, que classifica os intervalos musicais em graus de:

- Consonância perfeita (uníssono e oitava);

○ Consonância média (5ª e $4^{\text {a }}$ Justa);

○ Consonância imperfeita (3ª maior e menor);

○ Dissonância imperfeita (6 $6^{\underline{a}}$ maior e $7^{\text {a }}$ menor);

○ Dissonância média (6 $6^{\underline{a}}$ menor e $2^{\underline{a}}$ maior);

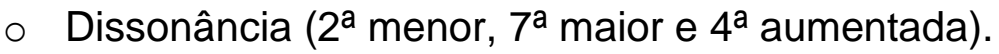

Esta classificação de dissonância de John of Garland é também ilustrada na tabela 1.

\begin{tabular}{|c|c|c|c|c|c|c|c|c|c|c|c|c|}
\hline & $8^{\mathrm{a}} \mathrm{J}$ & 5⿳亠口了 & 4 $\stackrel{\mathrm{a}}{\mathrm{J}}$ & $3^{\mathrm{a}} \mathrm{M}$ & $3^{\mathrm{a}} \mathrm{m}$ & 6⿳M & $6^{\mathrm{a}} \mathrm{m}$ & 2aㅗ & $7^{\mathrm{a}} \mathrm{m}$ & 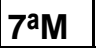 & $2^{a} \mathrm{~m}$ & Trítono \\
\hline $\begin{array}{l}\text { Musica (and Scholia) } \\
\text { Enchiriadis (anônimo, } \\
\text { séc. } 9-10 \text { ) }\end{array}$ & $\begin{array}{l}\text { C } \\
\text { ou } \\
\text { Cp }\end{array}$ & $\begin{array}{l}\text { C } \\
\text { ou } \\
\text { Cp }\end{array}$ & $\begin{array}{l}\text { C } \\
\text { ou } \\
\text { Cp }\end{array}$ & $\begin{array}{l}\text { D ou } \\
\text { Dp }\end{array}$ & $\begin{array}{l}\text { D ou } \\
\text { Dp }\end{array}$ & $\begin{array}{l}\text { D ou } \\
\text { Dp }\end{array}$ & $\begin{array}{l}\text { D ou } \\
\text { Dp }\end{array}$ & $\begin{array}{l}\text { D ou } \\
\text { Dp }\end{array}$ & $\begin{array}{l}\text { D ou } \\
\text { Dp }\end{array}$ & $\begin{array}{l}\text { D ou } \\
\text { Dp }\end{array}$ & $\begin{array}{l}\text { D ou } \\
\text { Dp }\end{array}$ & $\begin{array}{l}\text { D ou } \\
\text { Dp }\end{array}$ \\
\hline $\begin{array}{l}\text { De Mensurabili } \\
\text { Musica (1250) John of } \\
\text { Garland }\end{array}$ & $\begin{array}{l}\text { C } \\
\text { ou } \\
\text { Cp }\end{array}$ & $\mathrm{Cm}$ & $\mathrm{Cm}$ & $\mathrm{Ci}$ & $\mathrm{Ci}$ & Di & $\mathrm{Dm}$ & $\mathrm{Dm}$ & Di & $\begin{array}{l}\text { D ou } \\
\text { Dp }\end{array}$ & $\begin{array}{l}\text { D ou } \\
\text { Dp }\end{array}$ & $\begin{array}{l}\text { D ou } \\
\text { Dp } \\
\end{array}$ \\
\hline $\begin{array}{l}\text { Le Istitutioni } \\
\text { Harmoniche (1558), } \\
\text { Gioseffe Zarlino }\end{array}$ & $\begin{array}{l}\text { C } \\
\text { ou } \\
\text { Cp }\end{array}$ & $\begin{array}{l}\text { C } \\
\text { ou } \\
\text { Cp }\end{array}$ & $\begin{array}{l}\text { C } \\
\text { ou } \\
\text { Cp }\end{array}$ & $\mathrm{Ci}$ & $\mathrm{Ci}$ & $\mathrm{Ci}$ & $\mathrm{Ci}$ & $\begin{array}{l}\text { D ou } \\
\text { Dp }\end{array}$ & $\begin{array}{l}\text { D ou } \\
\text { Dp }\end{array}$ & $\begin{array}{l}\text { D ou } \\
\text { Dp }\end{array}$ & $\begin{array}{l}\text { D ou } \\
\text { Dp }\end{array}$ & $\begin{array}{l}\text { D ou } \\
\text { Dp }\end{array}$ \\
\hline
\end{tabular}

Tabela 1 - Atribuição de seis graus de consonância/dissonância aos intervalos de uma escala de 12 tons segundo três escolas de pensamento teórico, conforme Tenney (1988). C= Consonância; $\mathrm{C}-\mathrm{i}=$ Consonância Imperfeita; C-m= Consonância média; D-m= Dissonância média; D-i= Dissonância Imperfeita; D= Dissonância.

\footnotetext{
${ }^{3}$ Musica (and Scholia) Enchiriadis (anonymous, 9th-10th c.) é um tratado musical do século IX, e a ele é atribuída a primeira tentativa de sistematização da prática polifônica na música do Ocidente. (HOPPIN, 1978)

${ }^{4}$ De Mensurabili Musica é o primeiro tratado a teorizar sobre o ritmo e sua notação, além de trazer uma discussão teórica sobre a polifonia da escola de Notre Dame. (BALTZER, 2001)
} 
A terceira concepção (CCD3) possui uma conotação contrapontística. Esta concepção está relacionada com a prática do contraponto nos séculos XIII e XIV, criando novas regras e noções de consonância e dissonância, admitindo-as como ornamentos em tratamentos como apogiatura, notas de passagem, escapadas, entre outros procedimentos. Exemplo dessa classificação pode ser visto na tabela 1, referente ao tratado de Zarlino, em que só três graus são considerados (consonância perfeita, consonância imperfeita, e dissonância).

A quarta concepção (CCD4) possui uma conotação harmônica, ligada à dinâmica entre acordes, com o que ficou conhecido como harmonia funcional, uma das bases do pensamento harmônico de compositores como Koellreutter (1980). Esse conceito carrega a ideia de tonalidade, como suas dinâmicas de tensão e resolução, além das teorias ligadas à fundamental de acordes. Outro exemplo nesse contexto é o tratado de harmonia de Rameau (1722).

A quinta concepção (CCD5) possui uma conotação psicoacústica e está relacionada à ideia de dissonância sensorial, nosso foco de estudo. Considerando sua origem na teoria dos batimentos de Helmholtz (1875), seus refinamentos devidos a Plomp e Levelt (1965), e sua interdependência com os conceitos de banda crítica e rugosidade $^{5}$, o conceito de dissonância fica definitivamente atrelado a questões relacionadas à fisiologia do ouvido, e seus graus passaram a ser diferenciados para cada intervalo de frequências. Podemos observar na figura 1 um gráfico do nível de dissonância para os 13 intervalos da escala do temperamento por igual que divide a oitava em 12 partes.

\footnotetext{
5 Segundo a definição Vassilakis, a rugosidade é um fenômeno perceptivo decorrente das manifestações de interferência das ondas sonoras, e que é observado, por exemplo, quando dois tons puros estão em uma distância de cerca de $20 \mathrm{~Hz}$ até o final da banda crítica. (VASSILAKIS, 2001, p.24-25)
} 


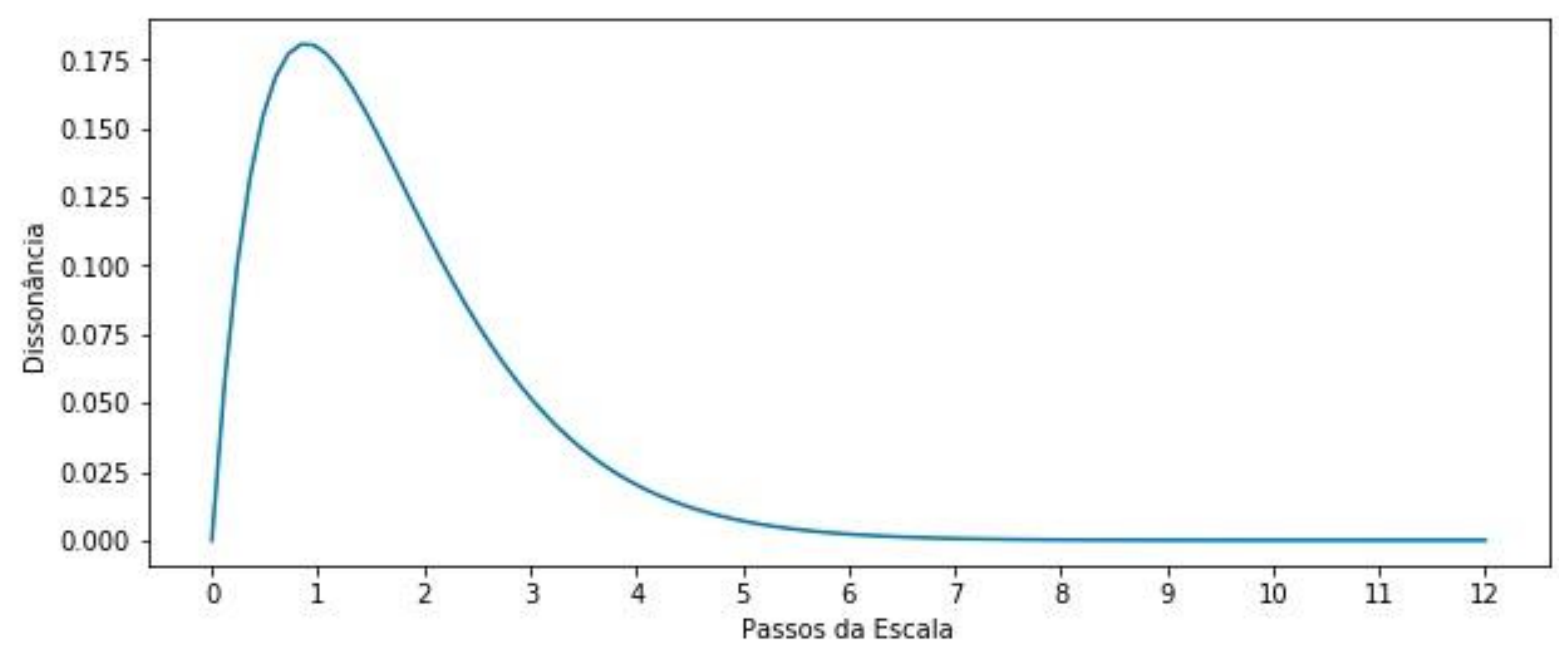

Figura 1- Percepção de dissonância para um par de tons puros, nos 12 graus da escala temperada, com frequência inicial de 523,25 (Do4), segundo o modelo de Plomp e Levelt (1965). Plotada com Jupyter (2017).

A partir dessa contextualização histórica, podemos perceber que o fenômeno da rugosidade não é a dissonância em si, mas desempenha um papel fundamental na sua construção cultural, no caso da música ocidental. Tendo isso em perspectiva, delimitamos o conceito de dissonância em nossa dissertação à dissonância sensorial, focando apenas em modelos que levam em conta a fisiologia do ouvido, e não em questões culturais ou estéticas.

\subsubsection{Modelos de dissonância sensorial}

As seções a seguir abordam os modelos, conceitos e experimentos pertencentes ao estudo da dissonância sensorial que foram selecionados nesta pesquisa com base em sua relevância reconhecida para a área.

\subsubsection{Os alinhamentos harmônicos e a visão de Helmholtz}

A contribuição precursora de Helmholtz 6 no século 19 para a concepção de dissonância sensorial baseia-se em pontos que julgamos fundamentais e que foram desenvolvidos posteriormente por outros pesquisadores. Primeiramente, 0 reconhecimento de que a sensação de dissonância está relacionada com a distância entre os parciais de um som e o estímulo sensorial resultante dessa relação. Como consequência disto, temos a compreensão de que o nível de dissonância está ligado

\footnotetext{
${ }^{6}$ Hermann von Helmholtz (1821-1894) foi matemático, médico e físico alemão, e focou parte de suas pesquisas na percepção humana (visual, espacial e sonora), tendo fundamental importância na música seu livro On the sensations of tone: As a physiological basis for the theory of music de 1875 .
} 
ao timbre, e que, portanto, a sensação de dissonância pode ser examinada caso a caso, e não com tabelas generalizantes, como no caso dos tratados de harmonia. Por exemplo, isso permitiu observar pela primeira vez que a sensação de dissonância de um acorde tocado ao piano difere da sensação de dissonância do mesmo acorde tocado em um grupo de clarinetes, por conta da diferença de conteúdo espectral e envelopes dinâmicos. Isso abriu caminho para a primeira tentativa de medir a dissonância utilizando-se uma escala objetiva de frequências. Assim, a partir da teoria de Helmholtz, a estimativa da dissonância não deveria ser baseada unicamente na relação intervalar, mas sim, estudando-a caso a caso, tendo como referência a análise dos espectros sonoros.

No modelo de Helmholtz a dissonância ocorreria quando a diferença nas frequências de um par de parciais do som contivesse uma relação de mais ou menos $40 \mathrm{~Hz}$ (HELMHOLTZ, 1875). No entanto, essa noção foi progressivamente substituída a partir de trabalhos que tinham como base testes subjetivos. Esses trabalhos e seus modelos são apresentados a seguir.

\subsubsection{O modelo de Plomp e Levelt}

Uma segunda contribuição substancial encontra-se no trabalho de Plomp e Levelt (1965) já de influência histórica na literatura pertinente. Na pesquisa em questão, os autores reformularam a teoria dos batimentos de Helmholtz (1875) a partir de dados obtidos em testes subjetivos, constatando uma correspondência entre dissonância sensorial e a largura da banda crítica? .

O modelo de Plomp e Levelt surge a partir de um teste subjetivo que questionava o nível de dissonância identificado na escuta de pares de tons puros. Considerando a determinante atuação que os métodos experimentais exercem sobre o êxito dos modelos e, contudo, a pouca evidência que se dá a eles em muitas análises, apresentamos detalhes destes testes a seguir.

O estímulo sonoro dos testes compreendeu em um par de tons puros para cada intervalo da escala 12 -tet $^{8}$, todos gerados em relação a uma frequência inicial. As escalas avaliadas tinham as seguintes frequências iniciais: 125, 250, 500, 1000 e

\footnotetext{
7 Banda crítica é o nome dado à divisão da extensão de frequências audíveis por faixas de frequências tal como introduzido por Fletcher (1933) e desenvolvida por teóricos como Zwicker (1961). Por ser um conceito importante neste trabalho, dedicamos a subseção 2.1.3. para uma explanação mais adequada.

8 tet - tone-equal-tempered (escala do temperamento por igual).
} 
$2000 \mathrm{~Hz}$. Os participantes quantificavam cada intervalo em uma escala de 7 pontos, onde 1 era o mais dissonante e 7, o mais consonante. Quando os participantes indagavam sobre o significado de consonância, os pesquisadores utilizavam sinônimos como bonito ou harmonioso para ilustrar o seu significado.

Os participantes foram homens adultos em torno dos 20 anos de idade com ensino médio completo. Para as frequências $125,250,500,1000$ e $2000 \mathrm{~Hz}$ o número de voluntários em testes realizados foi respectivamente 19, 22, 18, 11 e 18. Segundo os pesquisadores, para se descartar os participantes que não davam respostas consistentes foram mantidas somente as respostas que possuíam um coeficiente de correlação mínimo de 0,5 com o conjunto das respostas obtidas. Assim, o número de respostas caiu para 11, 10,11, 10 e 8 para as respectivas frequências acima citadas (uma redução de até $56 \%$ nas respostas válidas, por exemplo, para o último teste).

A partir dos resultados obtidos nos testes, Plomp e Levelt detectaram uma conexão entre a banda crítica de Zwicker (1961) e a ocorrência do pico de dissonância, encontrado em cerca de um quarto da banda crítica. Podemos observar essa correlação na fig. 2, onde o nível de dissonância (eixo vertical) está traçado em função da extensão da banda crítica (eixo horizontal).

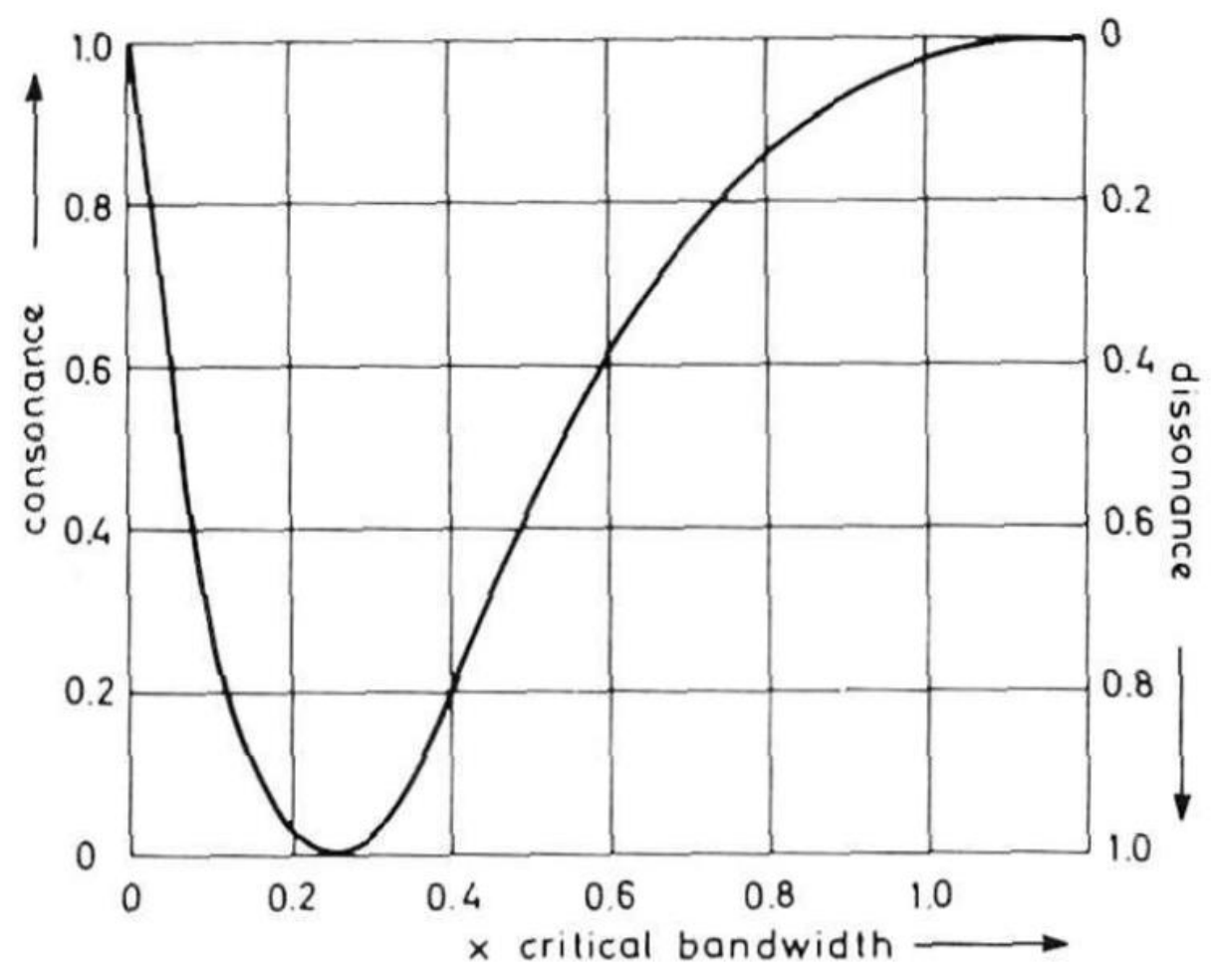

Figura 2- Curva derivada dos testes subjetivos de Plomp e Levelt, fornecendo uma medida de consonância em função da banda crítica para dois tons puros. (PLOMP e LEVELT, 1965) 
Esse resultado conduziu a um modelo primário para a rugosidade, sendo a partir da aproximação da curva da fig. 2 que Sethares (1998) e Vassilakis (2001) desenvolveram seus modelos de dissonância sensorial para sons complexos.

\subsubsection{O modelo de Hutchinson e Knopoff}

A partir dos testes empreendidos por Plomp e Levelt (1965), modelos matemáticos foram propostos com a função de representar o nível de rugosidade de um estímulo sonoro. Trataremos primeiro do modelo de Hutchinson e Knopoff (1978). Para fazer a estimativa de dissonância, os autores efetuaram primeiramente uma aproximação empírica para a largura das bandas críticas $(B C)$ em função das frequências, que é enunciado na seguinte equação:

$$
B C=1.72(\bar{f})^{0,65}
$$

sendo $\bar{f}=\frac{1}{2}\left(f_{1}+f_{2}\right)$.

Essa aproximação é a base para um fator de ponderação de dissonância (g), expresso na seguinte equação ${ }^{9}$ :

$$
g=\left|f_{1}-f_{2}\right| / B C(\bar{f})
$$

Para a aferição da dissonância em sons complexos, é realizada uma somatória do fator de dissonância gij para cada par de parciais $i$ e $j$, ponderada por suas amplitudes individuais $A$, e dividida pela soma total da energia das amplitudes de todos eles.

$$
D=\frac{\frac{1}{2} \sum_{i=j}^{N} \sum_{j=1}^{N} A_{i} A_{j} g_{i j}}{\sum_{i+1}^{N} A_{i}^{2}}
$$

sendo $N$ o número de tons puros.

\subsubsection{O modelo de Sethares}

O modelo que discutiremos agora é o proposto por William Sethares (1998). A base desse modelo é a curva de dissonância (fig. 2) determinada a partir dos

\footnotetext{
${ }^{9}$ Hutchinson e Knoppof, 1978, pag. 3.
} 
experimentos de Plomp e Levelt que estimaram o nível de dissonância para um par de tons puros. Utilizando essa curva, especulou-se a possibilidade de calcular o nível de dissonância para sons complexos a partir da soma da contribuição de cada parcial para o nível de dissonância global de um espectro sonoro.

A aproximação de Sethares para a curva de dissonância da fig. 2 é expressa na seguinte função:

$$
d(x)=e^{-b_{1} x}-e^{-b_{2} x}
$$

onde $x$ representa o valor absoluto da diferença de frequências entre dois tons puros e os expoentes $b_{1}$ e $b_{2}$ representam as taxas de crescimento e decrescimento da curva.

Partindo dessa aproximação, Sethares apresenta uma função para a dissonância $d$ (eq. 5) para dois tons de frequências $f_{1}$ e $f_{2}$ e loudness $l_{1}$ e $l_{2}{ }^{10}$, em que $f_{1}<f_{2}$ e $l_{12}$ é o menor valor dentre $l_{1}$ e $l_{2}$, isto é, $l_{12}=\min \left(l_{1}, l_{2}\right)$. O parâmetro $s$ é dado pela eq. 6 , em que $x^{*}=0,24$ é o ponto de máxima dissonância, pois a máxima dissonância ocorre em cerca de um quarto da banda crítica, $b_{1}=3,5, b_{2}=$ 5,75. Os parâmetros $s_{1}=0,021$ e $s_{2}=19$ são determinados, segundo Sethares, a partir da minimização de erros da curva parametrizada de Plomp e Levelt.

$$
\begin{gathered}
d\left(f_{1}, f_{2}, l_{1}, l_{2}\right)=l_{12}\left[e^{-b_{1} s\left(f_{2}-f_{1}\right)}-e^{-b 2 s\left(f_{2}-f_{1}\right)}\right] \\
s=\frac{x^{*}}{s_{1} f_{1}+s_{2}}
\end{gathered}
$$

Para sons complexos Sethares apresenta a dissonância em função das frequências e intensidades (loudness) de cada uma das componentes senoidais do som. Para um dado conjunto $F$ de $n$ parciais senoidais, a dissonância é dada assim pela eq. 7, um somatório dos cálculos de pares individuais.

\footnotetext{
${ }^{10}$ Expressas através da grandeza loudness, ou volume em português, medida em sones, e determinada a partir do Nível de Pressão Sonora (NPS), do inglês SPL - Sound Pressure Level, que é uma medida física preferencial para caracterizar a sensação subjetiva da intensidade dos sons. (Bistafa, 2008, p. 17).
} 


$$
D_{F}=\frac{1}{2} \sum_{i=1}^{n} \sum_{j=1}^{n} d\left(f_{i}, f_{j}, l_{i}, l_{j}\right)(7)
$$

A partir desta contribuição, a influência do volume dos parciais é explicitamente incorporada no cálculo da dissonância dos estímulos sonoros.

\subsubsection{A revisão de Vassilakis do modelo de Sethares}

Em seu doutorado, Vassilakis ${ }^{11}$ desenvolve uma modelagem matemática para a dissonância, tratando-a como um fenômeno decorrente da sensação da rugosidade. Segundo Vassilakis (2001), o modelo de Sethares superestima a influência do volume (loudness) e subestima o grau de flutuação de amplitude ${ }^{12}\left(F_{A}\right)$ dos parciais no cálculo da dissonância sensorial. Assim, propõe uma revisão deste modelo utilizando, para tanto, os resultados de uma série de testes subjetivos realizados por Terhardt (1974) que produziram constatações novas sobre a relação entre rugosidade, intensidade e variações de amplitude. Essa revisão afetará apenas a estimativa de rugosidade para tons puros de intensidades diferentes.

Os testes de Terhardt (1974) avaliavam: (1) A influência do nível de pressão sonora NPS e da profundidade de modulação $m$ na rugosidade de tons modulados em amplitude $\left(R_{M A}\right)$; (2) A relação entre o nível de rugosidade de um tom modulado em amplitude $\left(R_{M A}\right)$ e o nível de rugosidade de um par de tons puros com mesmo nível de flutuação de amplitude $\left(F_{A}\right)$.

Levando-se em consideração que os achados de Terhardt indicavam que a percepção da rugosidade variava em função do nível de pressão sonora (NPS) e do nível de flutuação de amplitude ${ }^{13}\left(F_{A}\right)$, Vassilakis (2001, p.21-46) considera três expressões para o cálculo da rugosidade, a saber:

\footnotetext{
${ }^{11}$ Pesquisador especialista nas áreas de acústica, ciências auditivas, etnomusicologia e cognição musical, tendo desenvolvido suas últimas pesquisas na Universidade da Califórnia, Los Angeles, desde meados dos anos 2000.

${ }^{12}$ A flutuação de amplitude é definida aqui como a diferença de nível entre o pico do sinal e o seu vale adjacente. (VASSILAKIS, 2001, pag. 25).

${ }^{13}$ As flutuações de amplitude são manifestações de interferência das ondas sonoras e podem ser colocadas em três categorias perceptivas, relacionadas à taxa de flutuação. As flutuações de amplitude mais lentas (até aproximadamente +- 20 por segundo) são ouvidas como mudanças na percepção da intensidade e percebidas como batimentos. À medida que a taxa de flutuação aumenta, a percepção de intensidade do som parece ser constante e as flutuações são percebidas como rugosidade. Com uma taxa de flutuação da amplitude mais alta (em aproximadamente 75-150 flutuações por segundo, dependendo do registro da freqüência), a rugosidade atinge uma taxa máxima e depois diminui gradualmente até desaparecer. (VASSILAKIS, 2001, p.24-25)
} 
1- Rugosidade de um tom modulado em amplitude ${ }^{14}$ em função da flutuação de amplitude $\left(F_{A}\right)$ é dada por:

$$
R_{F A}=c F_{A}^{3,11}
$$

em substituição à função $R=c F_{A}^{2}$ proposta por Terhardt, onde $c$ é uma constante, e assumia-se que a flutuação de amplitude $F_{A}$ era equivalente à profundidade da modulação de amplitude $m$. Vassilakis (2001, p. 29), entretanto, mostra que estes parâmetros não são iguais, e a relação entre ambas pode ser expressa por meio da equação:

$$
F_{A}=\frac{2 m}{1+m}
$$

Acrescentando que:

a) $F_{A}=m$ apenas para $m=0$ ou $m=1$.

b) Se $m \rightarrow \infty, F_{A} \rightarrow 2$.

A proposta de $R_{F A}$ na eq. 8 decorre de constatações feitas por Terhardt de que mudanças na rugosidade por um fator de 0,5 correspondiam a mudanças na profundidade da modulação $m$ por um fator de 0,7 assumindo-se $F_{A}=m$. Os dados foram obtidos através de testes subjetivos em que os voluntários eram instruídos a assinalar a metade da rugosidade e o dobro da rugosidade com relação a um som padrão ${ }^{15}$, enquanto era variada a profundidade de modulação do som que ele assumia ser idêntica à flutuação de amplitude.

2- Rugosidade de um tom modulado em amplitude em função do nível de pressão sonora (NPS) é dada por:

$$
R_{N P S}=c N P S^{\frac{1}{10}}
$$

\footnotetext{
${ }^{14}$ Técnica de síntese sonora onde uma senóide (onda portadora car) é multiplicada por outra senóide (onda moduladora mod), produzindo uma modulação de amplitude e resultando em um espectro com três frequências $(\mathrm{Hz}): f_{1}=c a r-m o d ; f_{2}=c a r ; f_{3}=c a r+$ mod. (VASSILAKIS, 2001, p.24)

${ }^{15}$ Pares de tons modulados em amplitude cada um com duração de $1 \mathrm{~s}$ separados por um silêncio de $0,5 \mathrm{~s}$.
} 
sendo $c$ uma constante. Os testes de Terhardt constataram que, em termos de rugosidade, reduzir o NPS de um tom modulado em amplitude de $80 \mathrm{~dB}$ para $40 \mathrm{~dB}$ (à metade) é equivalente a reduzir a profundidade de modulação de $m=1$ para $m=$ 0,91, o que, segundo Vassilakis leva à equação 10 .

3- Rugosidade de um par de tons puros $\left(R_{\text {par }}\right)$ com frequências $\left(f_{1}, f_{2}\right)$ e amplitudes $\left(A_{1}, A_{2}\right)$ em função da rugosidade de um tom modulado em amplitude $\left(R_{M A}\right)$ onde a frequência de modulação $f_{\text {mod }}=\left|f_{1}-f_{2}\right|$ e $A_{1}=A_{2}$ é dada, segundo Terhardt, por:

$$
R_{\text {par }}=0,5 R_{M A}
$$

Para calcular a dissonância entre dois tons com frequências e amplitudes $\left(f_{1}, f_{2}, A_{1}, A_{2}\right)$ Vassilakis deriva então uma expressão composta para a rugosidade $R=$ $f\left(R_{F A}, R_{N P S}, R_{\text {par }}\right)$ que leva em consideração os ajustes acima e é dada por:

$$
R\left(f_{1}, f_{2}, A_{1}, A_{2}\right)=\frac{1}{2}\left(A_{1} * A_{2}\right)^{0,1}\left(\frac{2 A_{2}}{A_{1}+A_{2}}\right)^{3,11}\left[e^{-b_{1} s\left(f_{2}-f_{1}\right)}-e^{-b_{2} s\left(f_{2}-f_{1}\right)}\right]
$$

onde $b_{1}=3,5, b_{2}=5,75, s=\frac{0,24}{s_{1} f_{1}+s_{2}}, s_{1}=0,0207$ e $s_{2}=18,96$.

Esta expressão derivada por Vassilakis forneceria, então, uma estimativa mais precisa para a rugosidade entre dois tons, levando-se em consideração suas intensidades e relações de modulação ou combinação entre eles (situações comuns na música) e aplicada como na eq. 7 pode ser utilizada para quantificar a dissonância em um som complexo com vários parciais.

\subsubsection{Avaliando o modelo de Vassilakis}

Vassilakis efetuou um teste para validar sua teoria que tinha como finalidade observar a ligação entre a concepção de dissonância da música ocidental com a percepção de rugosidade entre dois sons, confrontando os resultados dos testes com o modelo de rugosidade da eq. 12. Ele expõe sua hipótese da seguinte maneira: 
Para os músicos dentro da tradição da música ocidental, as avaliações para a rugosidade de intervalos harmônicos concordam com os graus de rugosidade estimados usando-se o modelo de estimativa de rugosidade proposto e correlacionam com os graus de dissonância sugeridos pela teoria musical ocidental. Além disso, as avaliações de dissonância correlacionam-se com graus de rugosidade indicando que, na tradição musical ocidental, onde a rugosidade sensorial é geralmente evitada como dissonante, a hierarquia de consonância dos intervalos harmônicos corresponde principalmente a variações em graus de rugosidade ${ }^{16}$. (Vassilakis, 2001)

Os intervalos em uma oitava da escala $12-$ tet $^{17}$ serviram como base do teste, partindo do Dó4 (256 Hz). O espectro sonoro usado no seu experimento consistia em um espectro harmônico com seis parciais (onda dente-de-serra, com amplitudes de 1/parcial) com uma leve desafinação nos componentes, para dar "naturalidade" ao som. Essa leve desafinação não influencia na sensação de rugosidade, segundo os experimentos de von Békésy (1960) e Terhardt (1974).

Os participantes foram separados em dois grupos de 10 pessoas cada. 0 primeiro grupo deveria quantificar os estímulos em um nível entre Não-rugoso e Rugoso. O segundo grupo deveria responder um grau para o estímulo entre Não dissonante e Dissonante.

As respostas eram atribuídas sobre uma barra de rolagem de 42 pontos, sendo $0=$ Não rugoso/Não dissonante e 42= Rugoso/Dissonante. Os voluntários dispuseram de um tempo para se habituar com o conceito de rugosidade em uma sessão de treinamento que incluía tons puros modulados em amplitude como estímulos, com vários valores de profundidade de modulação.

O gráfico 1 e a tabela 2 apresentam os resultados deste experimento ao lado de três modelos de estimativa de rugosidade: o de Helmholtz (1875), o de Hutchinson \& Knopoff (1978), e o da equação 12.

\footnotetext{
${ }^{16}$ Original: "For musicians within the Western musical tradition, roughness ratings of harmonic intervals agree with the roughness degrees estimated using the proposed roughness estimation model and correlate with the dissonance degrees suggested by Western music theory. Additionally, dissonance ratings correlate with roughness degrees indicating that, in the Western musical tradition where sensory roughness is in general avoided as dissonant, the consonance hierarchy of harmonic intervals corresponds mainly to variations in roughness degrees."

17 12-Tone Equal Temperament, isto é, escala de temperamento por igual de 12 tons.
} 
Observamos nos resultados uma maior correlação entre o modelo proposto por Vassilakis (eq. 12) e os resultados obtidos nos testes, seguidos pelos modelos de Hutchinson e Knopoff e por último de Helmholtz. Também verificamos a partir desses resultados uma correspondência entre a alteração de nível de rugosidade e a variação no nível de dissonância, confirmando a hipótese de que a rugosidade é um parâmetro decisivo para a sensação de dissonância. As maiores diferenças na avaliação entre nível de dissonância e nível de rugosidade ocorreram, contudo, nos intervalos de trítono ( $4^{\mathrm{a}}$ Aum $)$ e segunda maior $\left(2^{\mathrm{a}} \mathrm{M}\right)$, como revela a tabela 2.

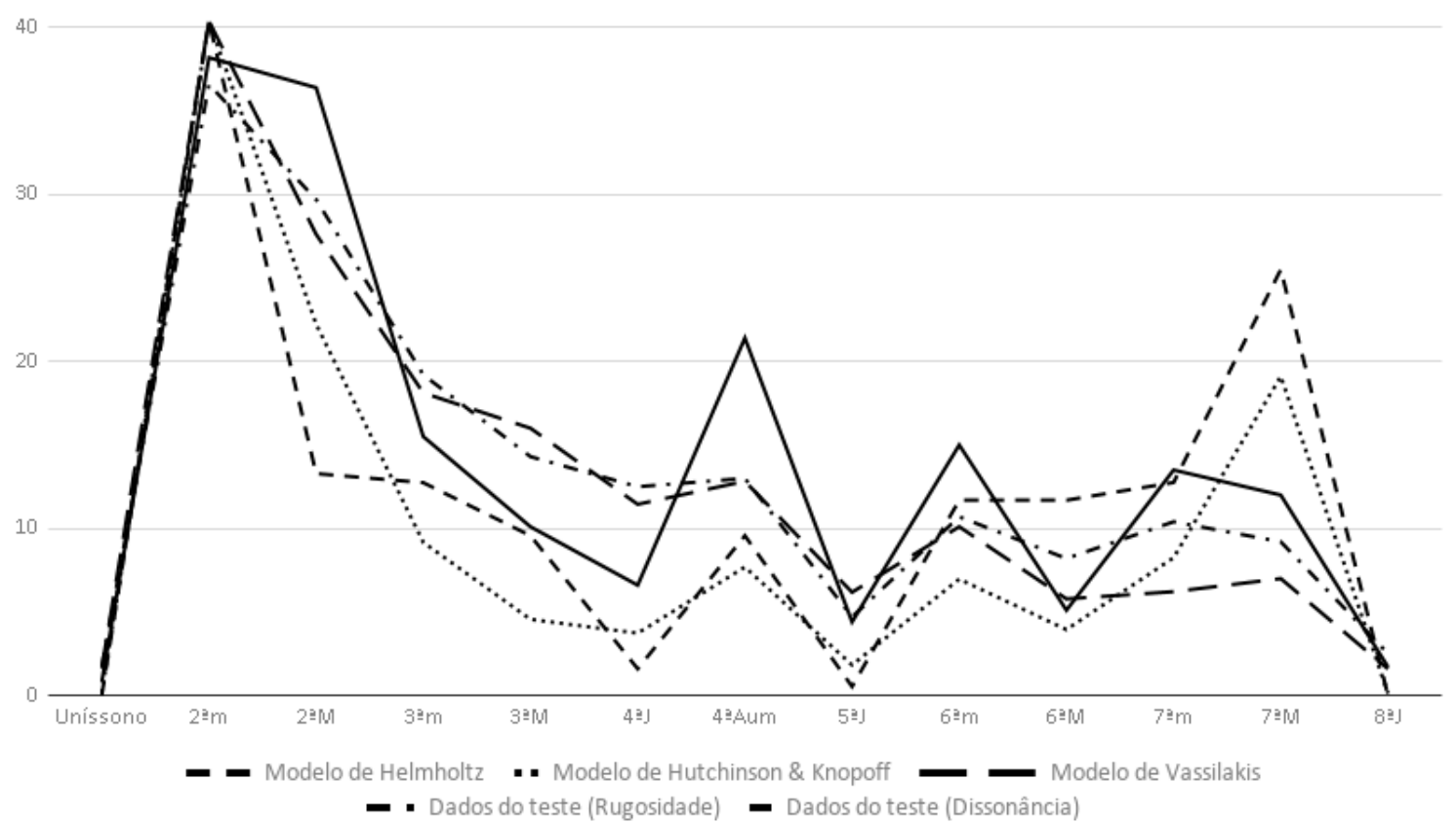

Gráfico 1- Resultados do experimento de Vassilakis comparados com os modelos de Helmholtz, Hutchinson \& Knopoff e Vassilakis, plotado a partir dos valores da tabela 2. 


\begin{tabular}{|c|c|c|c|c|c|}
\hline Intervalo & $\begin{array}{l}\text { Modelo de } \\
\text { Helmholtz }\end{array}$ & $\begin{array}{l}\text { Modelo de } \\
\text { Hutchinson \& } \\
\text { Knopoff }\end{array}$ & $\begin{array}{l}\text { Modelo de } \\
\text { Vassilakis }\end{array}$ & $\begin{array}{l}\text { Dados do teste } \\
\text { (Rugosidade) }\end{array}$ & $\begin{array}{l}\text { Dados do teste } \\
\text { (Dissonância) }\end{array}$ \\
\hline Uníssono & 0 & 0,157 & 1,614 & 1,7 & 0,8 \\
\hline $2^{a} m$ & 40,383 & 40,383 & 40,383 & 36,6 & 38,2 \\
\hline 2aM & 13,284 & 22,233 & 27,617 & 29,7 & 36,4 \\
\hline $3 a m$ & 12,743 & 9,166 & 18,117 & 19,2 & 15,5 \\
\hline 3aM & 9,564 & 4,554 & 16,002 & 14,3 & 10,1 \\
\hline 4a J & 1,594 & 3,727 & 11,446 & 12,5 & 6,6 \\
\hline 4aum & 9,564 & 7,686 & 12,826 & 13 & 21,4 \\
\hline 5aj & 0,531 & 1,826 & 6,17877 & 4,7 & 4,4 \\
\hline 6am & 11,69 & 6,967 & 10,103 & 10,7 & 15 \\
\hline 6aM & 11,69 & 3,942 & 5,782 & 8,2 & 5,1 \\
\hline $7 \mathfrak{a} m$ & 12,753 & 8,249 & 6,214 & 10,4 & 13,5 \\
\hline 7ㅁM & 25,506 & 19,109 & 6,996 & 9,2 & 12 \\
\hline 8a J & 0 & 0,116 & 1,589 & 2,5 & 1,7 \\
\hline
\end{tabular}

Tabela 2- Resultados do experimento comparado dos modelos de Helmholtz, Hutchinson \& Knopoff e Vassilakis. Valores variam de 0 (máxima consonância) a 42 (máxima dissonância).

\subsubsection{Percepção da dissonância sensorial em sons inarmônicos}

Conquanto muitos testes subjetivos tenham sido efetuados com o objetivo de validar modelos de dissonância, esses testes, em sua maioria, focam apenas em sons harmônicos. Nesse sentido, o trabalho de Geary é de grande relevância, pois implementa a avaliação experimental do nível de dissonância para sons inarmônicos.

A variável independente (estímulo sonoro) utilizado no teste executado por Geary (1980) foi um som inarmônico gerado a partir de uma modulação de banda lateral única (single-side-band modulation) resultando num espectro com parciais distantes de $\sqrt{2} f_{0}$.

Segundo o autor, a amplitude dos parciais foi escolhida de maneira facultativa, e maiores detalhes sobre a construção do espectro não foram relatados em seu artigo. Seis tons usando este espectro foram sintetizados, e tocados na forma de díades (em relação a um tom fundamental). Os tons \#1, \#4 e \#6 (vide fig. 3) possuem fundamentais em intervalos de quarta justa (4a J), quinta justa (5 $5^{\mathrm{a}}$ ) e de sexta maior $\left(6^{\mathrm{a}} \mathrm{M}\right)$, respectivamente. Os demais tons tiveram as suas fundamentais escolhidas visando o alinhamento dos parciais do espectro acima citado. Na fig. 3 podemos observar as razões das díades tocadas e o alinhamento dos parciais em cada uma destas díades. 


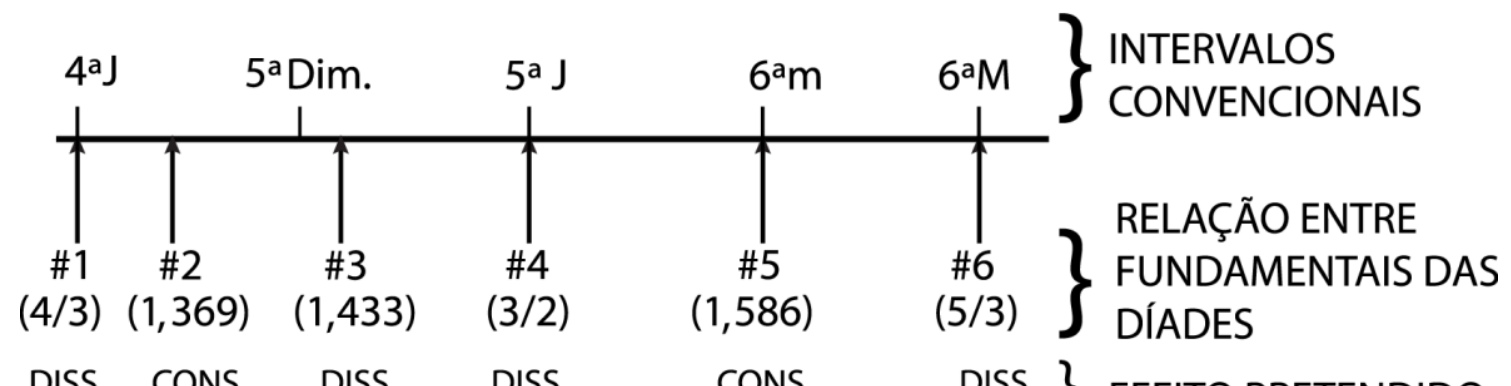

DISS. CONS. DISS. DISS. CONS. DISS. $\}$ EFEITO PRETENDIDO

Figura 3- Díades executadas no experimento de Geary. Figura adaptada de GEARY (1980).

O experimento contou com 14 participantes com vivência musical diversificada. Nele, os participantes eram apresentados a dois pares de díades, tocadas uma após a outra, e deveriam escolher qual era mais consonante, ou não escolher nenhuma das duas, realizando assim a metodologia de comparação pareada não forçada. Os participantes distinguiam por meio de um formulário as díades que consideravam mais consonantes.

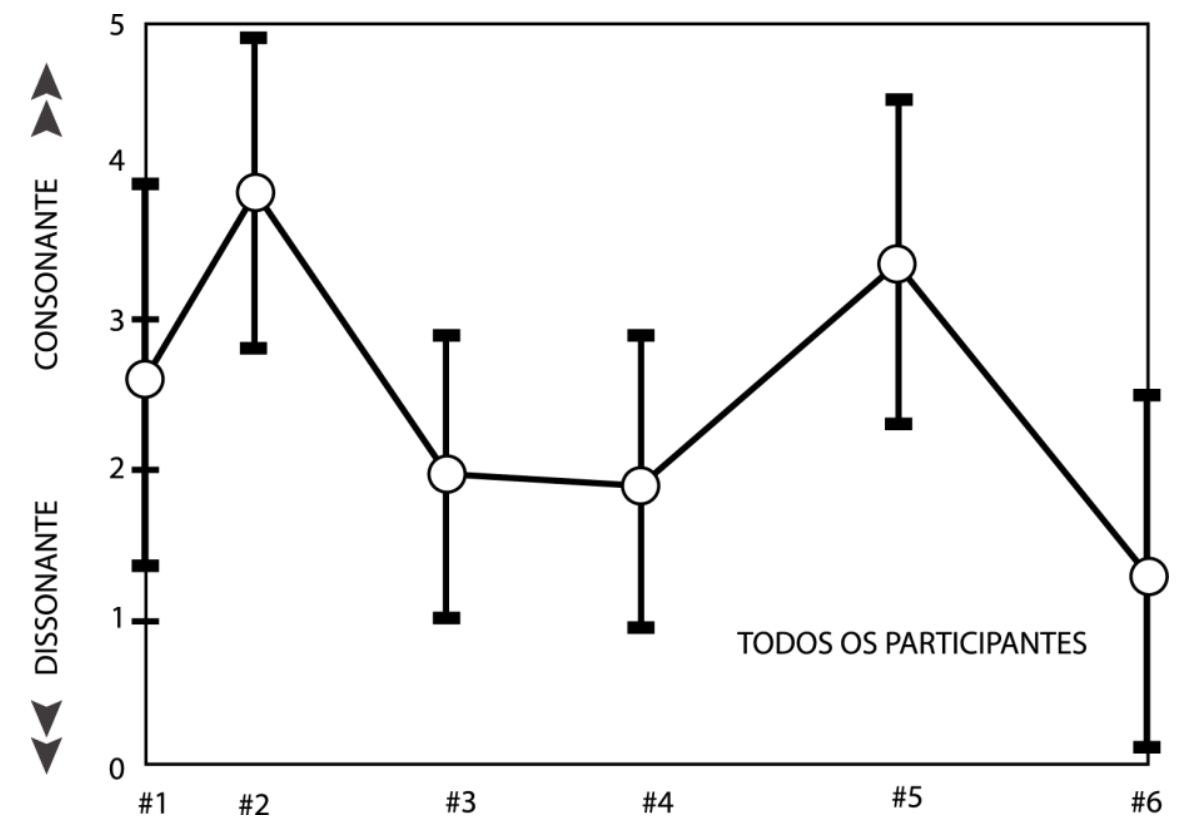

Figura 4- Resultado da escolha dos participantes para cada díade. Figura adaptada de GEARY (1980).

$\mathrm{Na}$ análise dos resultados, se uma díade fosse selecionada todas as vezes que é comparada com as outras 5 díades, ela era considerada totalmente consonante (rating=5). Se ela nunca era selecionada, era considerada totalmente dissonante (rating=0). Uma resposta indecisa acrescentava $1 / 2$ ponto na estimativa de ambas as 
díades. A figura 4 revela o resultado do experimento. Identificamos nos resultados uma clara inclinação a estimar como mais consonantes as díades construídas visando evitar o choque entre os parciais, ou seja, os sons inarmônicos (díades \#3 e \#5). Dos 14 participantes do experimento, 3 geraram resultados $100 \%$ compatíveis com a hipótese do experimento, enquanto os outros 12 ficaram próximos do resultado esperado pelo teste. A partir de um teste de significância realizado, o autor constatou que apenas 2 participantes ficaram muito abaixo do resultado esperado.

\subsubsection{Banda Crítica e a formalização matemática de Traunmüller}

Realizaremos aqui uma breve revisão do conceito de Banda Crítica por ser fundamental para a implementação do algoritmo redutor de dissonância que será apresentado na seção 3.1 desta dissertação.

Banda crítica é o nome dado à divisão da extensão de frequências audíveis por faixas de frequências tal como introduzido por Fletcher (1933) e desenvolvida por Zwicker (1961). Essa divisão é bastante conveniente no estudo da dissonância sensorial pois ela é uma boa representação funcional para segmentação da cóclea (em particular, de sua membrana basilar), e por consequência, um bom parâmetro para a observação e quantificação de diversos fenômenos psicoacústicos.

As bandas críticas são estimadas a partir de avaliações subjetivas, como por exemplo, em teste de limiares auditivos, testes de mascaramento em frequência, percepção de mudança de fase, e percepção de SPL constante (Zwicker e Fastl, 2013).

Uma segmentação proposta por Zwicker divide toda a extensão de frequências audíveis em 24 bandas críticas, e utiliza-se a unidade Bark para representar cada banda. A tabela 3 apresenta estas 24 bandas críticas, tendo na primeira coluna a representação dos segmentos em Barks, na segunda coluna a frequência central de cada banda (em Hertz), na terceira a frequência de corte, e na quarta coluna, a sua extensão ou largura (também em Hertz). 


\begin{tabular}{|c|c|c|c|}
\hline Bark & Frequência central $(\mathrm{Hz})$ & Frequência de corte $(\mathrm{Hz})$ & Largura da Banda \\
\hline & & 20 & \\
\hline 1 & 50 & 100 & 80 \\
\hline 2 & 150 & 200 & 100 \\
\hline 3 & 250 & 300 & 100 \\
\hline 4 & 350 & 400 & 100 \\
\hline 5 & 450 & 510 & 110 \\
\hline 6 & 570 & 630 & 120 \\
\hline 7 & 700 & 770 & 140 \\
\hline 8 & 840 & 920 & 150 \\
\hline 9 & 1000 & 1080 & 160 \\
\hline 10 & 1170 & 1270 & 190 \\
\hline 11 & 1370 & 1480 & 210 \\
\hline 12 & 1600 & 1720 & 240 \\
\hline 13 & 1850 & 2000 & 280 \\
\hline 14 & 2150 & 2320 & 320 \\
\hline 15 & 2500 & 2700 & 380 \\
\hline 16 & 2900 & 3150 & 450 \\
\hline 17 & 3400 & 3700 & 550 \\
\hline 18 & 4000 & 4400 & 700 \\
\hline 19 & 4800 & 5300 & 900 \\
\hline 20 & 5800 & 6400 & 1100 \\
\hline 21 & 7000 & 7700 & 1300 \\
\hline 22 & 8500 & 9500 & 1800 \\
\hline 23 & 10500 & 12000 & 2500 \\
\hline 24 & 13500 & 15500 & 3500 \\
\hline
\end{tabular}

Tabela 3- Valores das faixas de frequência da Banda Crítica. (Zwicker, 1961)

Segundo a proposta de Traunmüller (1990), a conversão de frequências para banda críticas, representadas por $z$ e dadas em Barks, pode ser feita a partir das equações de 13 e 14.

$$
z=\left\{\begin{array}{c}
z^{\prime}+0,15\left(2-z^{\prime}\right), \text { se } z^{\prime}<2 \\
z^{\prime}, \text { se } 2<z^{\prime}<20,1 \\
z^{\prime}+0,22\left(z^{\prime}-20,1\right), \text { se } z^{\prime}>20,1
\end{array}\right.
$$




$$
\begin{array}{r}
\text { onde } \\
z^{\prime}=\frac{26,81 f}{1960+f}-0,53
\end{array}
$$

Essa conversão nos será útil para a implementação de um algoritmo para a construção de espectros a partir da redução da dissonância sensorial em escalas do temperamento por igual, conforme será exposto na seção 3.1.

\subsection{O temperamento por igual}

Na história da música ocidental, um dos parâmetros sonoros mais explorados é o da altura e a sua organização sistemática. Além de sua abordagem em disciplinas como harmonia ou contraponto, sempre extremamente ligadas à prática musical, as discussões sobre os sistemas de afinação sempre estiveram presentes na música, sofrendo diversas teorizações e transformações ao longo do tempo.

Um dos pontos altos desse desenvolvimento histórico é o nascimento do sistema de afinação conhecido como temperamento por igual, sistema que abrange qualquer escala que divida um dado intervalo de altura - como uma oitava ${ }^{18}$ - em $n$ partes iguais.

O temperamento por igual tem sua primeira menção na obra Pratica Musicae (1496) de Franchinus Gafirus e suas primeiras regras podem ser encontradas na obra Scintille de Música de Giovanni Maria Lanfranco, publicada em 1553. Esse sistema surgiu com uma necessidade estrutural da música que envolve tanto questões relacionadas à linguagem musical quanto à construção dos instrumentos.

Ao longo da história da teoria musical, foram exploradas diversas possibilidades de divisões do temperamento por igual, levando-se em conta aproximações com intervalos justos, como por exemplo, com as quintas e terças. Essas especulações têm sua base em trabalhos bem antigos sobre afinação. Dirk de Klerk (1979) cita propostas como a de Nicolas Mercator (1620-87) e de Christian Huygens (1629-95) que constataram que, em uma divisão da oitava em 53 ou 31 partes iguais, o resultado era a obtenção de quintas justas e terças maiores com boas aproximações.

18 Neste trabalho, em todos os casos, definimos a oitava como a razão 2:1. 
Em nosso texto tomaremos como referência o trabalho de Easley Blackwood (1991 e 2014) sobre o temperamento por igual, onde ele é abordado a partir de aproximações e afastamentos das razões da escala maior. Essa organização nos é útil pois dialoga diretamente com a percepção de dissonância, como veremos no tópico a seguir.

\subsubsection{A organização do temperamento por igual na obra de Easley Blackwood}

Em seu artigo Modes and Chords Progressions in Equal Tunings, de 1991, Blackwood descreve diversas divisões do temperamento por igual tendo como objetivo a proximidade com a escala maior e a obtenção de funções harmônicas da tonalidade (tônica, dominante e subdominante). No artigo Six American Composers on Nonstandard Tunings (Keislar, 1991) ele sintetiza seu modo de pensar o temperamento da seguinte maneira:

"Tenho explorado principalmente divisões iguais da escala de 12 a 24 partes por oitava. A escolha de qual afinação usar depende muito do estilo desejado. Certas afinações são mais versáteis ou bonitas que outras. Divisões de doze, dezessete, dezenove, vinte e dois e vinte e quatro contém escalas diatônicas reconhecíveis. Se o que você quer são dissonâncias aleatórias, a pior de todas as afinações é a de doze divisões porque ela contém uma grande concentração de consonâncias e harmonias em um pequeno número de notas. A mais eficaz para dissonâncias aleatórias é a de onze divisões. Não existem duas notas nessa afinação que gere algum tipo de consonância". (Keislar, 1991, p. 176)

Blackwood (1991) ainda destaca as escalas de 5, 6, 8, 15 ou 16 divisões por oitava, que tem sua estrutura ligada aos acordes simétricos da tonalidade, como é o caso das escalas 8-tet ${ }^{19}$ e 16-tet, cujas razões dos intervalos permitem a execução de um acorde diminuto com a mesma razão dos intervalos da escala 12-tet.

${ }^{19}$ tet - tone-equal-tempered (escala do temperamento por igual). 


\subsubsection{A matemática do temperamento por igual}

Realizamos aqui uma breve revisão da matemática do temperamento por igual, pois isso nos será útil para entender as implementações realizadas nos capítulos 3 e 4.

Uma escala do temperamento por igual consiste em qualquer escala que divida um intervalo $i$ em $n$ partes. Para calcularmos as frequências de uma escala 12-tet a partir de uma frequência inicial $f$, devemos multiplicar a frequência inicial por uma razão $r$ e suas potências, obtendo as seguintes frequências:

$$
f, f r, f r^{2}, f r^{3}, f r^{4}, \ldots, f r^{12}
$$

Para obtermos a razão da escala tendo como base a oitava $(i=2)$, devemos ter $r^{12}=2$, ou seja $r=\sqrt[12]{2}$, cuja solução é $r=1.05946$. Podemos generalizar o caso para qualquer escala $n$-tet com intervalo i na seguinte equação:

$$
r=\sqrt[n]{i}
$$

A razão da oitava de cada grau da escala para qualquer temperamento por igual é dada por:

$$
O_{g}=r^{g+n}
$$

onde $g$ (grau da escala) é somado a $n$ (número de divisões da escala). Por exemplo, para obter a oitava de $f r^{2}$ (passo 2) de uma escala 8-tet com frequência inicial $f$, temos $f r^{2+8}=f r^{10}$.

\subsubsection{Um exemplo de aproximação diatônica com a escala 17-tet}

Como citamos acima, um dos grupos de escalas utilizados nas composições de Blackwood são aqueles que possuem intervalos que acomodam bem a escala maior. Segundo ele, quando estamos trabalhando com escalas que não tem repertório ou tradição, é útil proceder comparações com escalas já em uso no repertório (Blackwood, 1991, p. 166). Além disso, apesar da possibilidade de execução da escala maior, o seu uso não é idêntico ao do praticado utilizando a 
escala 12-tet. As pequenas diferenças entre as razões dos intervalos dos acordes nos dão novas sensações de timbres e abrem novas possibilidades de modulação.

Partindo da escala 12-tet, Blackwood (1991, p. 168) observa que cada $t$ (tom) da escala maior possui 2/12 e cada $s$ (semitom) possui 1/12 partes da escala, sendo que a soma desses intervalos completa a oitava, pois $5\left(\frac{2}{12}\right)+2\left(\frac{1}{12}\right)=2$. Partindo desse raciocínio, ele constrói uma escala maior para a escala 17-tet onde o $t=3 / 17$ e $s=1 / 17$, que somados a quantidades de tons e semitons da escala maior, completam a oitava, pois $5\left(\frac{3}{17}\right)+2\left(\frac{1}{17}\right)=2$. Dessa maneira, obtemos as notas de uma escala maior mostrada na fig. 5 , destacando como primeira consequência o fato de os sustenidos possuírem alturas diferentes dos bemóis.

\begin{tabular}{|l|l|l|l|l|l|l|l|l|l|l|l|l|l|l|l|l|l|}
\hline 0 & 1 & 2 & 3 & 4 & 5 & 6 & 7 & 8 & 9 & 10 & 11 & 12 & 13 & 14 & 15 & 16 & 17 \\
\hline Do & Reb & Do\# & Re & Mib & Re\# & Mi & Fa & Solb & Fa\# & Sol & Lab & Sol\# & La & Sib & La\# & Si & Do \\
\hline
\end{tabular}

Figura 5- Disposição de uma escala maior em uma escala 17-tet.

Nessa configuração da escala maior, o tom seria maior que o da 12-tet, com 211,76 cents e o semitom menor, com 70,59 cents. Uma quinta justa (passo $10 \mathrm{da}$ 17-tet), poussui 705,882 cents, maior que a quinta da afinação justa em 3,927 cents. Uma terça maior (passo 6 da 17-tet) possui 423,529 cents. Ela é maior que a terça justa em 37,216 cents, e maior que a Pitagórica em 15,709 cents. A terça menor, com 282,353 cents é menor que a justa em 33,288 cents. 


\section{Modelagem da dissonância em timbres de espectros inarmônicos}

Nesta seção apresentaremos a contribuição central de nosso trabalho no estudo da dissonância sensorial. No tópico 3.1, apresentaremos um algoritmo para a geração de espectros com dissonância reduzida para escalas do temperamento por igual, seguido da descrição da implementação desse algoritmo em Python ${ }^{20}$ utilizando a ferramenta Jupyter Notebook ${ }^{21}$. Visando verificar a eficácia deste método, sintetizamos um timbre inarmônico para uma escala temperada 8-tet que foi avaliado por meio de um teste subjetivo, cuja metodologia é apresentada na seção 3.3 e cujos resultados são apresentados na seção 3.4.

\subsection{Algoritmo gerador espectros reduzidos em dissonância}

A construção de timbres relacionados com escalas tem como objetivo minimizar a dissonância sensorial por meio da redução da rugosidade, tendo como meio a modelagem espectral. Propomos neste tópico um algoritmo para a construção de espectros que minimizem a dissonância em escalas de temperamento por igual. Essa proposta tem como base as experiências de Sethares (1998) e Pierce (1966) na construção de espectros relacionados com escalas.

As entradas do algoritmo, determinadas pelo usuário são: 1- O número de graus da escala n-tet que será reduzida em dissonância e sua frequência inicial. 2Os graus da n-tet que serão minimizados em dissonância. A saída do algoritmo será um espectro cuja medida da dissonância esteja reduzida.

Os processamentos computacionais executados pelo algoritmo são:

1. O algoritmo primeiro utiliza a informação da escala n-tet escolhida com sua respectiva frequência inicial para gerar a série de frequências, correspondentes aos graus da escala.

2. A partir da escolha do usuário, o computador seleciona apenas as frequências correspondentes aos graus da escala escolhidos pelo usuário para otimização.

\footnotetext{
${ }^{20}$ Linguagem de programação de alto nível, interpretada e com orientação a objetos.

21 "O Jupyter Notebook é um aplicativo da web de código aberto que permite criar e compartilhar documentos que contêm código ativo, equações, visualizações e texto narrativo". Acessível em: http://jupyter.org/.
} 
3. O algoritmo seleciona apenas um parcial por banda crítica.

4. O algoritmo retorna uma série de frequências que correspondem ao espectro reduzido em dissonância.

Esses processamentos estão ilustrados no fluxograma da figura 6:

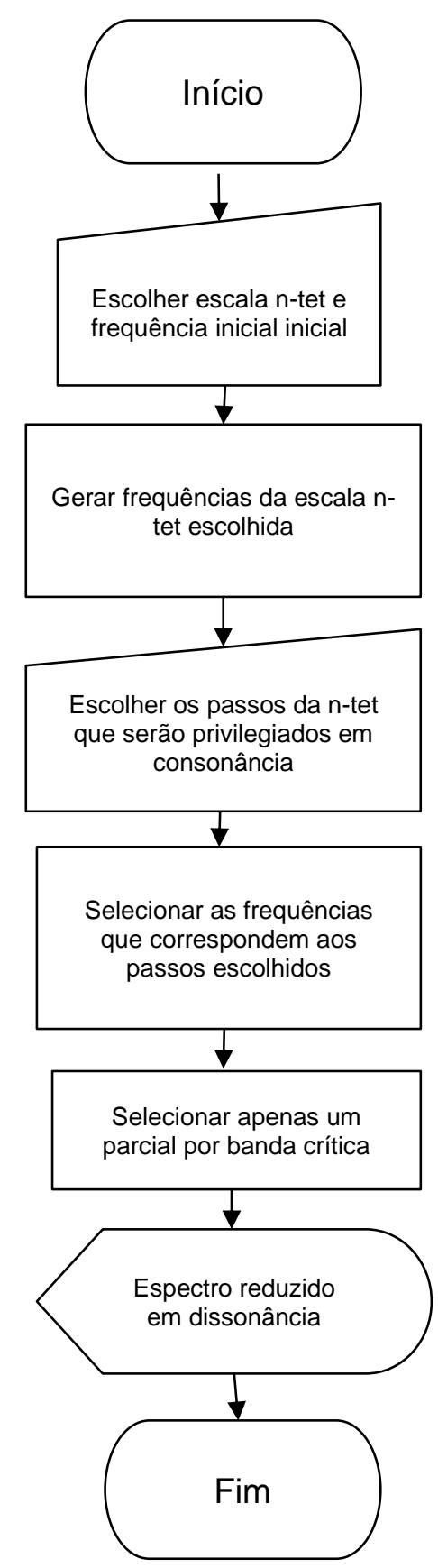

Figura 6- Fluxograma do algoritmo minimizador de dissonância em escalas do temperamento por igual. Os blocos retangulares correspondem a processos do algoritmo. Os trapezoidais correspondem a seleções devidas ao usuário.

Esse algoritmo está implementado em uma biblioteca computacional em Python. Abaixo, apresentam-se os objetos criados, relacionados aos graus do 
fluxograma mostrado na figura 6 , reunidos em uma biblioteca denominada ntetconsonance.

\begin{tabular}{|c|c|}
\hline Objetos em Python & Passo correspondente do algoritmo \\
\hline fullPartials & Gerar frequências da escala n-tet escolhida \\
\hline fullPartialsList & $\begin{array}{c}\text { Selecionar as frequências que } \\
\text { correspondem aos graus escolhidos }\end{array}$ \\
\cline { 1 - 1 } hz2bark & $\begin{array}{c}\text { Selecionar apenas um parcial por banda } \\
\text { crítca }\end{array}$ \\
\hline barkDiff & \\
\hline exclude1bark & \\
\hline
\end{tabular}

O objeto fullPartials da biblioteca tem por função de gerar uma série de parciais determinados pelos parâmetros dados pelo usuário.

Esse objeto admite a entrada de:

- Escala n-tet (número inteiro $\mathrm{n}$ )

- Frequência inicial da escala (número real/decimalf)

1. def fullPartials $(n, f, c=$ None, $q=10, i=2)$ : \# número de divisões; frequência inicial; numero de oitavas;

2 .

3. $r=i * *(1 / n)$

4. mat=np.zeros $([q, n])$ \# q linhas e $n$ colunas.

5.

6. for $k$ in range $(n)$ :

7. $\operatorname{mat}[0][k]=f^{*}\left(r^{* *} k\right)$ \#O é a primeira linha.

8.

9.

10.

for $j$ in range $(1, q)$ :

$\operatorname{mat}[j][k]=\operatorname{mat}[j-1][k] * 2$

11 .

12.

13.

14.

15.

16.

17.

18. $\quad$ return $\operatorname{mat}[:, \mathrm{C}]$ 
O objeto fullPartialsList filtra a lista de parciais gerado pelo objeto fullPartials, escolhendo apenas graus da escala conforme a escolha do usuário.

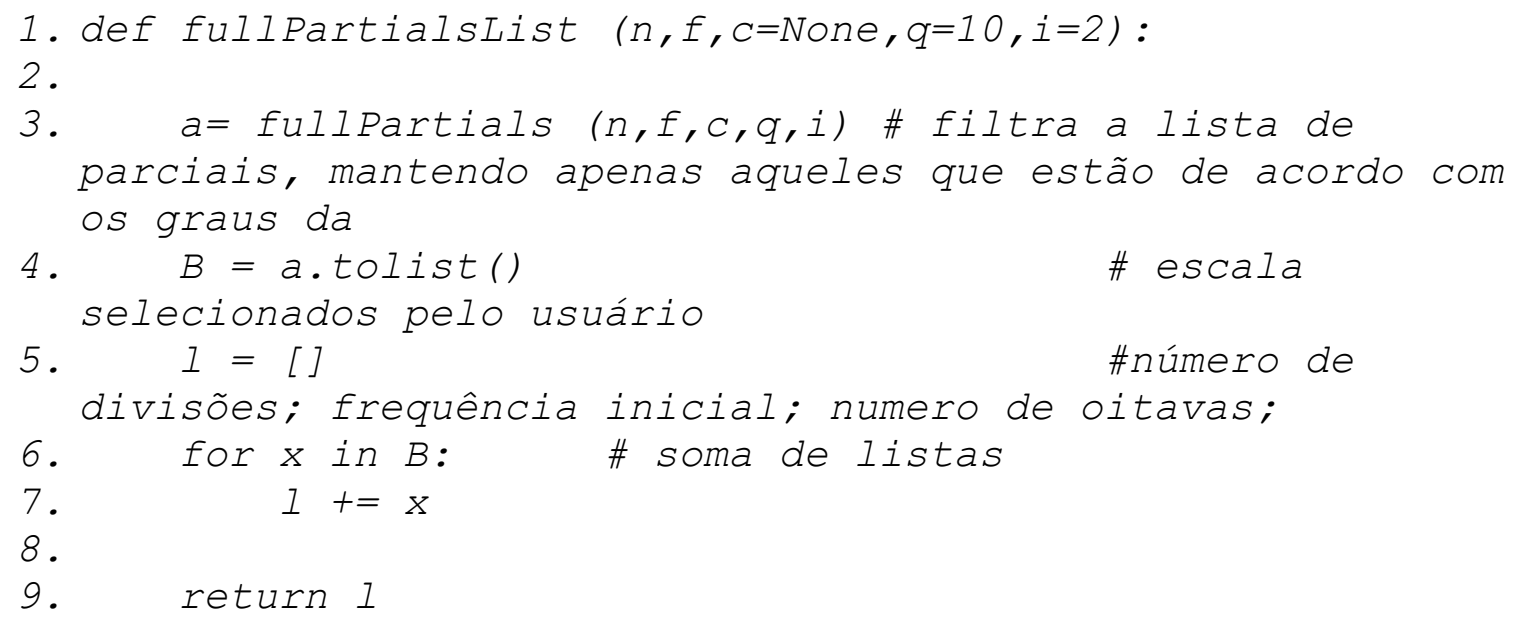

O objeto $h z 2 b a r k$ tem como função realizar a conversão de Hertz para a escala Bark (ZWICKER 1961) utilizando a formalização proposta por Traunmüller (1990), expostas nas equações de 2.13 a 2.16. Essa conversão será utilizada com o objeto barkDiff para a aplicação do filtro de bandas críticas em graus posteriores do algoritmo.

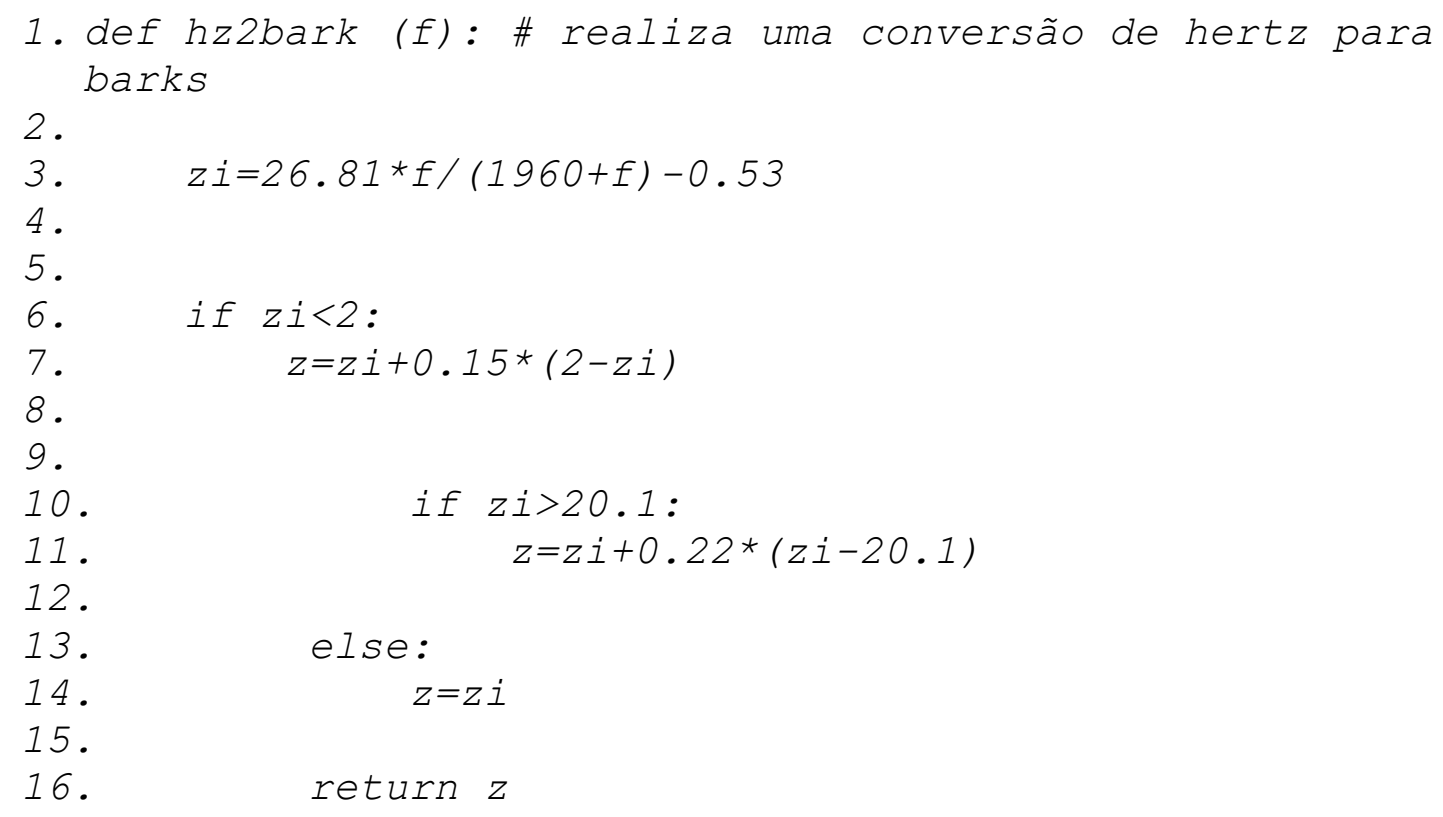


O objeto barkDiff tem por função calcular a diferença em barks de duas frequências.

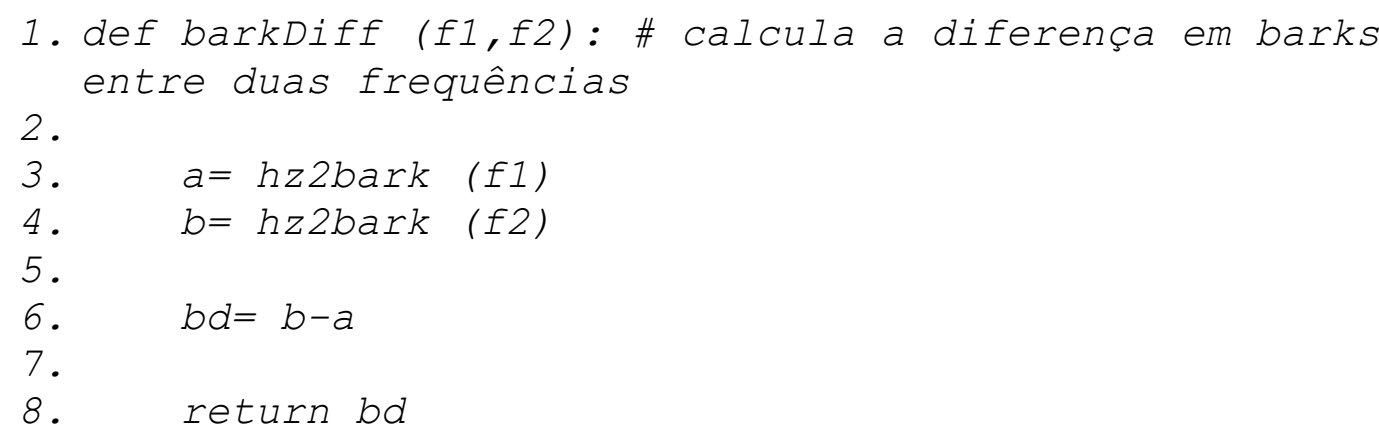

O objeto exclude1bark filtra a lista de parciais, não permitindo parciais com diferenças de menos de um bark, ou seja, não permitindo dois parciais dentro de uma mesma banda crítica.

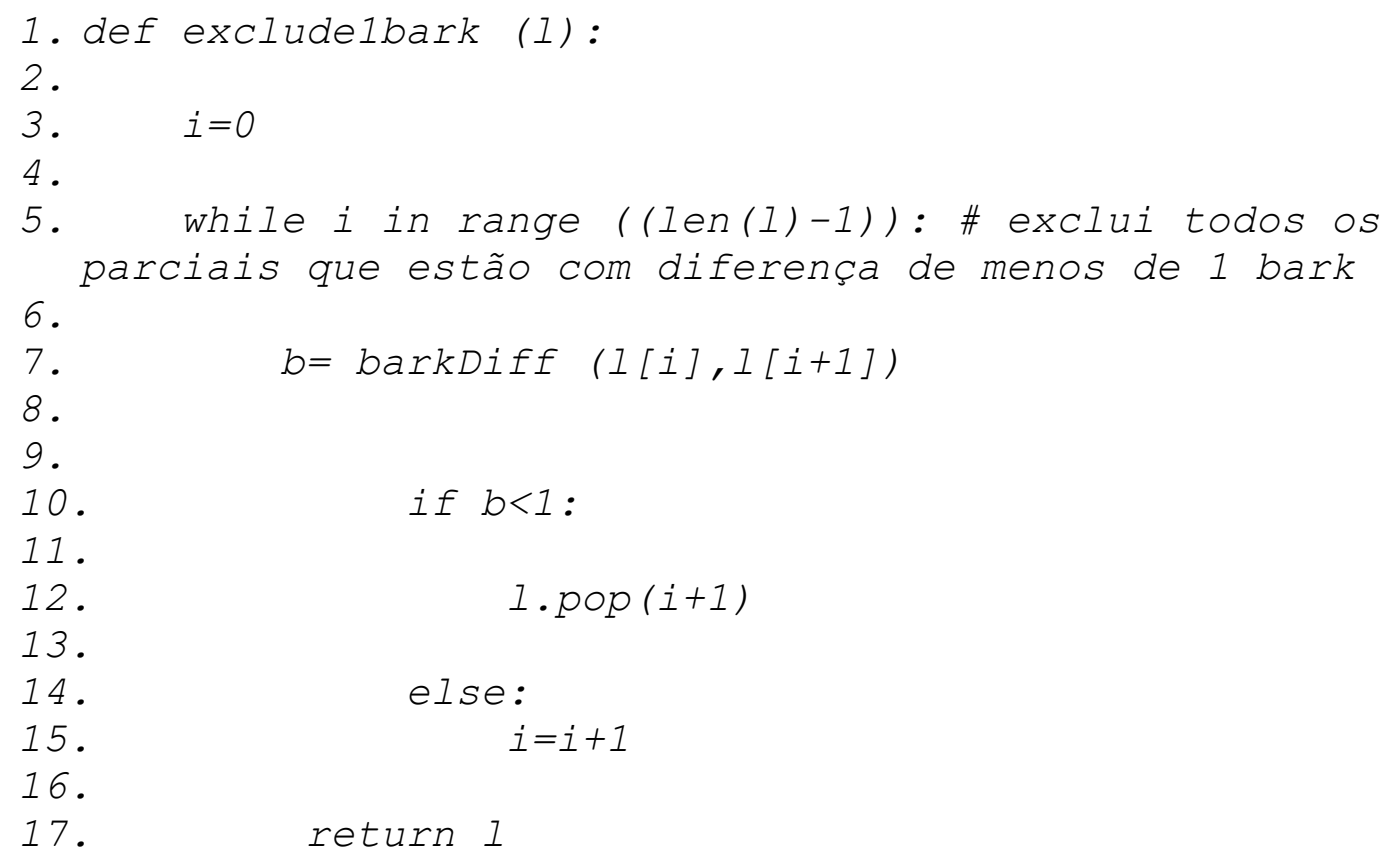

Utilizando os objetos expostos acima, podemos calcular a dissonância utilizando o seguinte código:

1. import ntetconsonance as nt

2. np.array (nt.excludelbark (nt. fullPartialsList $(n, f, c))) / f$ 


\subsection{Validação da dissonância modelada por meio de teste subjetivo}

Nesta seção detalharemos a metodologia utilizada em nosso experimento, iniciando pela exposição da hipótese experimental, a metodologia de análise sensorial escolhida, a infra estrutura e o desenho experimental.

Convencionamos nomear os timbres estudados usando um código de letras e números. $O$ código $8 M$ representa assim um timbre inarmônico, com as parciais escolhidas para minimizar a dissonância em uma escala 8-tet, conforme exposto no tópico 3.3.5. Já o código $8 R$ representa um timbre inarmônico, cujo espectro consiste em parciais de um espectro harmônico desviadas randomicamente, com intenção de maximizar a dissonância em uma escala 8-tet, procedimento também exposto no tópico 3.3.5. Os números representam os graus da escala que foram submetidos a teste. Por exemplo:

- 8M0-0 representa um timbre minimizado em dissonância executado com uma díade com os graus 0 e 0 da escala 8-tet.

- $8 R 0-7$ representa um timbre $8 R$ executado com uma díade com os graus 0 e 7 da escala 8 -tet.

\subsubsection{Hipótese experimental}

Hipótese principal: É possível, via técnica de síntese aditiva ${ }^{22}$, criar um espectro tendo como objetivo gerar consonância em díades previamente escolhidas. Portanto, haverá uma grande proximidade entre o nível de dissonância sensorial percebido pelo voluntário e aquele estimado pela curva de dissonância.

Hipótese secundária: Sendo as curvas de dissonância sensorial derivadas de modelos relacionados à fisiologia do ouvido, como é o caso dos modelos baseados na banda crítica, haverá uma grande proximidade entre a sensação de dissonância sensorial percebida por uma população de músicos e uma população de nãomúsicos.

\subsubsection{Método experimental}

Escolhemos como metodologia para o nosso experimento 0 teste de comparação pareada não forçada em análise sensorial, conforme a norma NBR

${ }^{22}$ Técnica de síntese digital que consiste na criação de um espectro complexo por meio da soma de tons puros (senoidais) gerados por osciladores. 
13088, ISO 5495 Análise Sensorial - Metodologia - Teste de comparação pareada (ASSOCIAÇÃO BRASILEIRA DE NORMAS TÉCNICAS, 1994). Escolhemos essa metodologia por ela permitir que o participante faça a escolha de uma amostra dentre duas possíveis tendo como referência um atributo psicofísico que, no caso, é a rugosidade/ dissonância. Além disso, essa metodologia foi a mesma utilizada por Geary (1980) em seu experimento com espectros inarmônicos, o que nos permite criar um diálogo mais próximo com a esta referência de relevo.

Partindo da hipótese de que é possível criar um espectro para minimizar a rugosidade em qualquer escala do temperamento por igual, a primeira parte do teste (ou Teste 1) executou a comparação entre díades da escala 8-tet comparando um espectro $8 M$ com um espectro $8 R^{23}$. A segunda parte do teste (ou Teste 2) verificou a percepção da rugosidade em cada passo da escala 8-tet com um espectro $8 \mathrm{M}$. Os participantes foram expostos a dois pares de estímulos (teste por comparação pareada ${ }^{24}$ ) e responderam em qual percebem o maior nível de rugosidade: o primeiro, o segundo, ou respondem "não sei" para todas as outras situações complementares. Para todas as amostras sonoras foi executado o mesmo sinal para ambos os ouvidos (fonte monaural). Os testes foram programados usando-se o software PsychoPy ${ }^{25}$.

\subsubsection{Infra-estrutura experimental}

- Fones de ouvido marca Sennheiser modelo HD 180.

- Computador marca Lenovo modelo Thinkpad T440p, com processador de 2,60GHz Intel(R) Core(TM) i5, 8GB de memória RAM, sistema operacional "Windows 10" Home Single Language (64 bits).

-Software PsychoPy v1.84.2 (PEIRCE, 2009).

\subsubsection{Protocolo experimental}

Antes do teste o voluntário preencheu um Termo de Consentimento Livre e Esclarecido (TCLE) para participar do experimento, e um questionário para registrar o seu nível de experiência musical e avaliar o enquadramento no critério de inclusão (situação de audição normal).

\footnotetext{
${ }^{23}$ Terminologias para os espectros conforme descrito na seção 3.3.6.

24 Teste usado por Geary (1980).

${ }^{25}$ Accessível em http://www.psychopy.org/.
} 
O teste contou com 5 blocos: 1- Apresentação; 2- Treinamento; 3- Teste 1: 8M versus $8 R$; 4 - Teste $2: 8 M$ versus $8 M$; 5 - Agradecimento. A ordem de apresentação do teste segue as recomendações da norma ITU-R BS.1116-1 (INTERNATIONAL TELECOMMUNICATIONS UNION, 1994) que versa sobre métodos para a avaliação subjetiva de pequenas deficiências e variações em sistemas de áudio. ${ }^{26}$

Bloco 1- $\mathrm{Na}$ apresentação (cf. recomendação ITU-R BS.1116-1), os voluntários recebem instruções para iniciar o teste. A única instrução dada ao voluntário neste bloco se refere ao mecanismo de resposta do teste, que se dará por meio do teclado do computador, como podemos ver nas telas de apresentação exibidas aos usuários, mostradas nas figuras 7 e 8.

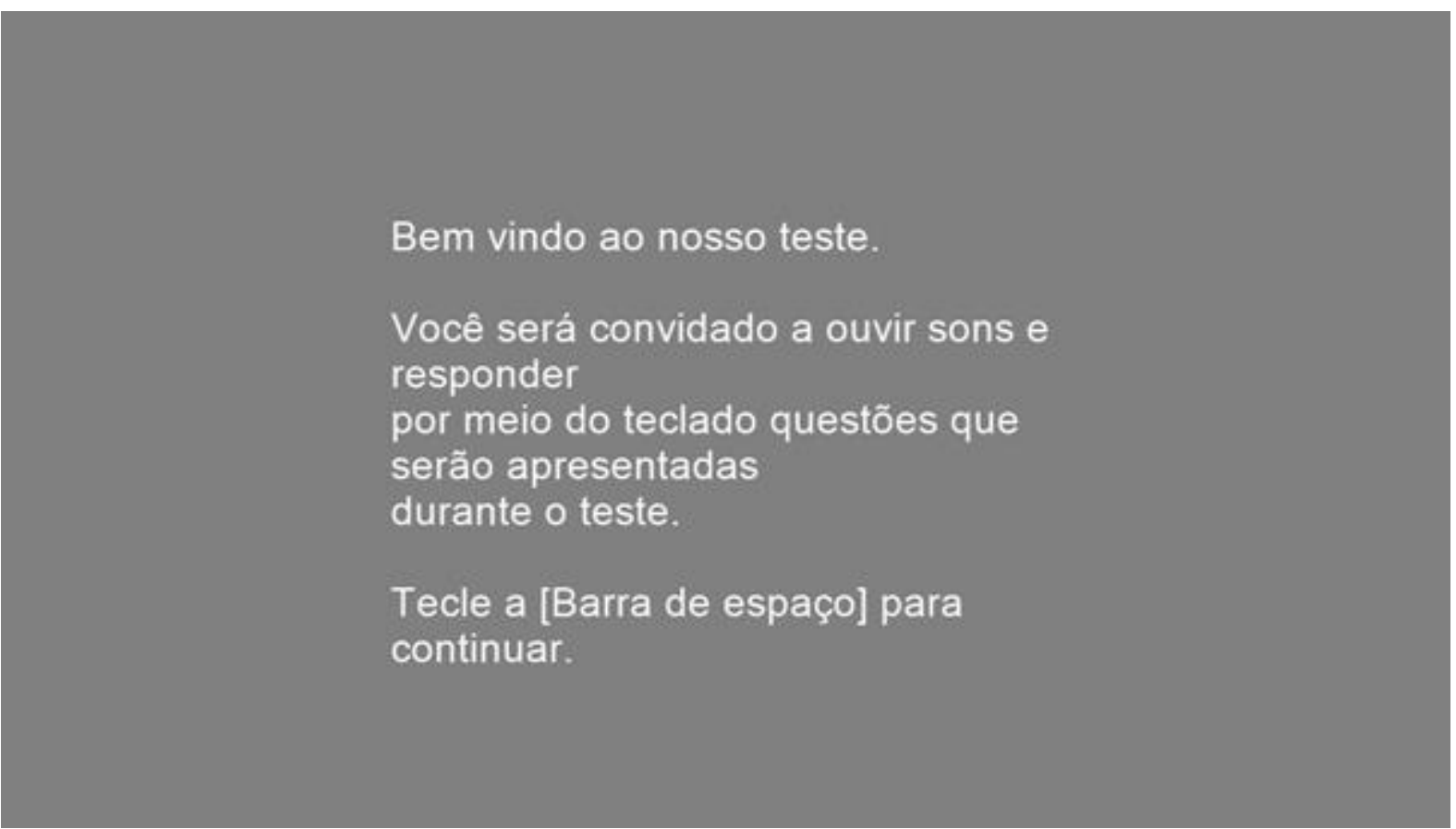

Figura 7- Exemplo da tela de Apresentação (primeira parte) do teste subjetivo.

${ }^{26}$ Esta norma tem como título "Methods for the subjective assessment of small impairments in audio systems including multichannel sound systems". 


\section{Antes do inicio do teste, faremos um \\ pequeno \\ treino onde você será convidado a \\ escolher um \\ som mediante a questão que lhe será \\ apresentada. \\ Para responder você usara as teclas: \\ [A] Para escolher o primeiro som. \\ [L] Para escolher o segundo som. \\ [Barra de espaço] Para "não sei". \\ Tecle a [Barra de Espaço] para \\ começar o treino.}

Figura 8- Exemplo da tela de Instrução sobre a fase de treino para o teste subjetivo.

Bloco 2- No treinamento (cf. recomendação ITU-R BS.1116-1), os voluntários têm de responder à mesma questão que respondem no teste, que consiste no seguinte: Os participantes são expostos a dois pares de sons complexos (isto é, duas díades, onde cada tom da díade contém 8 parciais em arranjo inarmônico) sequencialmente, cada um com duração de 2,5 segundos intercalados com 2 segundos de silêncio. Em seguida, são apresentados à questão mostrada na figura 9: "Qual som possui a combinação mais dissonante, áspera e tensa? O primeiro? [Tecla A]; O segundo? [Tecla L]; Não sei [Barra de espaço]". Essa questão tem como base o teste de comparação pareada não forçada em análise sensorial (cf. NBR 13088, ISO 5495 - Análise Sensorial). A escolha dos termos utilizados têm como referência os trabalhos de Geer et. al. (1966), Maher e Berlyne (1982) e Costa et. al. (2000) que trabalham com escalas semânticas relacionadas a atributos auditivos. Os participantes responderam às questões utilizando o teclado. Se o participante não possuísse dúvidas após o treinamento, começava imediatamente os blocos de teste. 
Figura 9- Pergunta do treino e do teste.

Bloco 3- Após a apresentação, o bloco 3 (Teste 1) tem por objetivo avaliar qual espectro gera menor sensação de rugosidade em uma escala 8-tet: um espectro $8 M$ ou um espectro $8 R$ (ver seção 3.3.5). Portanto, em cada questão os participantes são expostos a uma díade da escala $8 M$ executada com um dos espectros acima citados ( $8 M$ ou $8 R$ ), seguido da mesma díade com o outro espectro ( $8 M$ ou $8 R$ ). As díades e os espectros são sorteados pelo software em ordem aleatória e apresentados em um total de 3 vezes no bloco. As respostas admissíveis incluem a escolha de uma das díades como mais dissonante ou não sei. As escolhas relacionadas à apresentação dos timbres neste bloco foram baseadas nos experimentos de Geary (1980) e o número de repetições dos estímulos, no experimento de Plomp e Levelt (1965).

Bloco 4- Este bloco tem por objetivo avaliar em quais díades da escala 8-tet obtemos o maior nível de rugosidade (Teste 2). Para isso, os participantes foram expostos a uma díade da escala 8-tet seguida de outra díade, ambas executadas com um espectro 8M. Assim como no bloco anterior, as díades e os espectros foram sorteados pelo software em ordem aleatória e apresentados em um total de 3 vezes no bloco. As respostas admissíveis também incluíam a escolha de uma das díades como mais dissonante ou não sei.

Bloco 5 - O teste encerra-se com uma tela de agradecimento aos participantes. O teste tem uma duração total de cerca de 30 minutos. Ao final, o 
participante pode fazer um relato sobre a sua experiência durante o teste, preenchendo um questionário facultativo entregue a ele/ela.

Os critérios de inclusão e exclusão do experimento foram:

\section{A- Inclusão:}

- Indivíduos maiores de idade, sem estudo musical formal.

- Indivíduos maiores de idade, com estudo musical formal de nível médio ou superior.

\section{B- Exclusão:}

- Indivíduos com deficiências auditivas.

- Indivíduos com epilepsia.

\subsubsection{Estímulos sonoros do teste}

A escala musical utilizada como estímulo sonoro nesse teste foi a 8-tet. Foram executadas díades ${ }^{27}$ com o passo 0 combinado com cada passo da escala 8-tet. As notas das díades foram tocadas com diferença de 0,5 segundo entre a entrada da primeira para a segunda nota, e têm duração total de 2,5 segundos. As díades são executadas com uma pausa (silêncio) de 2 segundos entre elas.

Na primeira parte do teste, foram comparadas díades da 8-tet com espectros diferentes: o espectro $8 M$ e o espectro $8 R$.

O espectro $8 M$ foi construído a partir do algoritmo exposto na seção 3.1 . As frequências do espectro são 1,00f; 2,38f; 4,00f; 4,76f; 5,66f; 6,73f; 8,00f; 9,51f; com atenuação de amplitude de 1/parcial. As parciais do espectro estão ilustradas na fig. 10.

${ }^{27}$ Combinação de dois estímulos sonoros. 


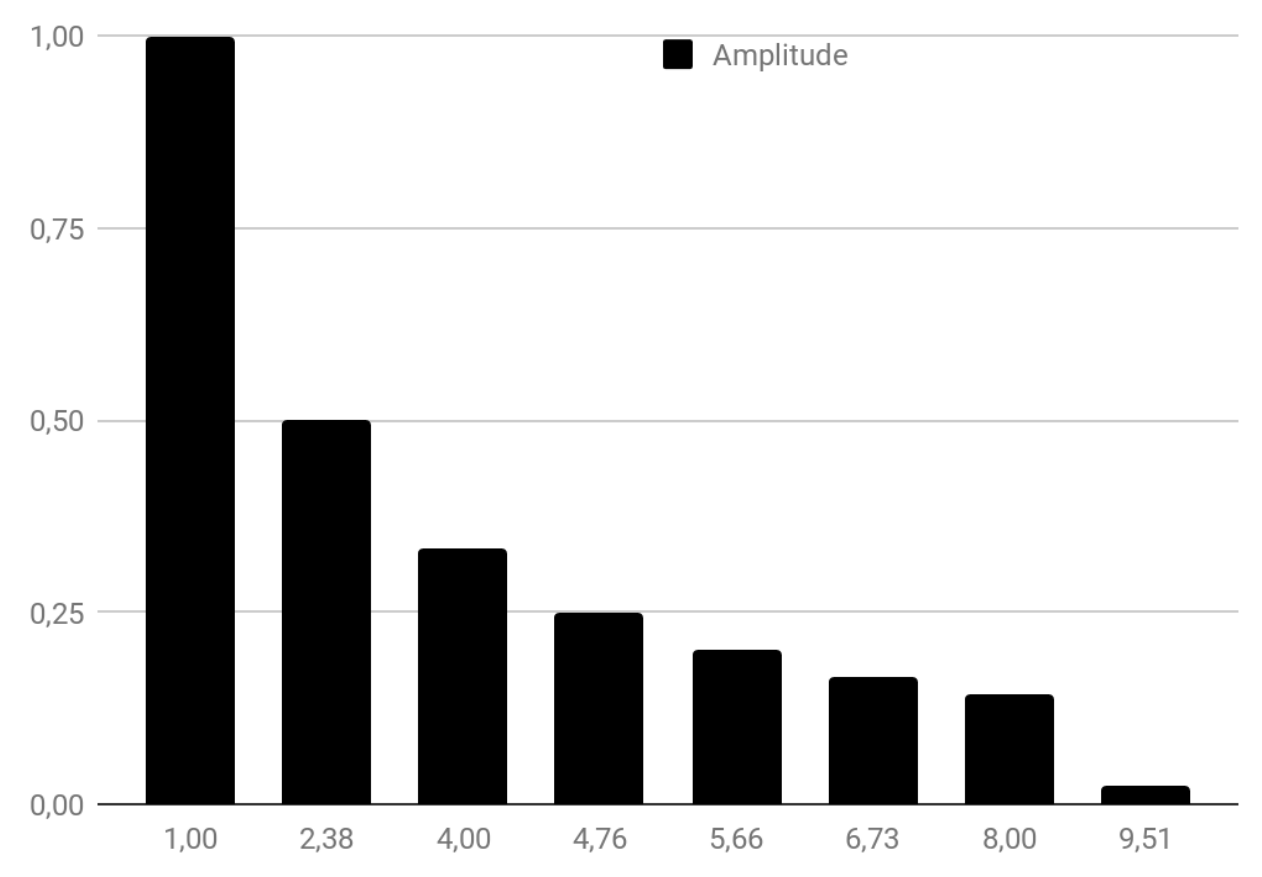

Figura 10- Parciais do espectro 8M.

O espectro $8 R$ foi construído a partir de pequenos desvios aleatórios nas parciais de um espectro harmônico, resultando nas parciais 1,00f, 2,74f; 3,56f; 4,76f; 5,48f; 6,55f; 7,72f e 8,19f, com atenuação de amplitude de 1/parcial. As parciais do espectro estão ilustradas na fig. 11. 


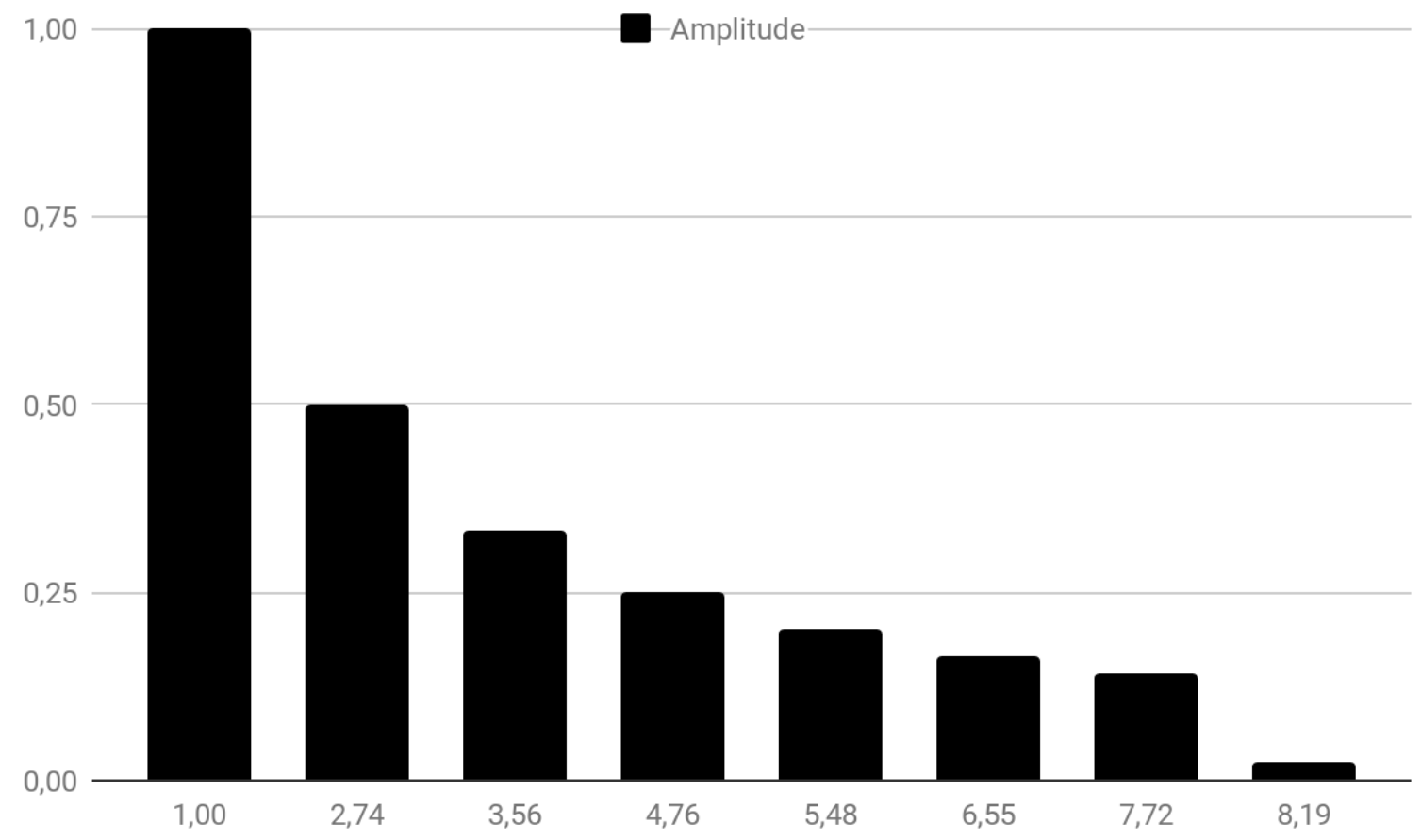

Figura 11- Parciais do espectro 8R.

Na figura 12 podemos verificar as curvas de dissonância esperada para os espectros $8 \mathrm{M}$ e $8 \mathrm{R}$, geradas a partir do modelo de Vassilakis (2001) para os dois espectros citados. A partir dessas curvas podemos observar que o espectro $8 R$ gera níveis de dissonância mais altos em todos os pontos da escala quando comparado com o espectro $8 \mathrm{M}$. Esse dado nos será útil para observar a preferência dos participantes por um espectro ou outro e observar o coeficiente de correlação entre as curvas do modelo estudado e os resultados dos testes subjetivos.

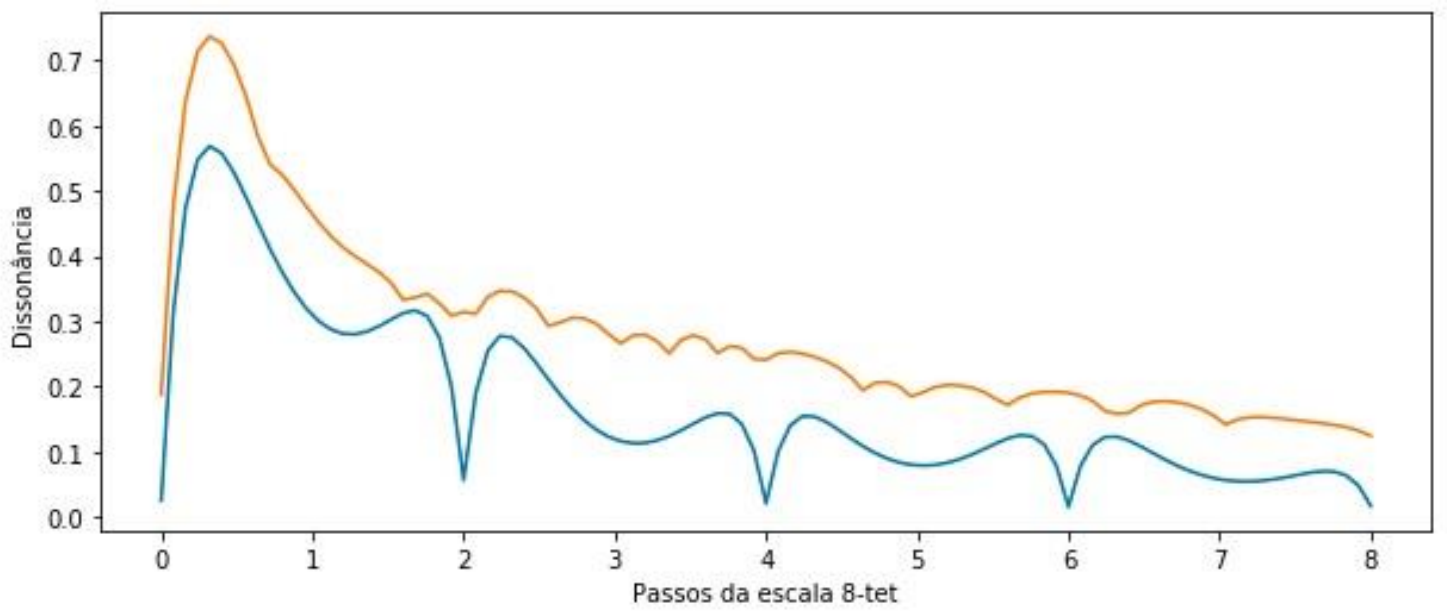

Figura 12- Comparação das curvas de dissonância esperadas segundo o modelo de Vassilakis com o espectro 8M (abaixo) e com o espectro 8R (acima) para uma escala 8-tet, com frequência inicial em $500 \mathrm{~Hz}$. 


\subsection{Resultado das avaliações dos testes subjetivos}

Esta seção apresenta os resultados dos testes subjetivos feitos a partir de análises estatísticas. No Teste 1, fizemos a compilação dos dados utilizando porcentagens, conforme recomendação da norma NBR 13088. No Teste 2, realizamos a compilação utilizando pontuações (scores) de dissonância, baseados em Geary (1980). Realizamos também cálculos de correlação linear ${ }^{28}$ para avaliar as diferenças dos resultados entre populações e o quanto os resultados se aproximam dos modelos de dissonância.

Nesta seção realizamos apenas a apresentação dos dados obtidos, sendo que a análise dos resultados se encontra no tópico 5.1 desta dissertação.

\subsubsection{Teste 1 - Comparação de díades da escala 8-tet para timbres distintos}

Nesta seção apresentamos os resultados do teste 1. Neste teste, optamos por fazer uma análise a partir de porcentagens, conforme uma das sugestões de análises de dados sugerida pela norma NBR 13088. Isso nos permite aferir a preferência dos participantes com relação aos timbres testados e posteriormente realizar comparações com os resultados esperados. Foram realizados também cálculos de correlação para avaliar diferenças nos resultados entre populações distintas e 0 quanto os resultados se aproximam dos modelos de dissonância.

Observando ambas as populações (músicos e não-músicos, gráfico 2), os voluntários escolheram o timbre $8 R$ como mais dissonante apenas nas díades 0-0 e $0-4$. Nas díades $0-1,0-5,0-6,0-7$ e $0-8$, os participantes escolheram como mais dissonante o timbre $8 M$. As díades 0-2 e 0-3 possuem pontuações muito próximas entre ambos os timbres, revelando não haver uma diferença sensorial muito expressiva com relação a esses intervalos. Em todos os casos a opção por não sei foi abaixo de $20 \%$, exceto para a díade $0-3$ e $0-8$, que foram respectivamente $21 \%$ e $24 \%$.

\footnotetext{
28 Utilizamos o Coeficiente de Correlação Linear, que é expresso na equação Correl $(X, Y)=(x-x)(y-$ $y) /(x-x) 2(y-y) 2$, sendo uma função para análise estatística de vetores usualmente disponível em software de planilhas como Excel e similares.
} 


\section{Teste 1 - Ambas Populações}

80

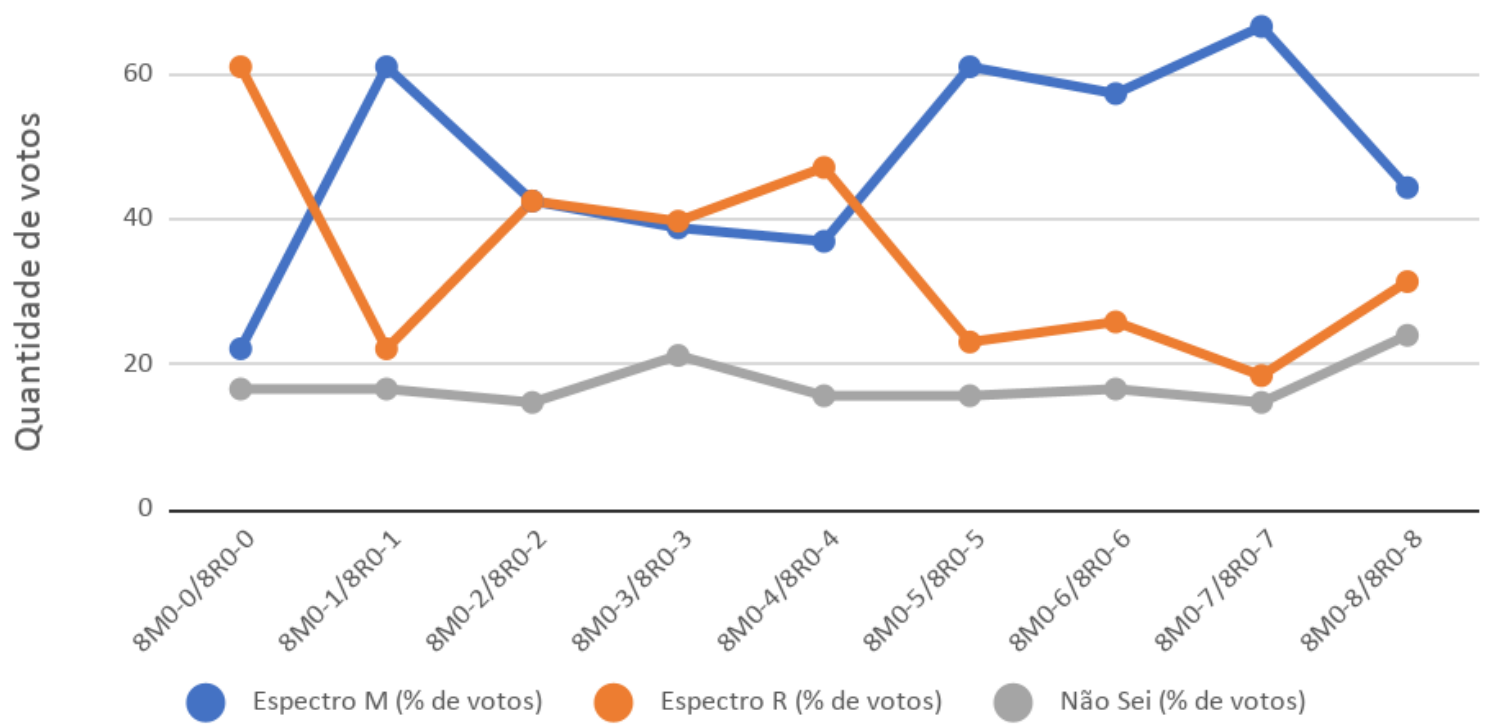

Gráfico 2- Resultado do teste 1, em porcentagem, plotando os resultados para ambas as populações.

Observando agora os dados das respostas dos músicos (gráfico 3), podemos notar uma diferença. Nas díades 0-0, 0-2, 0-3 e 0-4, houve uma maior quantidade de votos no timbre $8 R$ como mais dissonante. Já nos graus $0-1,0-5,0-6,0-7$ e 0-8, encontramos uma preferência pelo timbre $8 \mathrm{M}$ como mais dissonante. Em todos os casos a opção por não sei foi abaixo de $22 \%$. 


\section{Teste 1 - Músicos}

80

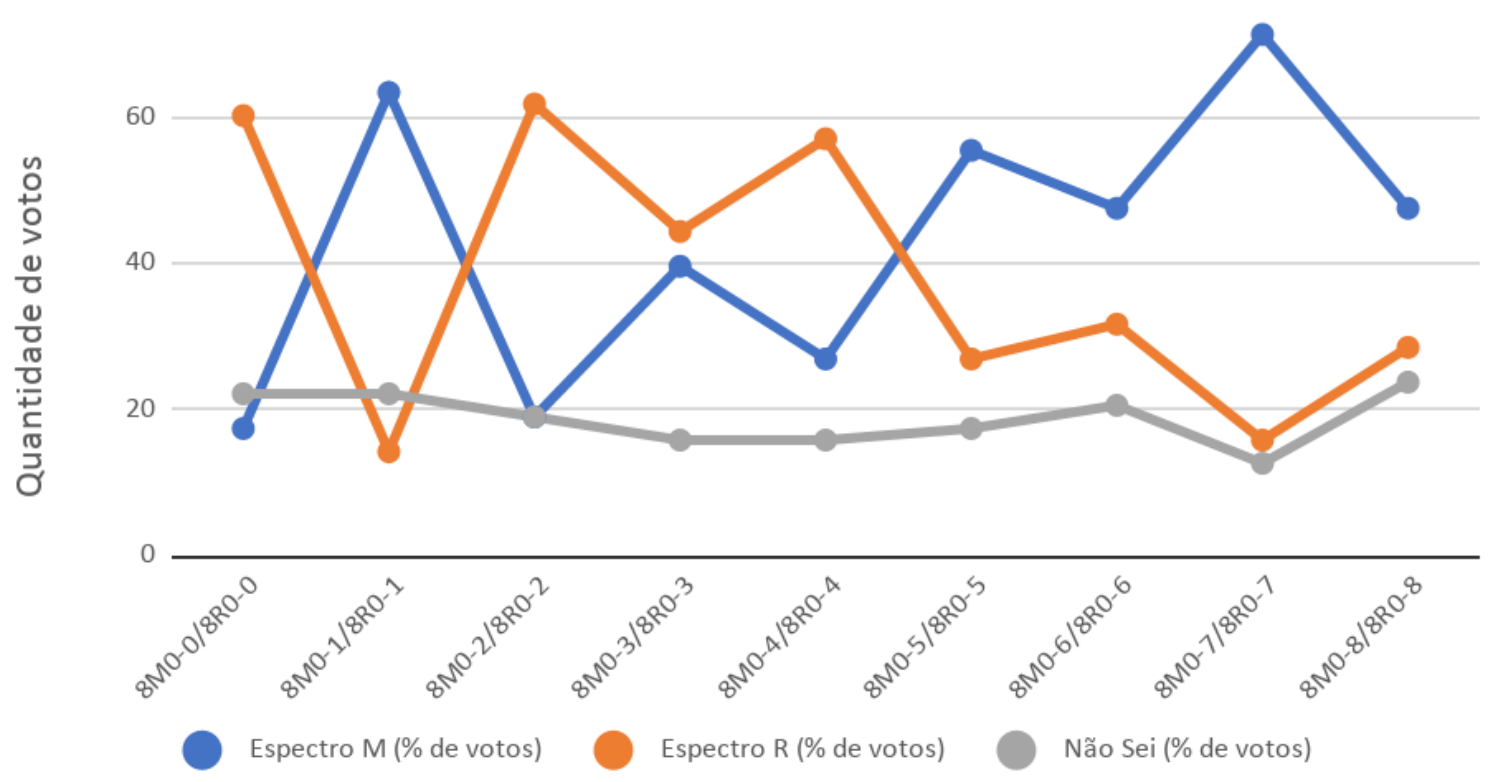

Gráfico 3- Resultado do teste 1, em porcentagem, plotando os resultados para a população músicos.

Já observando os dados da população de não-músicos (gráfico 4), percebemos uma tendência de preferir como dissonante o timbre $8 M$, já que em todos os casos a preferência foi pelo timbre $8 M$, exceto no passo 0-0 da escala. Há pontos de maior proximidade, como é o caso da díade $0-3$, onde os valores para os timbres $8 M, 8 R$ e a escolha por não sei apresentam respectivamente $37,7 \%, 33,3 \%$ e $28,8 \%$ e na díade $0-8$, onde os valores para os timbres $8 M$ e $8 R$ são respectivamente $40 \%$ e $35,55 \%$. Em todos os casos a opção por não sei foi abaixo de 17\%, exceto nas díades 0-3 e $0-8$, onde os valores foram respectivamente $28,88 \%$ e $24,44 \%$. 


\section{Teste 1 - Não-Músicos}

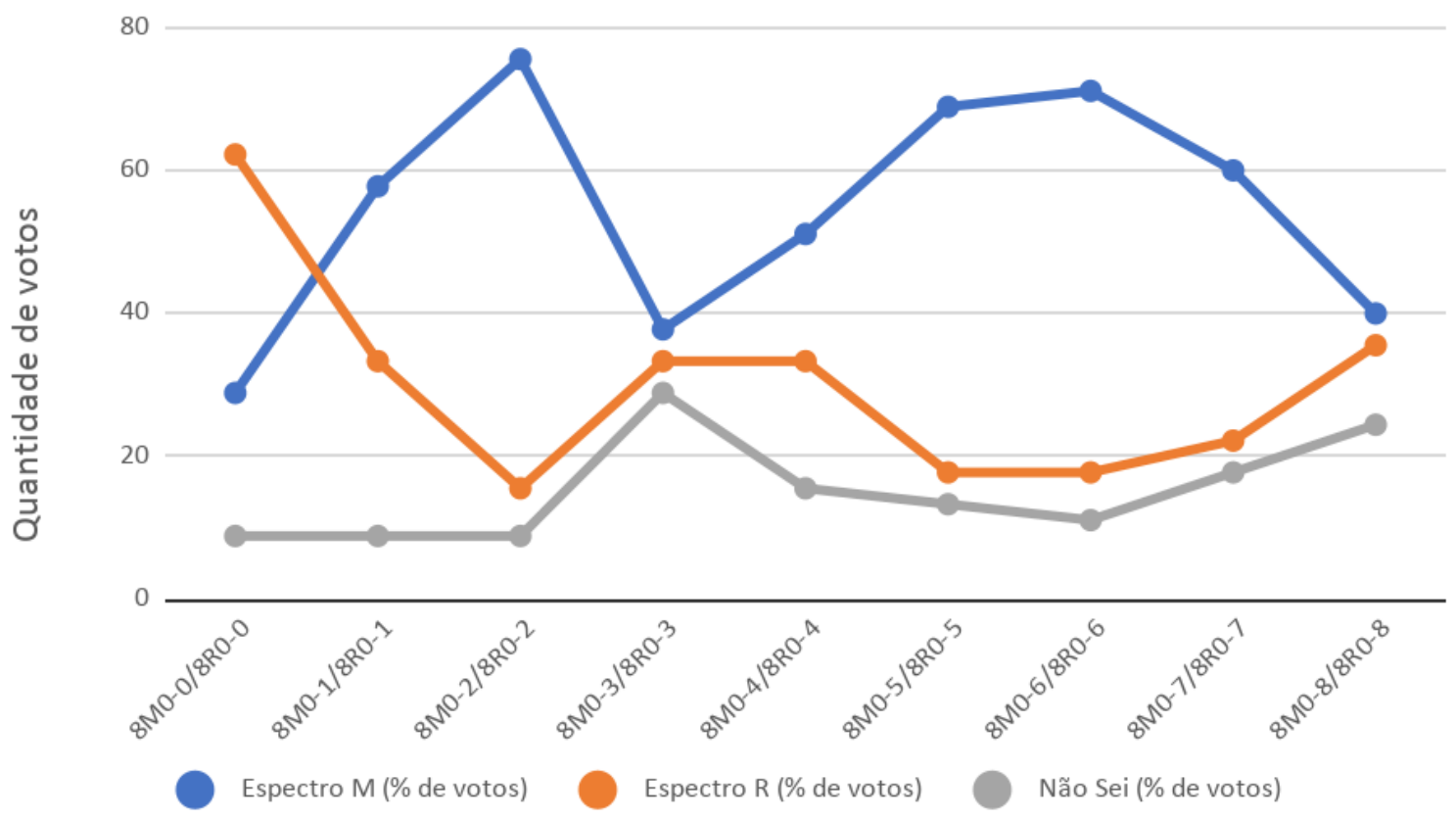

Gráfico 4- Resultado do teste 1, em porcentagem, plotando os resultados para a população de não músicos.

Abaixo, observamos no gráfico 5 a diferença entre os votos das duas populações, que nos permite constatar onde houve maior acordo e maior desacordo. A maior parte das diferenças ficou abaixo de $20 \%$, exceto nas díades 0-2, 0-4 e 0-6, sendo que o maior desacordo está nas respostas da díade 0-2. 
Teste 1 - Diferença entre Voto de Músicos e Não-Músicos (\% absoluto)

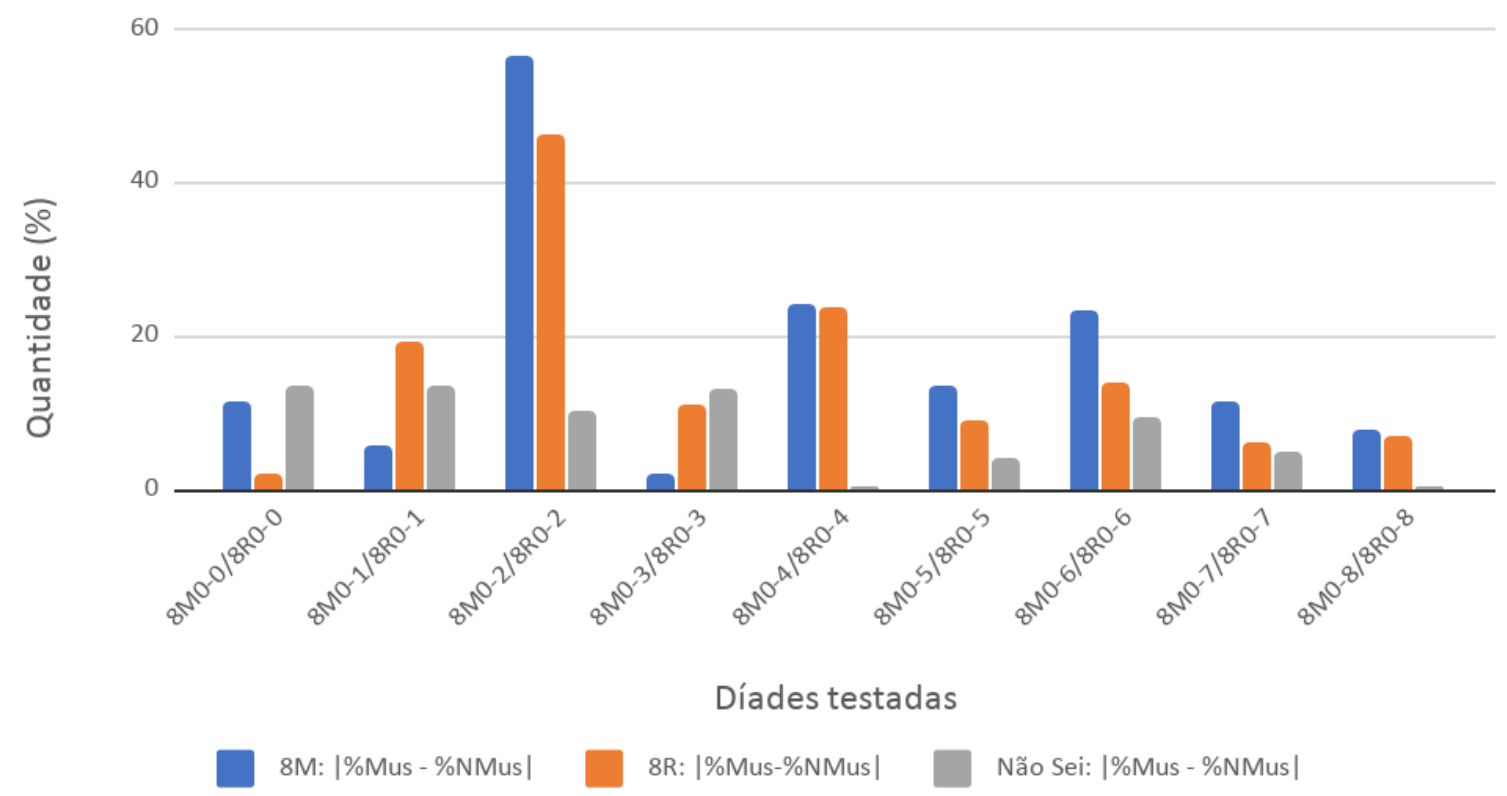

Gráfico 5- Diferença, em porcentagem, nos resultados entre Músicos e Não-Músicos para o Teste 1.

Calcularam-se os coeficientes de correlação entre as escolhas de músicos e não-músicos para as três respostas (timbre $8 M$ considerado mais consonante; timbre $8 R$ considerado mais dissonante; e não-sel) e os resultados foram, respectivamente $p=0,2703, p=0,3300$ e $p=-0,2836$, revelando uma correlação fraca entre os resultados das duas populações.

Para auxiliar na análise dos resultados, traçamos uma curva da diferença em dissonância esperada entre os timbres $8 R$ e $8 M$ na escala 8-tet, que pode ser visto na figura 13: 


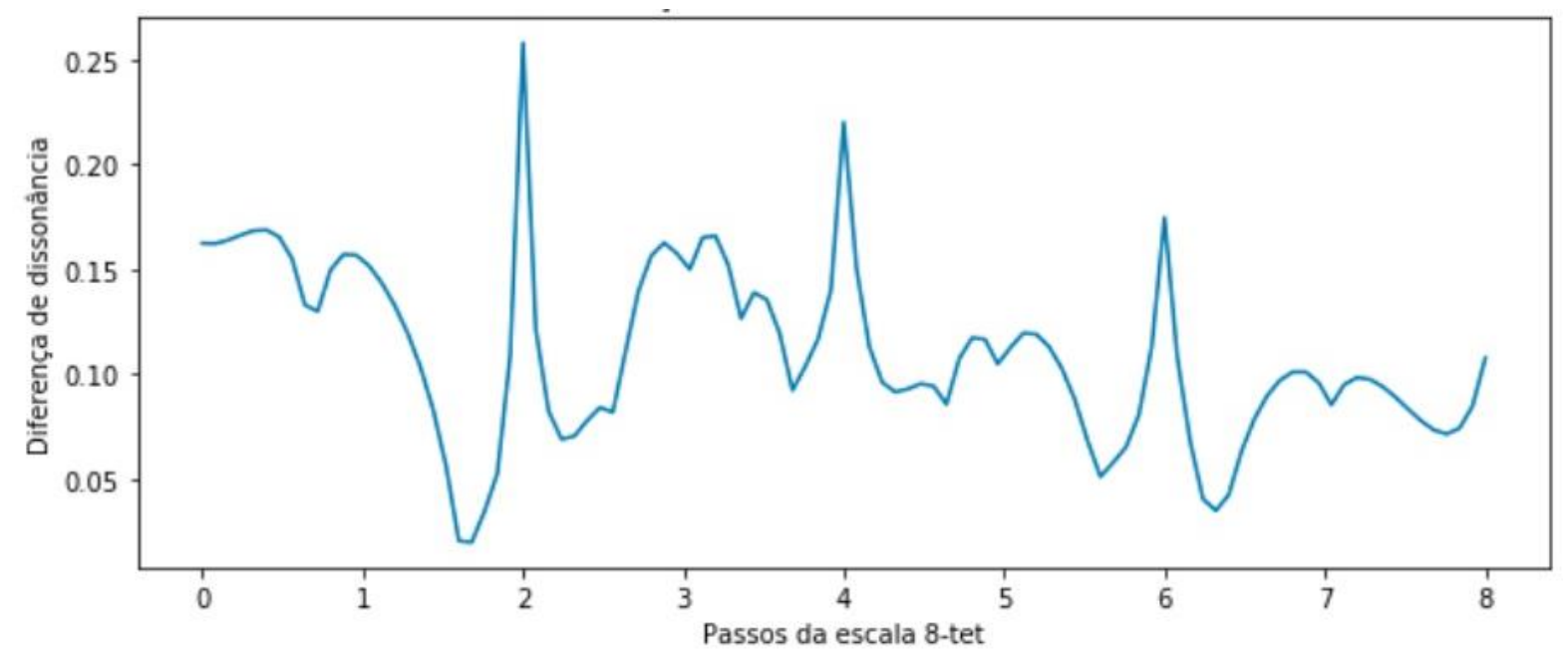

Figura 13- Curva da diferença de dissonância esperada entre os timbres 8R e 8M na escala 8-tet, segundo o modelo de Vassilakis.

A partir da curva da figura 13, podemos inferir que:

1. Em todos os casos, existe uma diferença de dissonância, sendo que o timbre mais dissonante é o $8 R$. Isso faz com que esperemos que em todos os casos as pessoas votem em $8 R$ como mais dissonante.

2. Pelo fato de a maior diferença de dissonância se encontrar nas díades 0-2, 04 e 0-6, espera-se, em conformidade com nossa hipótese, que nesses graus haja uma maior concordância e quantidade de votos pelo timbre $8 \mathrm{R}$ como mais dissonante.

Em nenhum dos casos essa hipótese se confirma completamente. No caso do gráfico 2 para ambas as populações, o único caso significativo de voto em $8 R$ foi no passo 0 -1. No caso do gráfico 3 para músicos, a preferência por $8 R$ ocorreu nas díades 0-0, 0-2, 0-3 e 0-4. No gráfico 4, para não-músicos, vemos a preferência por $8 R$ apenas na díade $0-0$.

Partindo do pressuposto que, quanto maior a diferença em dissonância entre os timbres, maior deveria ser a preferência dos participantes pelo timbre $8 R$, calculamos o coeficiente de correlação entre as escolhas de cada população pelo timbre $8 R$ e a curva de diferença de dissonância esperada, obtendo o seguinte resultado: para ambas as populações, $p=-0,3061$; para os músicos, $p=0,1153$; e para os não-Músicos, $p=-0,6722$. Estes valores não mostram correlações significativas entre os resultados experimentais e as previsões do modelo de dissonância de 
referência, além de também mostrarem discordâncias entre as populações, que serão examinadas mais adiante.

\subsubsection{Teste 2 - Comparação de díades da escala 8-tet de mesmo timbre}

Nesta seção, apresentamos os resultados do teste 2. Para compilar os resultados, utilizamos pontuações (scores) de dissonância, conforme o teste de Geary (1980), que foram calculados da seguinte maneira:

- Quando um som é votado como mais dissonante, recebe 1 ponto.

- Quando o participante vota não-sei são acrescentados 0,5 pontos em cada timbre da situação.

Isso nos permite fazer uma avaliação geral de dissonância para cada díade comparada em todas as situações, proporcionando uma possibilidade de comparação com as curvas de dissonância calculadas.

Observando o gráfico 6, da pontuação para ambas as populações, percebemos que as díades consideradas mais dissonantes são as 0-1 e 0-7 e as consideradas mais consonantes são as 0-0 e 0-2. De 0-2 a 0-5, temos um crescente nível de dissonância, interrompido com uma leve queda na díade 0-6. Após um pico de dissonância na díade 0-7, observa-se novamente uma queda na díade 0-8.

\section{Teste 2 - Ambas Populações}
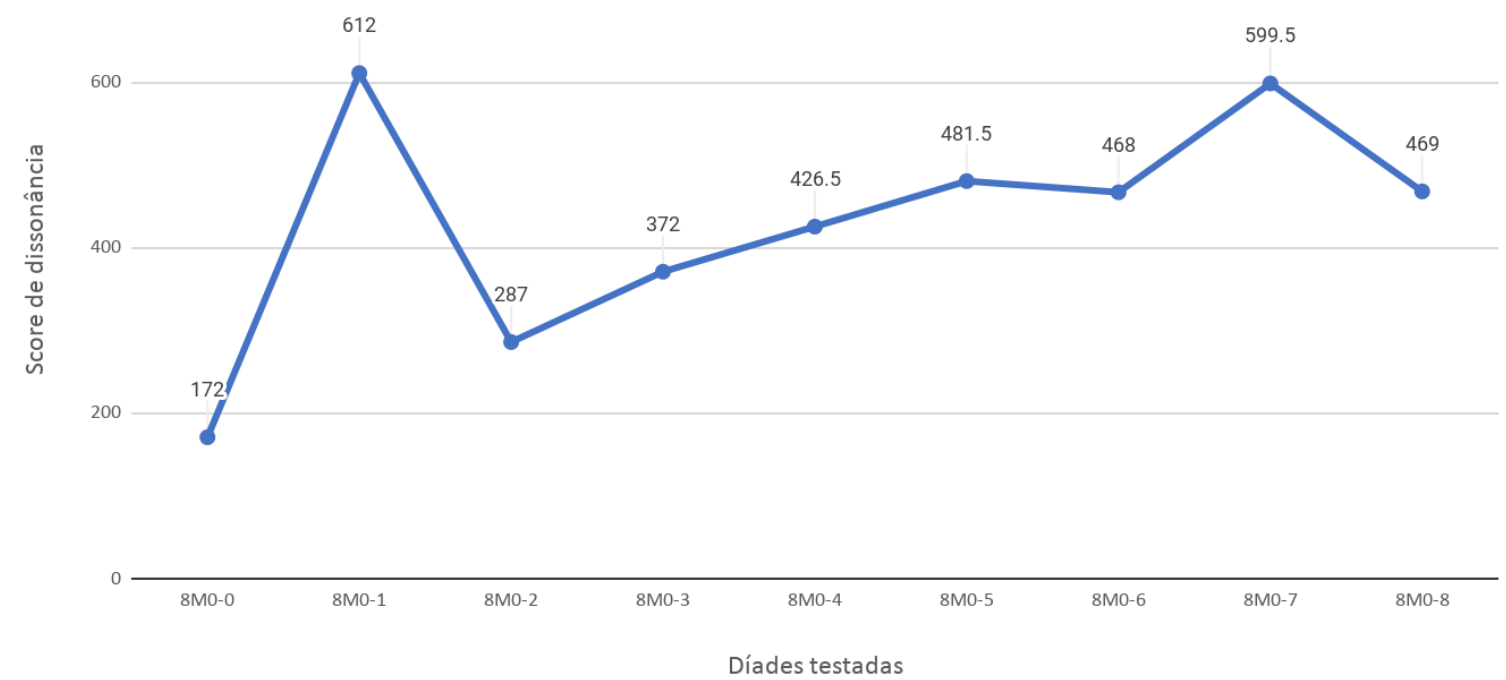

Gráfico 6- Pontuação (score) de dissonância para ambas as populações para o teste 2. 
Na pontuação obtida da população de músicos (gráfico 7 ) conseguimos observar o mesmo perfil do gráfico 6 , com as máximas e mínimas de dissonância nos mesmos pontos.

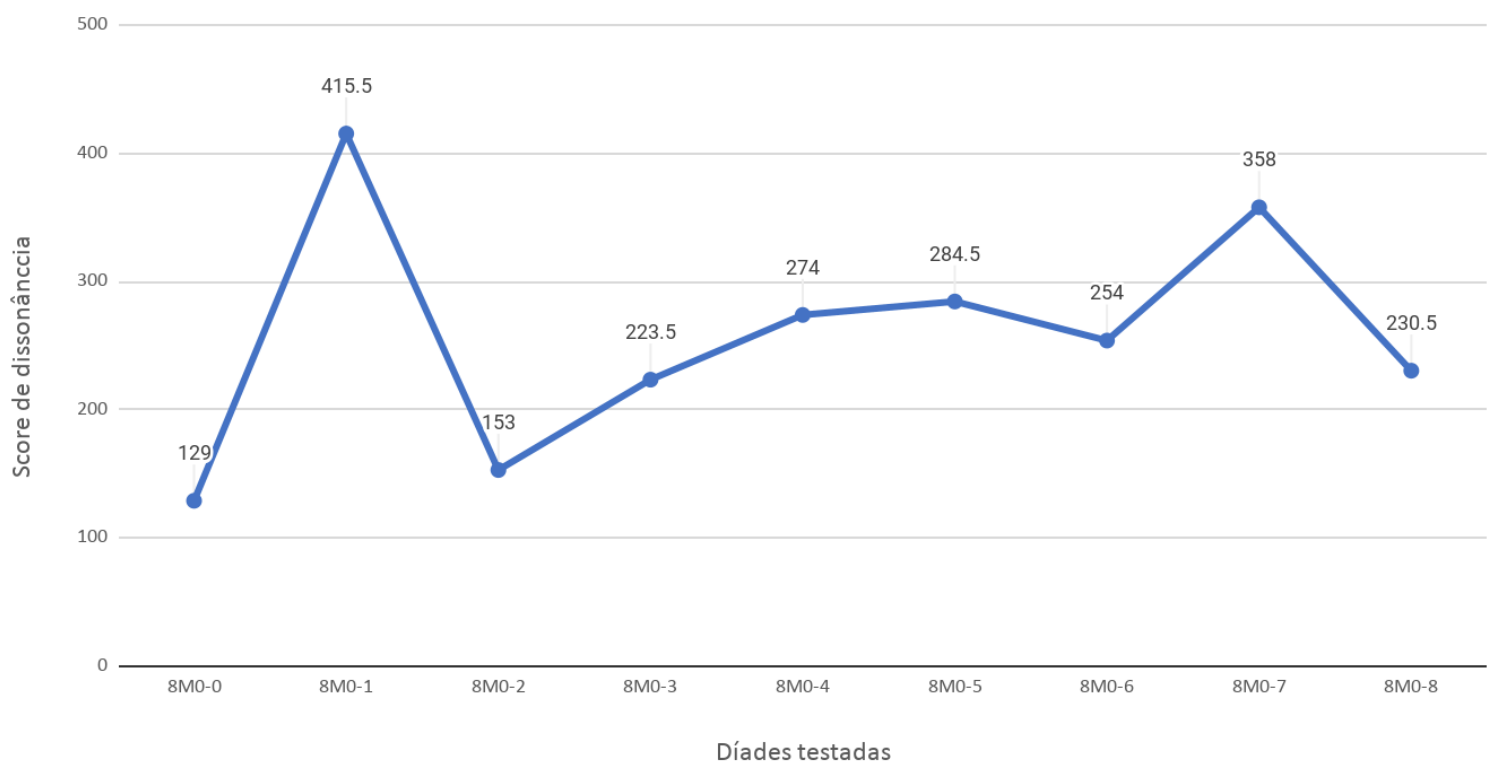

Gráfico 7- Pontuação de dissonância para a população Músicos para o Teste 2.

Já no gráfico 8, referente à população de não-músicos, observamos uma mudança no perfil com relação aos gráficos 6 e 7 . Embora as mínimas de dissonância ainda estejam nas díades 0-0 e 0-2, a máxima se encontra nas díades 0-7 e 0-8, seguidas da díade 0-1. Entre as díades 0-2 e 0-7, observa-se um crescente nos valores. 


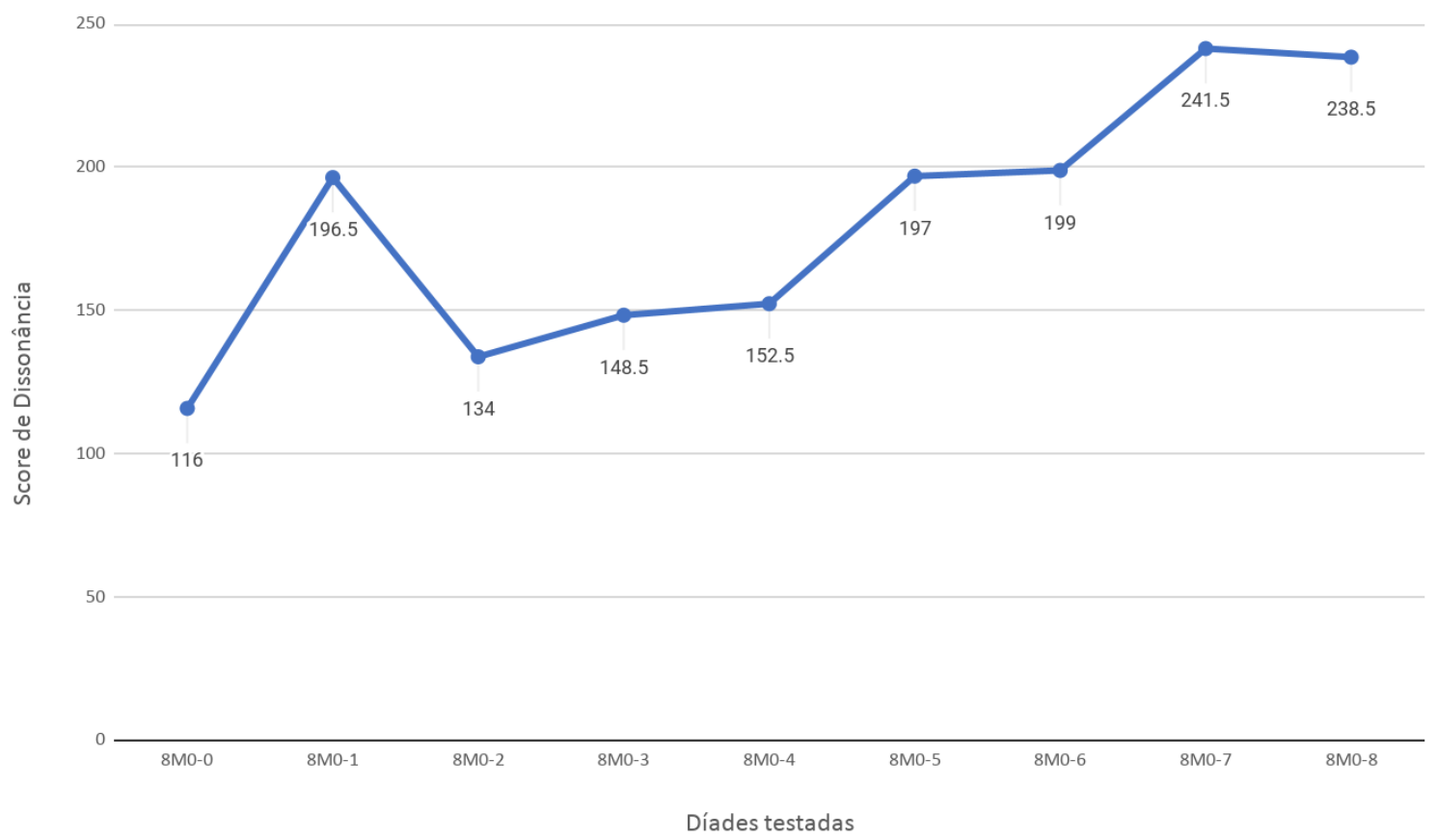

Gráfico 8- Pontuação de dissonância para a população de não-músicos para o Teste 2.

No gráfico 9, podemos observar as médias das pontuações para ambas as populações (músicos e não-músicos) comparadas. Calculando a correlação entre os resultados da população músicos com não-músicos, temos o valor $p=0,6551$, indicando uma correlação moderada entre as populações. 


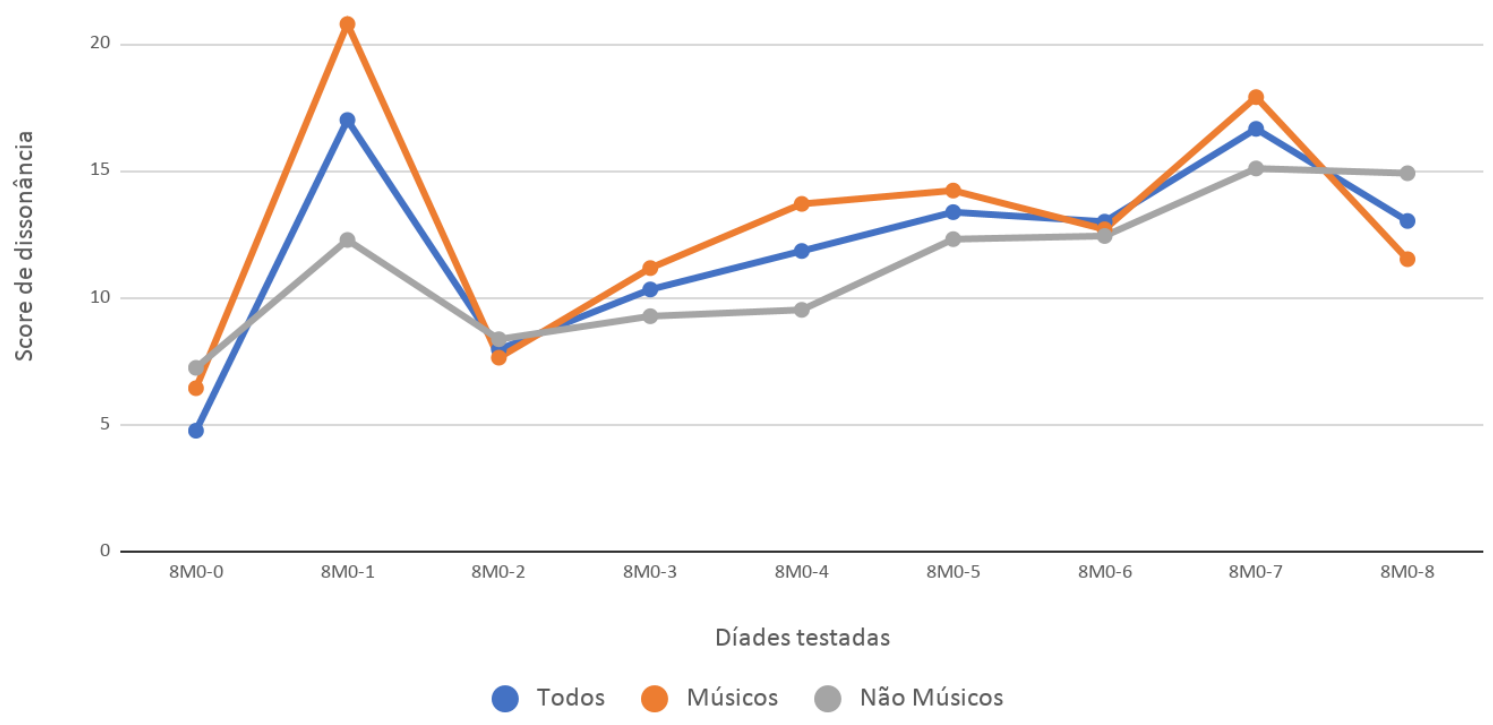

Gráfico 9- Média das pontuações (scores) de dissonância para o teste 2, comparando ambas as populações, de músicos e não-músicos.

Para realizar uma comparação de nossos resultados com os resultados esperados através do modelo de dissonância de Vassilakis (2001), calculamos 0 coeficiente de correlação entre a curva de dissonância esperada e a curva de dissonância obtida no teste 2. Entre os resultados considerados para todos os participantes (ambas as populações) e a curva de dissonância de Vassilakis (fig. 12), o valor é $p=0,4623$, indicando uma correlação fraca; na comparação com a população de músicos, é $p=0,6385$, indicando uma correlação moderada; e com a população de não-músicos, é $p=0,0739$, indicando uma correlação insignificante.

Estes resultados, que trazem dados reveladores que apontam diferenças entre modelos e resultados experimentais, e serão discutidos mais adiante neste texto, após serem apresentadas aplicações artísticas de natureza composicional que exploram as perspectivas da modelagem da dissonância. 


\section{Aplicações artísticas da dissonância modelada}

Neste capítulo apresentaremos as aplicações artísticas desenvolvidas durante o período de nossa pesquisa. Começaremos, no tópico 4.1, com a apresentação de um protótipo de mapeamento de escalas do temperamento por igual para serem tocadas em controladores e instrumentos digitais acessíveis, o que foi um passo fundamental para o início da exploração de timbres relacionados com escalas com divisões não convencionais. No tópico 4.2, apresentaremos algumas aplicações em composição musical.

\subsection{Protótipo instrumental: duas propostas de mapeamento de escalas do temperamento por igual em um teclado MIDI}

O foco de nossa pesquisa é a construção de timbres orientados por modelos psicoacústicos de dissonância, modelados para escalas do temperamento por igual, particularmente aquelas com divisões diferentes de 12 partes. Os protótipos aqui relatados foram construídos para funcionar com escalas de 5 a 24 divisões, todas baseadas na oitava. Esses protótipos foram utilizados em nossa pesquisa para a exploração das sonoridades das escalas, tanto para conhecimento dos timbres que foram utilizados nos testes subjetivos quanto para exploração de aplicações artísticas. Apresentamos a seguir duas propostas de mapeamento para um teclado MIDI de 25 teclas, implementadas em Pure Data (PD).

\subsubsection{Uma proposta para a escala de 5 a 24 divisões}

Uma primeira proposta, implementada em um patch de Pure Data (Silva, Faria e Bayeh, 2017), usa o controlador MIDI AKAI modelo APC Key 25 para executar escalas de 5 a 24 divisões. Expomos aqui a primeira proposta de adaptação das escalas $n$-tet para este controlador executando-se uma série de tarefas divididas em duas partes.

Parte 1- Cálculo das escalas: A entrada do algoritmo principal do patch utiliza a escala n-tet que o usuário desejar para fazer o cálculo da frequência das escalas. Em seguida, cria-se um dicionário que relaciona valores MIDI com as frequências ntet. Utilizamos como referência a nota MIDI $48(130.8 \mathrm{~Hz})$. A partir dessa referência, o algoritmo armazena esses valores em um conversor de MIDI versus Frequência. Essas etapas podem ser observadas no fluxograma da figura 14. 


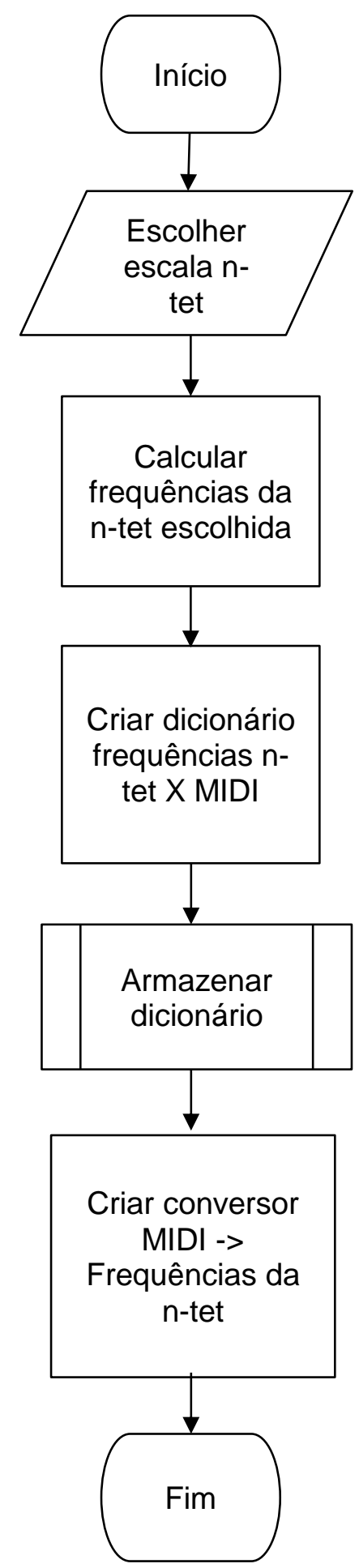

Figura 14- Tarefas para o cálculo de escalas n-tet para adaptação em um teclado MIDI.

Parte 2- Execução das escalas: A entrada do algoritmo é o valor executado pelo teclado MIDI. A partir de então, o valor MIDI da nota é convertido em frequência utilizando o dicionário da parte 1 , e enviam-se esses valores em frequência para 
serem executados em um sintetizador. Essas etapas podem ser vistas no fluxograma da figura 15.

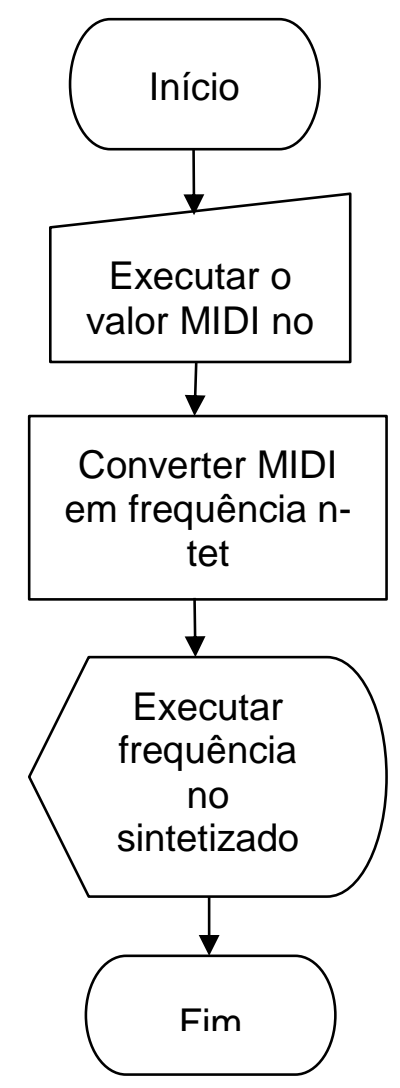

Figura 15-- Tarefas de execução de escalas n-tet para adaptação em um teclado MIDI.

Observando o resultado desse mapeamento no teclado do controlador, a escala terá a extensão de sua $n$-tet. A 5 -tet tem a extensão de 5 teclas, a 6 -tet de seis teclas, e assim também todas as outras.

A vantagem dessa configuração é que, embora as oitavas estejam em lugares diferentes, explora-se a tocabilidade inerente à experiência do intérprete para a execução em teclados. Além disso, aproveita-se a escrita musical tradicional para a notação das escalas de 5 a 24 divisões. Para tanto, basta que o compositor e/ou intérprete mapeie qual passo da escala está em cada tecla, o que é facilmente realizável utilizando-se uma conversão adequada de intervalos. Por exemplo: se a escala 5 -tet ocupa 5 teclas, isso significa que ela se repete a cada $4 \mathrm{~J}$ do teclado convencional. Isso pode ser observado na figura 16 , onde os graus 0 da escala 5 -tet estão marcados na cor vermelha. 


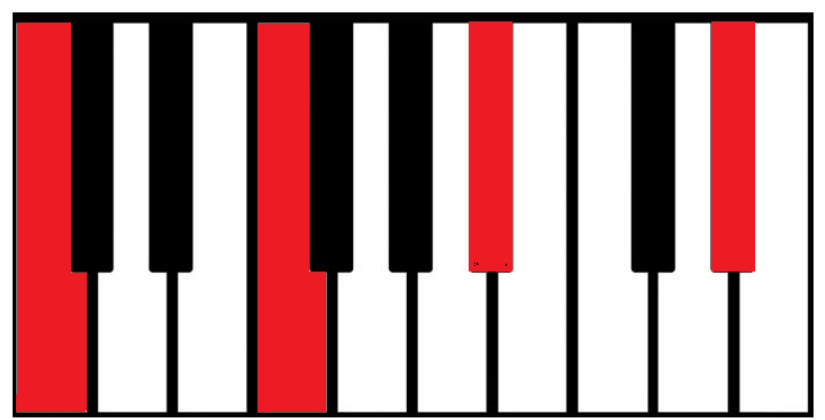

Figura 16- Graus 0 da escala 5-tet marcados em vermelho no teclado.

\subsubsection{Uma proposta para a escala 17-tet}

Para a escala 17-tet, realizamos uma proposta alternativa que é baseada na acomodação da escala maior, exposta no tópico 2.2.3. O ponto de partida dessa implementação é acomodar o máximo de escalas maiores com as frequências da escala 17-tet utilizando as 12 teclas da oitava do teclado convencional. Para isso, dividimos as escalas agrupando-as por notas em comum, chegando-se a três grupos:

Grupo A: Escalas Maiores de Fá, Do, Sol, Re, Lá e Mi

Grupo B: Escalas Maiores de Si, Fá\#, Do\# Sol\# Re\# e Lá\#

Grupo C: Escalas Maiores de Sib, Mib, Láb, Reb e Solb

Como um exemplo, as notas em comum das coleções do Grupo A mapeadas no teclado estão destacadas em amarelo na figura 17. Estão excluídas deste mapeamento em particular as notas Reb (altura 1), Mib (altura 4), Solb (altura 8), Láb (altura 11) e Lá\# (altura 15), totalizando 12 mapeamentos executados para este grupo. 


\begin{tabular}{|c|c|c|c|c|c|c|c|c|c|c|c|c|c|c|c|c|c|}
\hline 0 & 1 & 2 & 3 & 4 & 5 & 6 & 7 & 8 & 9 & 10 & 11 & 12 & 13 & 14 & 15 & 16 & 17 \\
\hline Do & Reb & Do\# & $\operatorname{Re}$ & Mib & Re\# & $\mathrm{Mi}$ & $\mathrm{Fa}$ & Solb & Fa\# & Sol & Lab & Sol\# & La & Sib & La\# & $\mathrm{Si}$ & Do \\
\hline Do & Reb & Do\# & $\mathrm{Re}$ & Mib & Re\# & $\mathrm{Mi}$ & $\mathrm{Fa}$ & Solb & Fa\# & Sol & Lab & Sol\# & La & Sib & La\# & $\mathrm{Si}$ & Do \\
\hline Do & Reb & Do\# & $\mathrm{Re}$ & Mib & Re\# & $\mathrm{Mi}$ & $\mathrm{Fa}$ & Solb & Fa\# & Sol & Lab & Sol\# & La & Sib & La\# & $\mathrm{Si}$ & Do \\
\hline Do & Reb & Do\# & $\mathrm{Re}$ & Mib & Re\# & $\mathrm{Mi}$ & $\mathrm{Fa}$ & Solb & Fa\# & Sol & Lab & Sol\# & La & Sib & La\# & $\mathrm{Si}$ & Do \\
\hline Do & Reb & Do\# & $\mathrm{Re}$ & Mib & Re\# & $\mathrm{Mi}$ & $\mathrm{Fa}$ & Solb & Fa\# & Sol & Lab & Sol\# & La & Sib & La\# & $\mathrm{Si}$ & Do \\
\hline Do & Reb & Do\# & $\mathrm{Re}$ & Mib & Re\# & $\mathrm{Mi}$ & $\mathrm{Fa}$ & Solb & Fa\# & Sol & Lab & Sol\# & La & Sib & La\# & $\mathrm{Si}$ & Do \\
\hline
\end{tabular}

Figura 17- Notas em comum (destacadas) das escalas do Grupo A.

$\mathrm{Na}$ implementação, a primeira escolha que o executor faz é definir qual grupo de escalas maiores ele quer acessar. Esta seleção é feita a partir das teclas de clip buttons (pads) do teclado. A partir disso, o programa seleciona os graus da escala que serão utilizados para aquelas configurações, e os envia 12 valores de frequências convertidos para MIDI. Nesse sistema, cada valor MIDI das teclas do controlador é mapeado para uma das notas da escala 17-tet para disparar a síntese das notas pelo programa. Este mapeamento está ilustrado na figura 18.

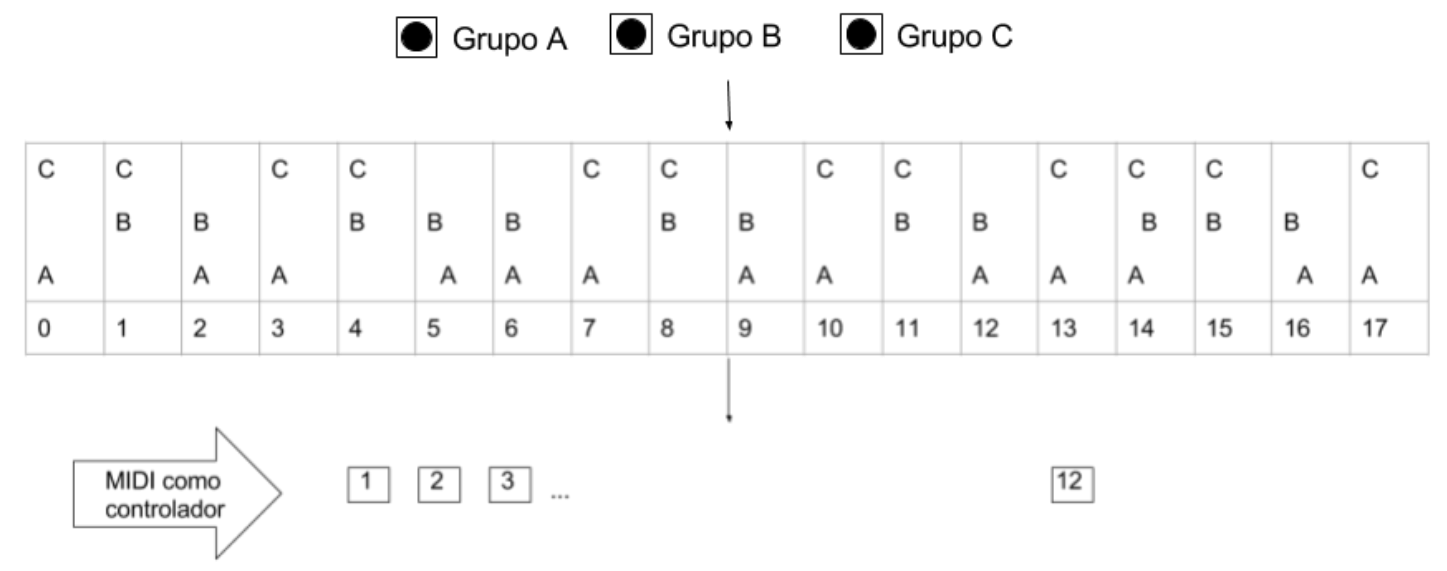

Figura 18-Controle dos três módulos de escalas, mapeando-se notas do teclado para notas da escala 17-tet. Para os grupos A e B, 12 notas da escala 17-tet são alcançadas por oitava. Para o grupo C, são mapeadas 11 notas por oitava. 
A vantagem desta implementação é que a oitava permanecerá no mesmo lugar do teclado tradicional, o que possibilita um maior aproveitamento da extensão do teclado, pois todas as divisões acima de 12 partes limitariam a tessitura do instrumento a menos de duas oitavas no teclado do controlador. Além disso, essa implementação possibilita a exploração de novas possibilidades tonais, utilizando novos timbres e formações de acordes com extensões diferentes das possíveis com a 12-tet, além do uso das 17 tonalidades.

\subsection{Em processos composicionais: Relatos de processos criativos}

Durante a presente pesquisa de mestrado, foram compostas 3 peças a partir de insights oriundos dos modelos de dissonância sensorial abordados, das quais relatamos duas nesta seção. No processo criativo destas peças, enfrentaram-se dois problemas:

1- Estabelecer estratégias para motivar o interesse musical nos timbres estudados em nossa pesquisa e

2- Explorar uma forma musical onde esses timbres e suas nuances de rugosidade fossem protagonistas na escuta da forma musical.

Nesta seção, nós realizaremos uma breve descrição do processo composicional destas peças, focando no que é de interesse da presente pesquisa. As peças são: Kalimba Super Consonante e Asperezas ${ }^{29}$, e serão abordadas a seguir nessa ordem.

\subsubsection{Kalimba Super Consonante}

O foco central da peça Kalimba Super Consonante era enfrentar o problema 1, visando a ampliar o interesse musical nos timbres estudados, conforme citado na introdução deste tópico. A peça inteira é composta a partir de um espectro gerado para minimizar a dissonância em uma escala 8-tet do timbre $8 M$ descrito no tópico 3.3.6. A peça conta com três partes: Introdução (0" a 51"); Parte 1 (52" a 2'20"); e Parte 2 (2'21" a 4'56"), destacadas no sonograma da figura 19.

\footnotetext{
${ }^{29}$ Ambas as peças estão disponíveis para escuta em sua versão binaural em https://soundcloud.com/micaelantunes. Acesso em 03 Out 2018.
} 


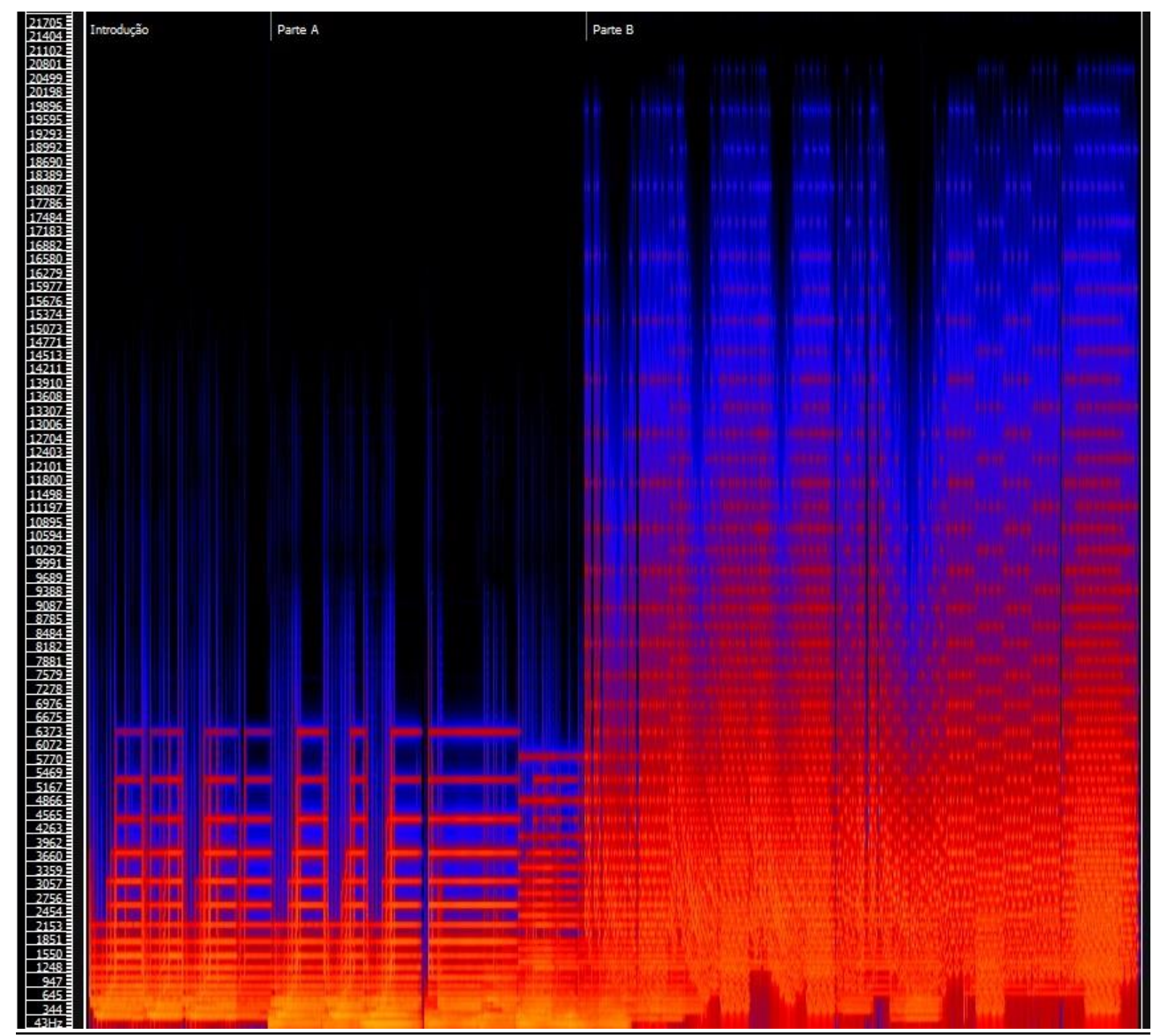

Figura 19- Sonograma da peça Kalimba Super Consonante, evidenciando na parte superior as três partes da peça.

Para confrontar a questão do interesse musical, começamos a nossa composição pela modelagem espectro-temporal da criação dos timbres, aplicando ao espectro 8M gerado uma variedade de envelopes dinâmicos, utilizando o sintetizador digital ZynAddSubFX (PAUL, 2005). Ao final foram escolhidos dois envelopes, sendo o primeiro com um ataque mais longo, com o objetivo de obter uma sonoridade que remete a um som de órgão, e o segundo com um ataque curto, que permitiu a exploração de sonoridades mais percussivas. Os envelopes selecionados para a peça são: 
1. Envelope A: Ataque $=118,6 \mathrm{~ms}$; Sustentação $=2,97 \mathrm{~s}$; Decaimento= $1,64 \mathrm{~s}$; representado na fig. 20 e destacado na peça no espectrograma da figura 22.

2. Envelope B: Ataque $=10 \mathrm{~ms}$; Sustentação $=2,97 \mathrm{~s}$; Decaimento $=1,64 \mathrm{~s}$; expostos na fig. 21 e destacado na peça no espectrograma da figura 23.

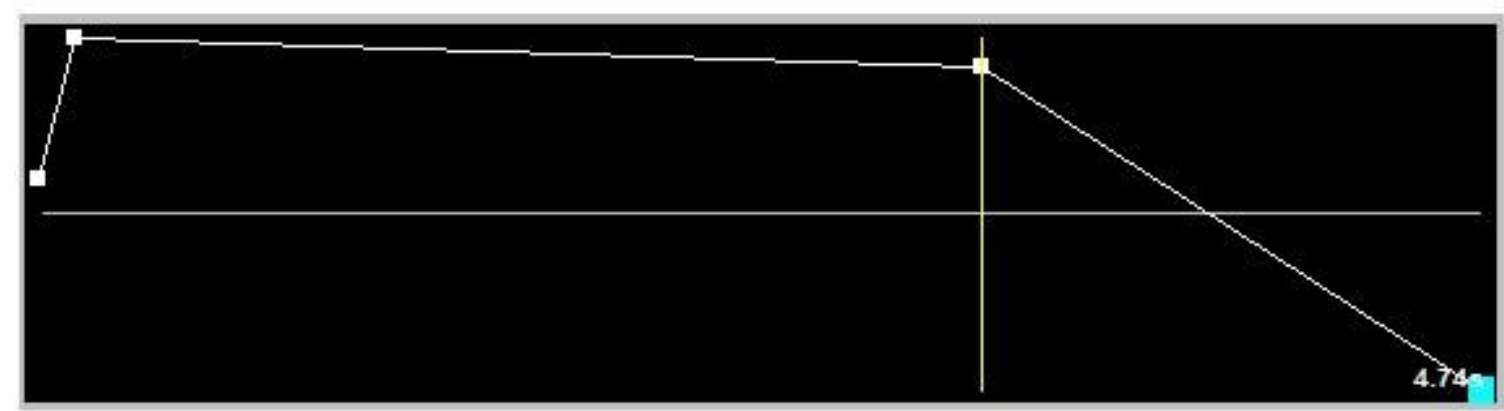

Figura 20- Envelope dinâmico A: Ataque=118,6ms: Sustentação=2,97s; Release=1,64s.

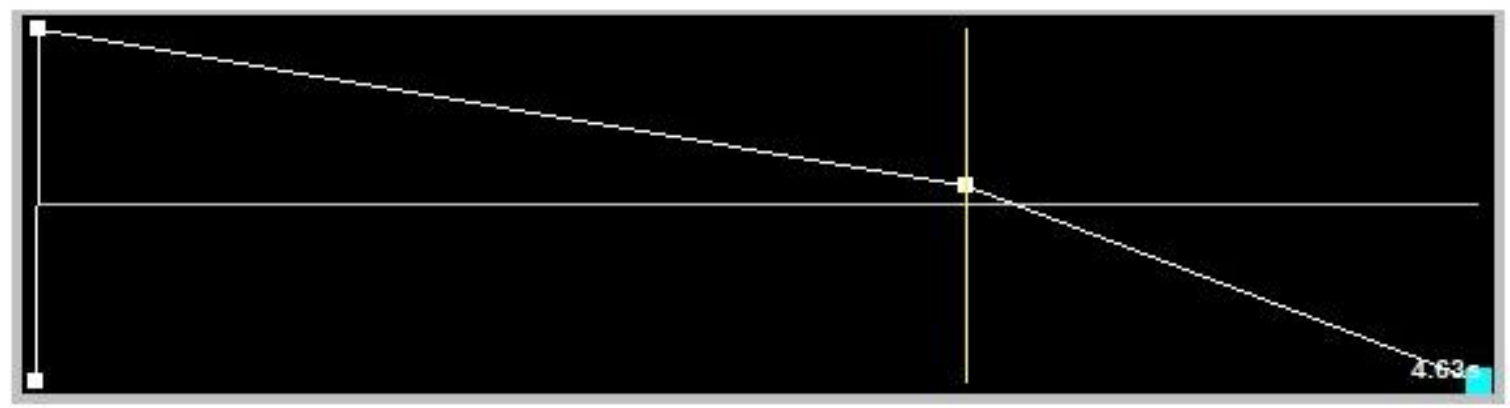

Figura 21- Envelope dinâmico B: Ataque=10ms: Sustentação=2,97s; Release =1,64s. 


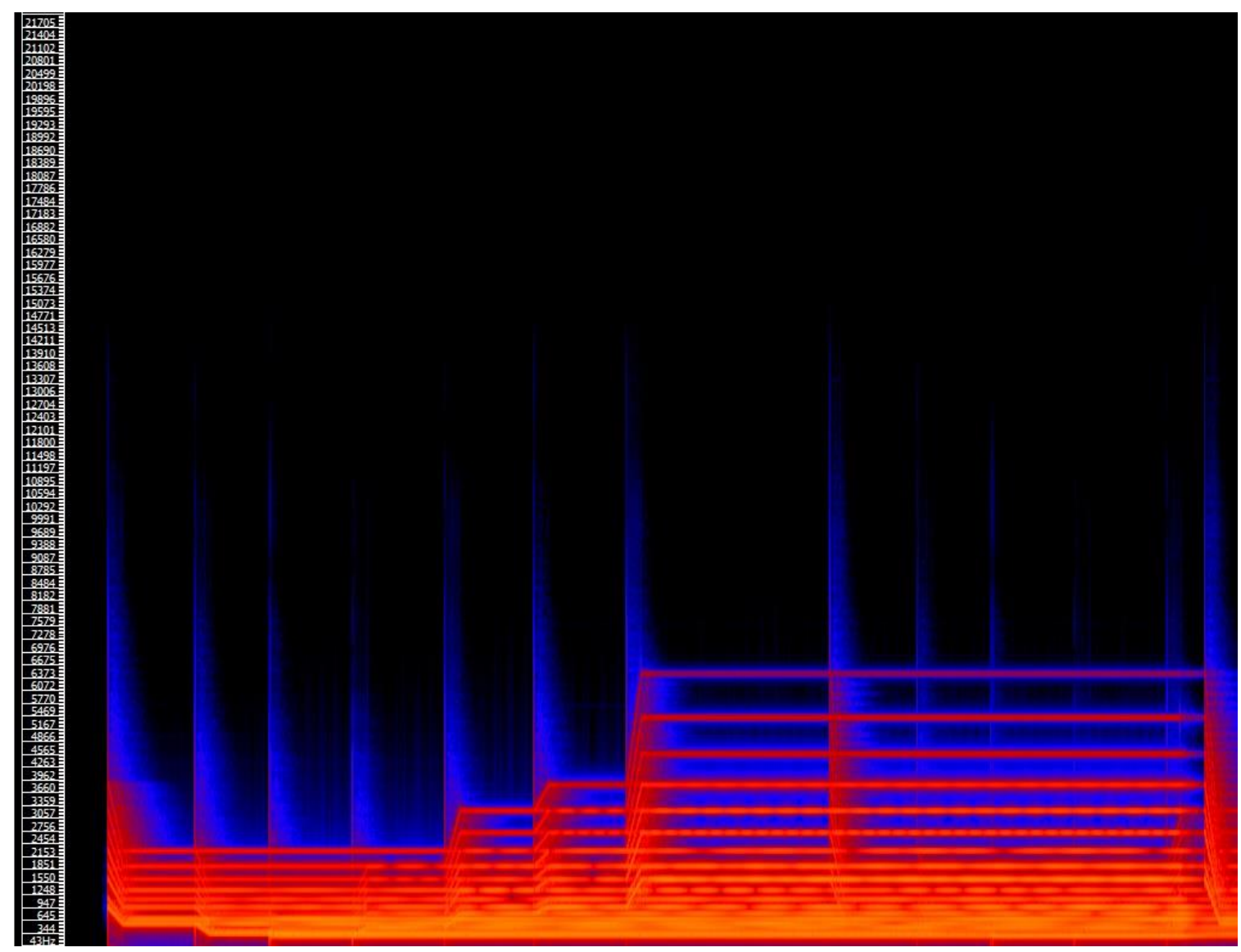

Figura 22- Sonograma da primeira apresentação do timbre com o envelope A, no início da peça.

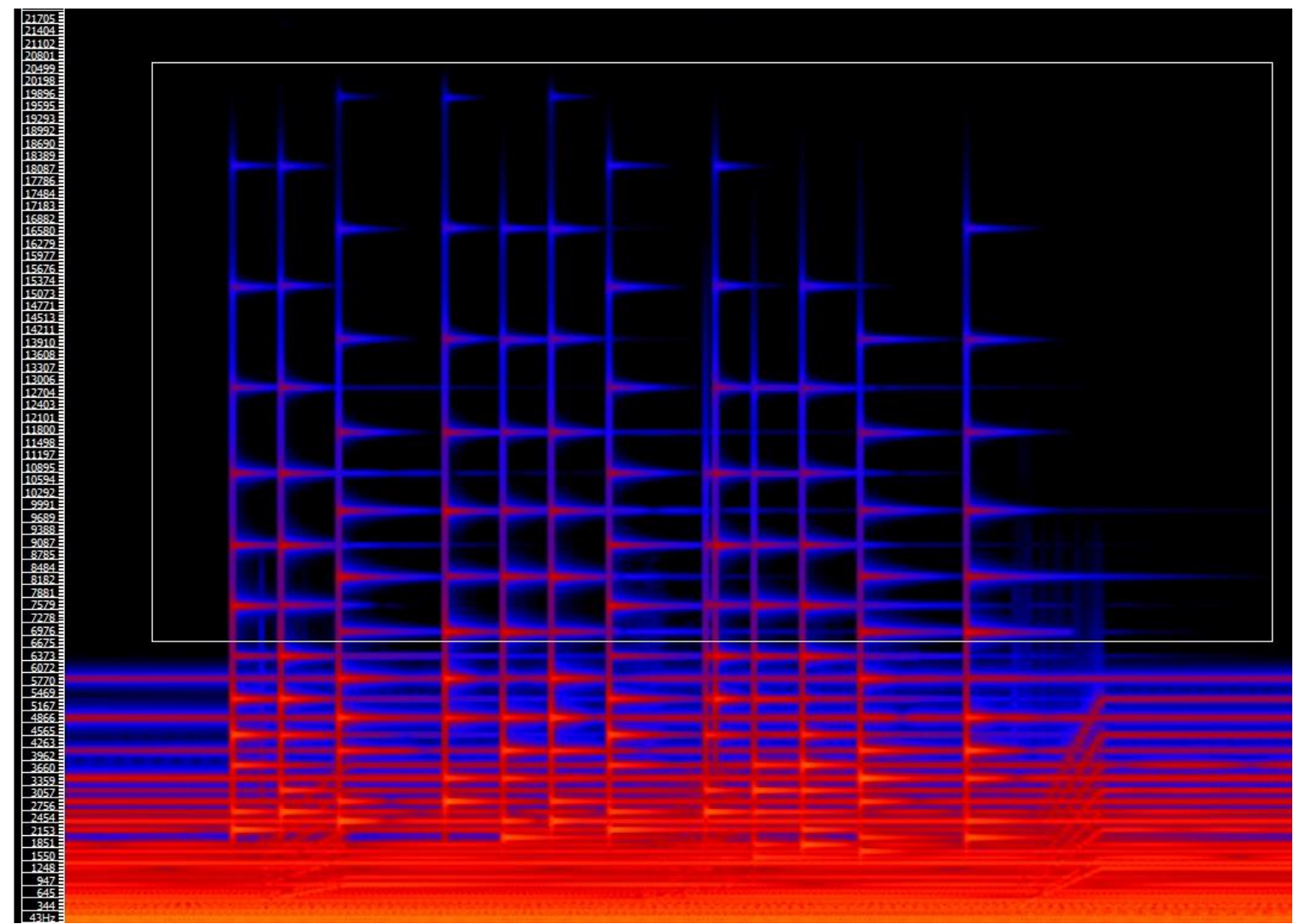

Figura 23- Sonograma da primeira apresentação do timbre com o envelope B, no início da seção 2 da peça. Timbre em destaque dentro do retângulo. 
No processo criativo da peça, partimos da improvisação, realizada com um controlador MIDI utilizando o mapeamento da escala 8-tet tal como descrito em 4.1.1. A improvisação nos serviu como uma ferramenta para familiarização com o material musical. As improvisações foram realizadas explorando pontos consonantes e dissonantes apontados pelas curvas de dissonância. Dentre os materiais improvisados, escolhemos uma ideia musical, que está na introdução, entre 0" e 51" da peça, que privilegia, em termos de consonância, acordes típicos da escala 8-tet. Essa ideia esta representada no sonograma da figura 24.

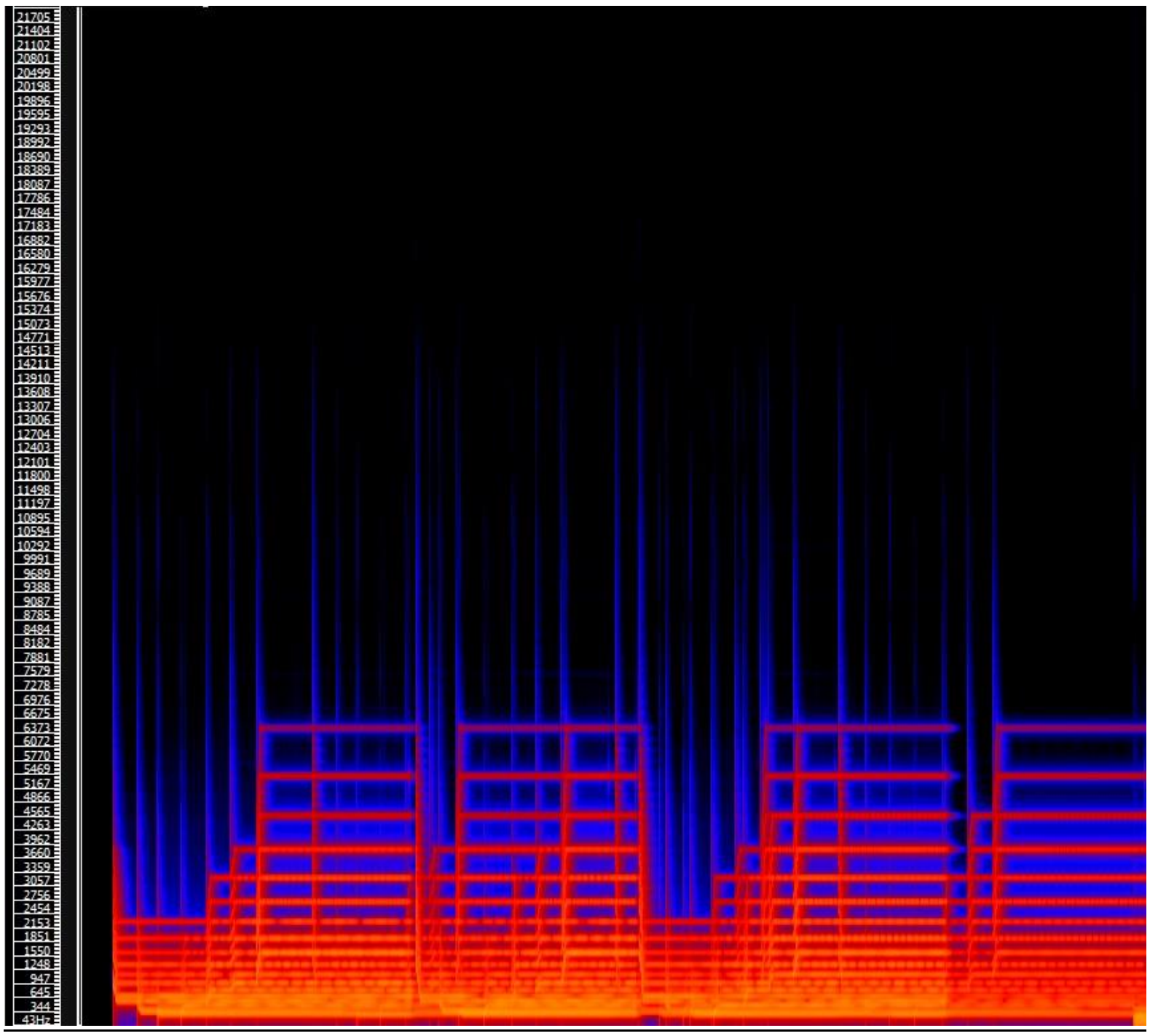

Figura 24- Sonograma apresentando a Introdução da Kalimba Super Consonante, expondo a primeira ideia musical da peça.

A partir dessa ideia inicial, desenvolveu se toda a Parte 1 (fig. 25) da peça (de 52 " a 2'20"), que dialoga com sonoridades que atuam em segundo plano, com o intuito de criar contraste e novas camadas de materiais, ora mais consonantes, ora mais dissonantes. 


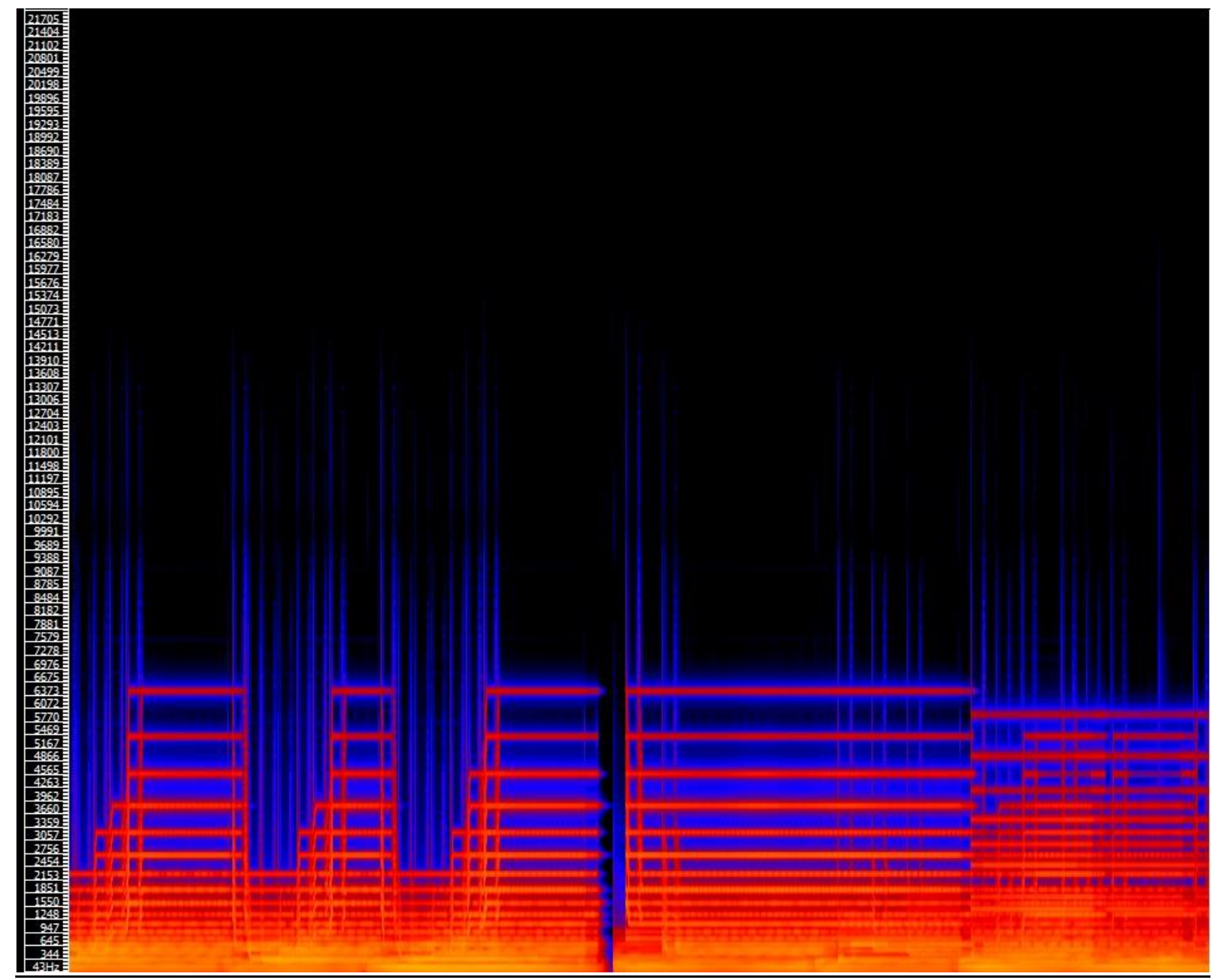

Figura 25- Sonograma da Primeira Parte da Kalimba Super Consonante, onde podemos observar o desenvolvimento da ideia apresentada na introdução da peça.

Na segunda parte da peça (Figura 26), uma nova ideia musical é exposta, também selecionada de nossas improvisações, e atua como protagonista. Essa ideia é contrastada com transposições, agora utilizando a escala 16-tet, que, devido a dobrar os graus dentro da oitava, mantém as características de consonância da 8-tet, tendo agora as máximas consonâncias nos graus 0, 4, 8, 12 e 16, como vemos na curva de dissonância da figura 27. Essas transposições têm por objetivos explorar pontos de dissonância aferidos pela curva. A essa ideia principal, é contrastado em segundo plano um material que compõe a camada secundária da parte 1, e ora atua com sonoridades mais densas e rugosas, ora atua no oposto dessas características. 


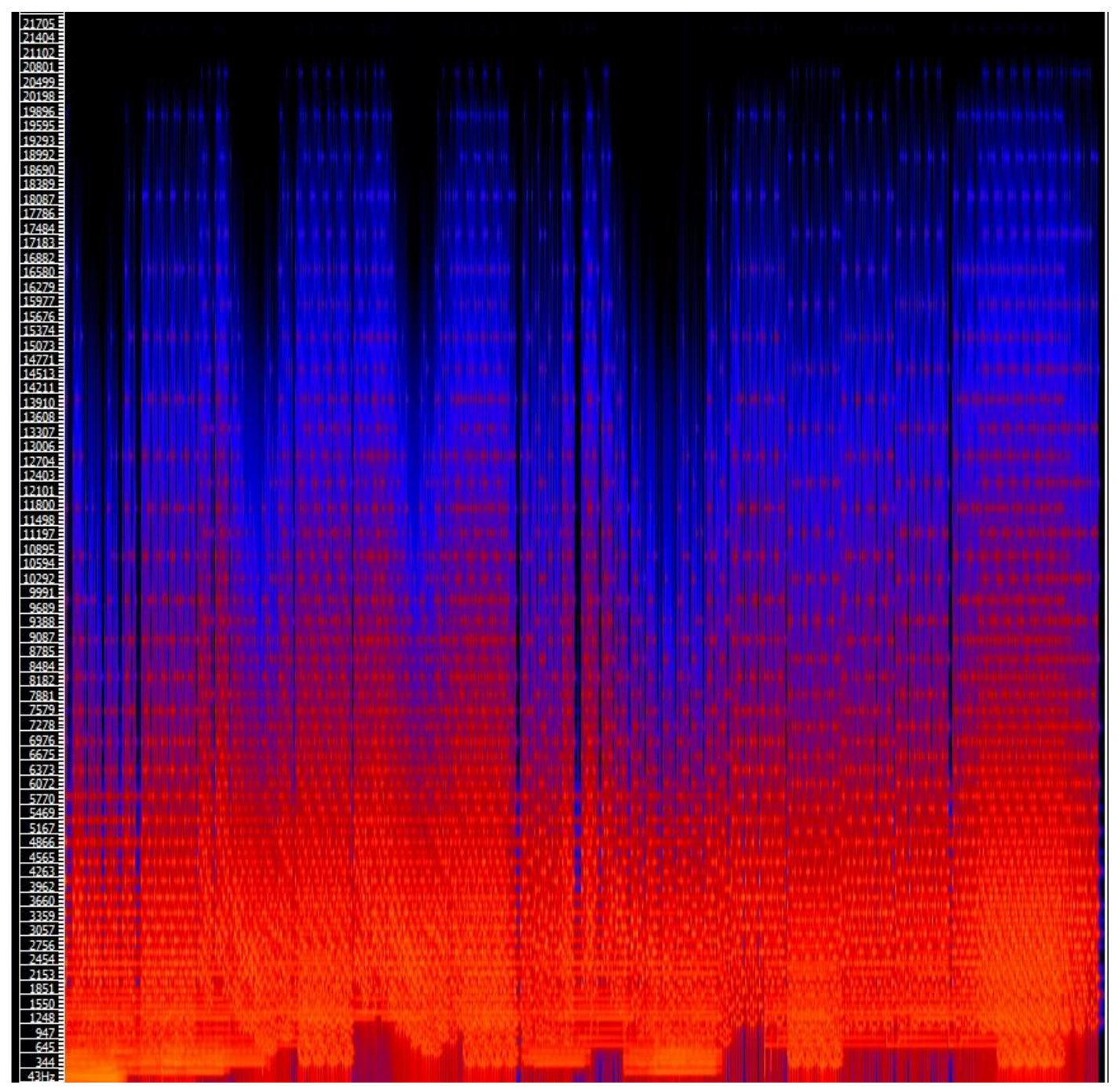

Figura 26- Sonograma da Segunda Parte da Kalimba Super Consonante, onde podemos observar a introdução de uma nova ideia musical em primeiro plano, contrastada com camadas ora mais densas, ora mais rarefeitas em segundo plano.

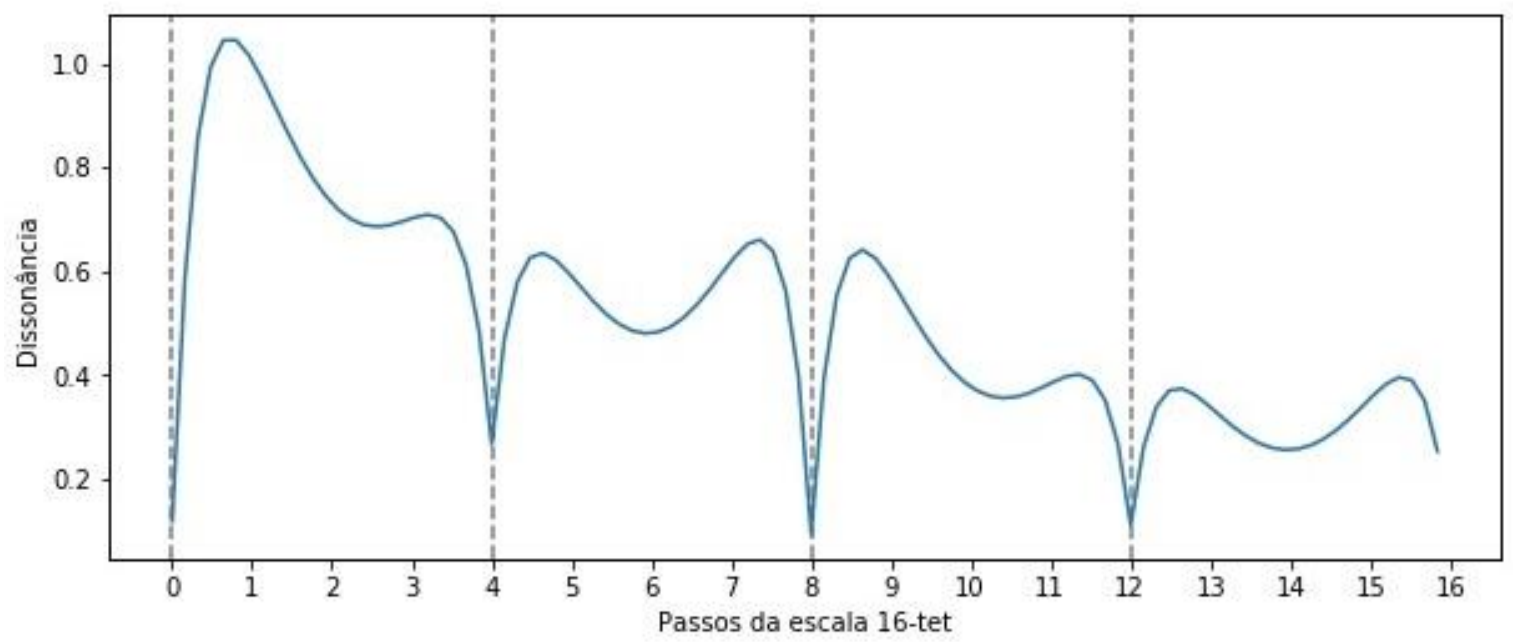

Figura 27- Curva de dissonância para a escala 16-tet, utilizando o timbre 8M, descrito no tópico 3.1. As linhas pontilhadas reforçam a posição da máxima consonância. 
Além das técnicas de síntese aqui expostas, essa peça contou com espacialização em Ambisonics, utilizando o plugin ATK for Reaper ${ }^{30}$, que nos permite exportar a peça em diferentes configurações de alto-falantes, além do uso de equalizadores necessários à mixagem e masterização da peça.

\title{
4.3.2. Asperezas
}

\begin{abstract}
As flutuações de amplitude são manifestações de interferência das ondas sonoras e podem ser colocadas em três categorias perceptivas, relacionadas à taxa de flutuação. As flutuações de amplitude mais lentas (até aproximadamente +- 20 por segundo) são ouvidas como mudanças na percepção da intensidade e percebidas como batimentos. À medida que a taxa de flutuação aumenta, a percepção de intensidade do som parece ser constante e as flutuações são percebidas como rugosidade. Com uma taxa de flutuação de amplitude mais alta (em aproximadamente 75-150 flutuações por segundo, dependendo do registro da frequência), a rugosidade atinge uma taxa máxima e depois diminui gradualmente até desaparecer. (VASSILAKIS, 2001, p. 24-25)
\end{abstract}

Essa é a definição de Vassilakis que delimita os limiares de batimentos e rugosidade, e é ela que guia a composição da peça Asperezas. A ideia que guia o processo composicional é que, em cada pequeno trecho da obra, o ouvinte passe por cada um desses estados de percepção de flutuação de amplitude.

Para atingir tal objetivo, geramos os timbres por meio de uma modulação cruzada (cross modulation). O esquema da modulação cruzada é apresentado na figura 28, e nessa modulação, o oscilador 1 (à esquerda) modula a fase do oscilador 2 (à direita) e o oscilador 2 modula a frequência do oscilador 1 .

${ }^{30}$ Ambisonics tool kit for Reaper. http://www.ambisonictoolkit.net/documentation/reaper/ Acessado em 30 de Jul. 2018. 


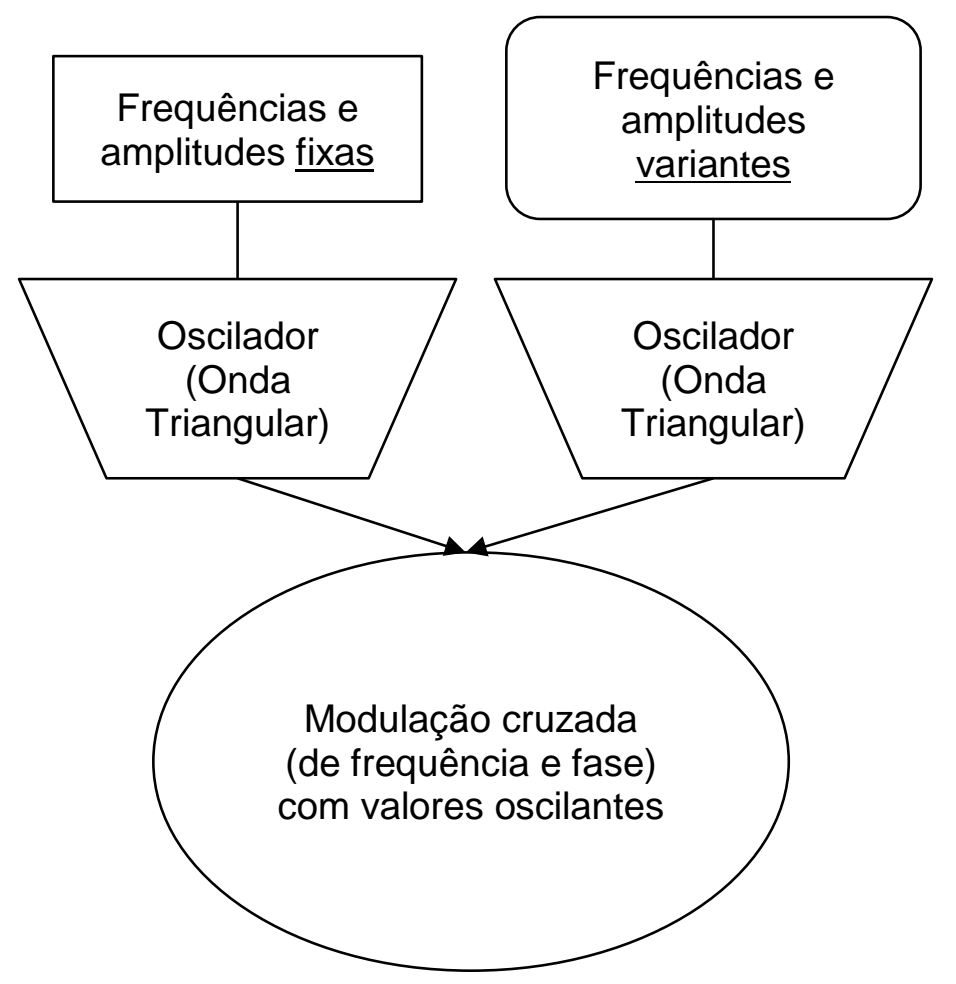

Figura 28- Esquema da modulação cruzada utilizada na peça Asperezas, onde o oscilador da esquerda modula a fase da direita, e o oscilador da direita modula a frequência do oscilador da esquerda. Os valores de frequência e amplitude dos osciladores são apresentados nas tabelas de 4 a 6 .

Além da síntese cruzada, as sonoridades da peça são construídas utilizando um oscilador de baixa frequência, que executa sempre uma frequência que é metade do valor da frequência do oscilador 1 , e um filtro passa baixa. $O$ esquema desses processamentos sonoros são revelados na figura 29.

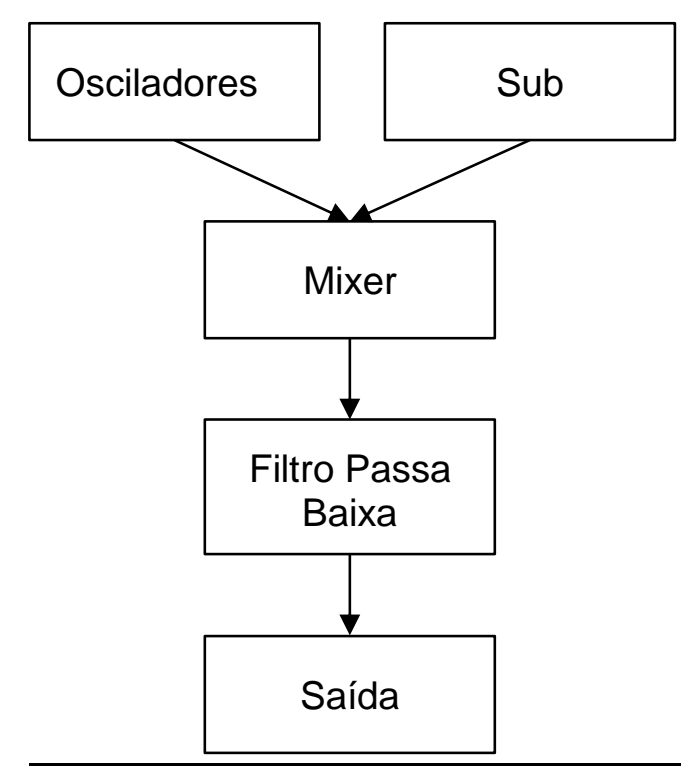

Figura 29- Esquema dos processamentos sonoros utilizados na peça Asperezas. 
Construímos um patch no sintetizador Helm (Tytel, 2016?), aproveitando-se de suas facilidades em automatizar este processo e alta qualidade de síntese. Neste patch, os parâmetros como intensidade e frequência dos osciladores e a profundidade de modulação sofrem lenta alteração no decorrer do tempo. Os parâmetros utilizados são descritos da seguinte maneira:

1- na tabela 4, expomos as configurações dos sintetizadores;

2- na tabela 5, exibimos as configurações dos filtros;

3- na tabela 6, revelamos as frequências dos osciladores em cada momento da peça.

Com isso, a cada momento que o sintetizador é ativado, passa-se pelos três estados perceptivos: batimento, rugosidade e ausência de rugosidade. Assim é construída a microforma. Esse movimento de oscilação da dissonância está representado nos gráficos de dissonância ${ }^{31} 10$ e 11, que correspondem aos dois primeiros minutos da peça.

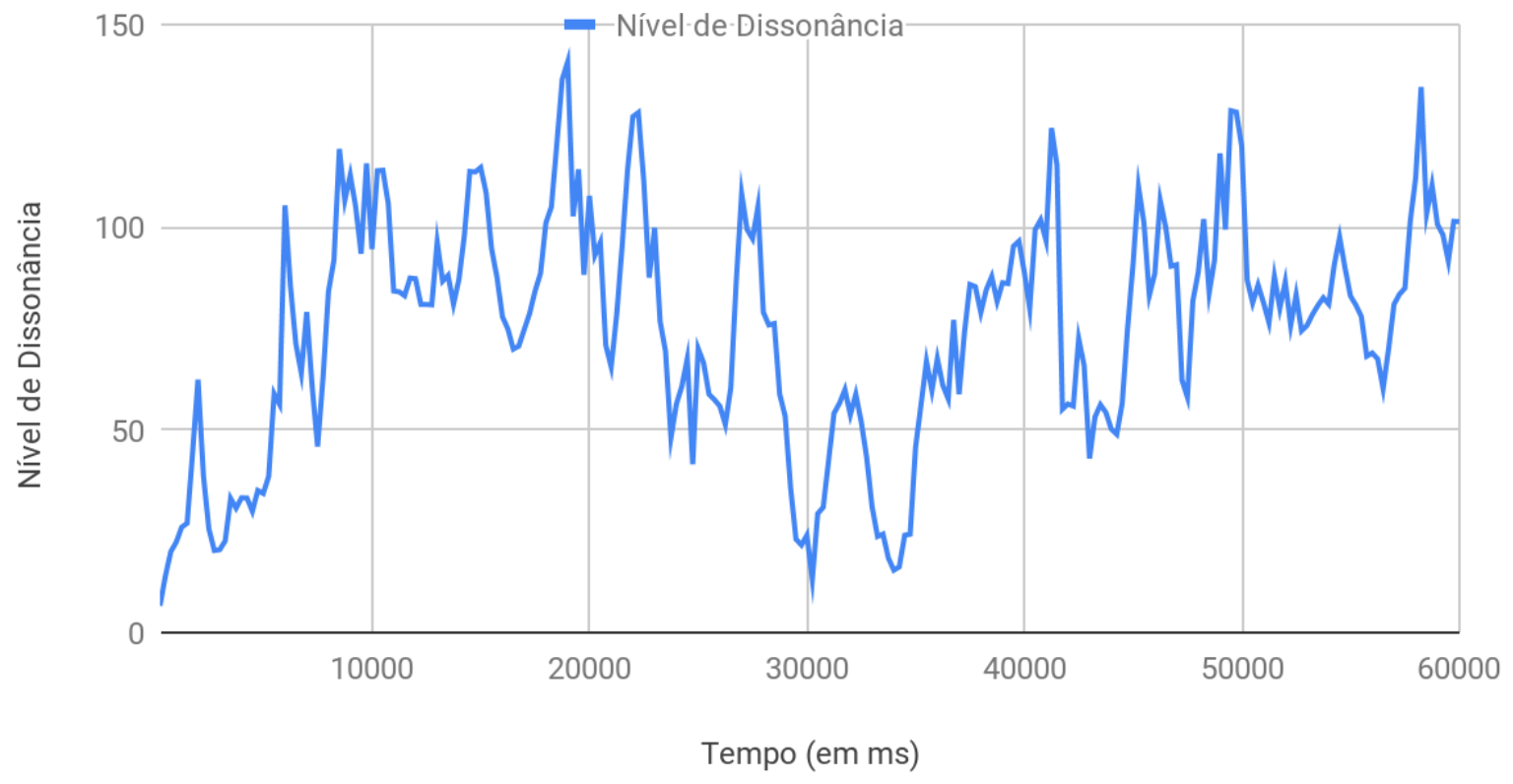

Gráfico 10- Curva de dissonância estimada da peça Asperezas, de 0 a 60.000 ms.

31 Utilizamos para gerar os valores de dissonância a ferramenta SRA, de Vassilakis e Fitz, 2007. 


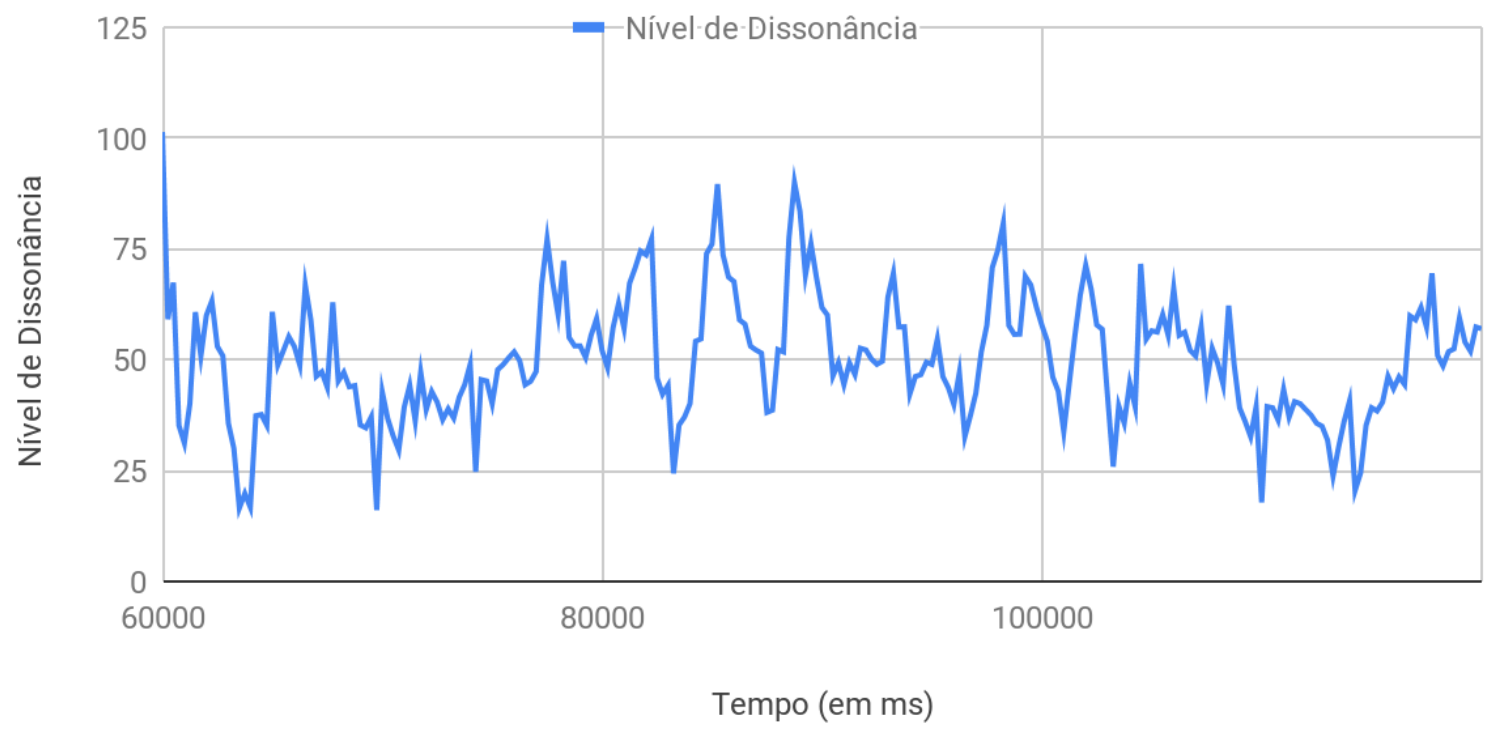

Gráfico 11- Curva de dissonância estimada da peça Asperezas, de 60.000 a 120.000 ms.

\begin{tabular}{|l|l|l|l|}
\hline & Forma de onda & Amplitude & $\begin{array}{l}\text { Profundidade de } \\
\text { modulação }\end{array}$ \\
\hline Oscilador 1 & $\begin{array}{l}\text { Onda triangular, com } \\
\text { frequências descritas na } \\
\text { tabela 6. }\end{array}$ & Fixa em 0,16 & $\begin{array}{l}\text { Variando ao redor de } \\
0,106, \text { com variação linear } \\
\text { de 1 (para cima e para } \\
\text { baixo), em uma } \\
\text { velocidade de 0.074Hz. }\end{array}$ \\
\hline Oscilador 2 & $\begin{array}{l}\text { Onda triangular, com } \\
\text { frequência central = } \\
\text { frequências da tabela 6, } \\
\text { variando em 6 semitons } \\
\text { com velocidade de } \\
\text { 0.025Hz para cima e para } \\
\text { baixo. }\end{array}$ & $\begin{array}{l}\text { Variando em torno de } \\
\text { de 0,608, com variação lineara cima e } \\
\text { para baixo), em uma } \\
\text { velocidade de 0,025Hz. }\end{array}$ & \\
\hline $\begin{array}{l}\text { LFo } \\
\text { (oscilador } \\
\text { de baixa } \\
\text { frequência) }\end{array}$ & $\begin{array}{l}\text { Onda quadrada, com } \\
\text { frequência igual à da } \\
\text { tabela 6 dividida por 2 } \\
\text { (oitava). }\end{array}$ & $\begin{array}{l}\text { Variando em torno de } \\
0,111, \text { com variação linear } \\
\text { de 0,602 (para cima e } \\
\text { para baixo), em uma } \\
\text { velocidade de 0,025Hz. }\end{array}$ & \\
\hline
\end{tabular}

Tabela 4- Configurações da síntese utilizadas na composição Asperezas, tendo como ferramenta o sintetizador Helm (Tytel, 2016?). 


\begin{tabular}{|l|l|l|l|l|}
\hline & Ataque & Decaimento & Sustentação & Release \\
\hline Envelope Geral & $16 "$ & $16^{\prime \prime}$ & $0,829^{\prime \prime}$ & $11,18^{\prime \prime}$ \\
\hline Envelope do Filtro32 & $16 "$ & $16^{\prime \prime}$ & $0.5^{\prime \prime}$ & $16^{\prime \prime}$ \\
\hline Envelope da modulação & $0 "$ & $2.25^{\prime \prime}$ & $0.5^{\prime \prime}$ & $2.25 "$ \\
\hline
\end{tabular}

Tabela 5- Configurações dos envelopes utilizadas na composição Asperezas, tendo como ferramenta o sintetizador Helm (Tytel, 2016?).

A macroforma da peça também explora a manipulação da dissonância. Para explicar essa questão, dividimos a peça em 11 seções (figura 30) a partir das frequências dos osciladores da tabela 6 , que geram toda a harmonia da peça. A forma da peça explora um crescente de dissonância que começa na seção 2 e vai até a seção 10. Essa direcionalidade foi construída a partir de frequências da escala 12-tet, que são a referência para os osciladores e estão expostas na tabela 4.3, e este crescente de dissonância pode ser observado na curva de dissonância da figura 4.20.

\begin{tabular}{|c|c|c|c|c|c|c|c|c|c|c|}
\hline $\mathbf{1}$ & $\mathbf{2}$ & $\mathbf{3}$ & $\mathbf{4}$ & $\mathbf{5}$ & $\mathbf{6}$ & $\mathbf{7}$ & $\mathbf{8}$ & $\mathbf{9}$ & $\mathbf{1 0}$ & $\mathbf{1 1}$ \\
\hline $\begin{array}{c}\text { De 0" } \\
\text { a 1' }\end{array}$ & $\begin{array}{c}\text { De 1' } \\
\text { a 2' }\end{array}$ & $\begin{array}{c}\text { De 2' } \\
\text { a 3' }\end{array}$ & $\begin{array}{c}\text { De 3' } \\
\text { a 4' }\end{array}$ & $\begin{array}{c}\text { De 4' } \\
\text { a } \\
4^{\prime} 49^{\prime \prime}\end{array}$ & $\begin{array}{c}\text { De } \\
4^{\prime} 49^{\prime \prime} \\
\text { a } \\
5^{\prime} 45^{\prime \prime}\end{array}$ & $\begin{array}{c}\text { De } \\
5^{\prime} 45^{\prime \prime} \\
\text { a } \\
6^{\prime} 36^{\prime \prime}\end{array}$ & $\begin{array}{c}\text { De } \\
6^{\prime} 36^{\prime \prime} \\
\text { a } \\
7^{\prime} 30^{\prime \prime}\end{array}$ & $\begin{array}{c}\text { De } \\
7^{\prime} 30^{\prime \prime} \\
\text { a } \\
8^{\prime} 26^{\prime \prime}\end{array}$ & $\begin{array}{c}\text { De } \\
8^{\prime} 26^{\prime \prime} \\
\text { a } \\
9^{\prime} 16^{\prime \prime}\end{array}$ & $\begin{array}{c}\text { De } \\
9^{\prime} 16^{\prime \prime} \\
\text { a } \\
10^{\prime} 16^{\prime \prime}\end{array}$ \\
\hline & & & & & 1318,5 & 1318,5 & 784 & & & \\
\hline 65,4 & 130,8 & 261,6 & 523,2 & 523,2 & 523,2 & 523,2 & 293,6 & 293,6 & 277,1 & 130,8 \\
\hline & & & & & & 277,1 & 277,1 & 277,1 & 261,6 & \\
\hline
\end{tabular}

Tabela 6- Frequências dos osciladores utilizadas na composição Asperezas, tendo como ferramenta o sintetizador Helm.

${ }^{32}$ Filtro passa baixa, com corte em 107,2 (em semitons) e valor de ressonância = 0,388. 


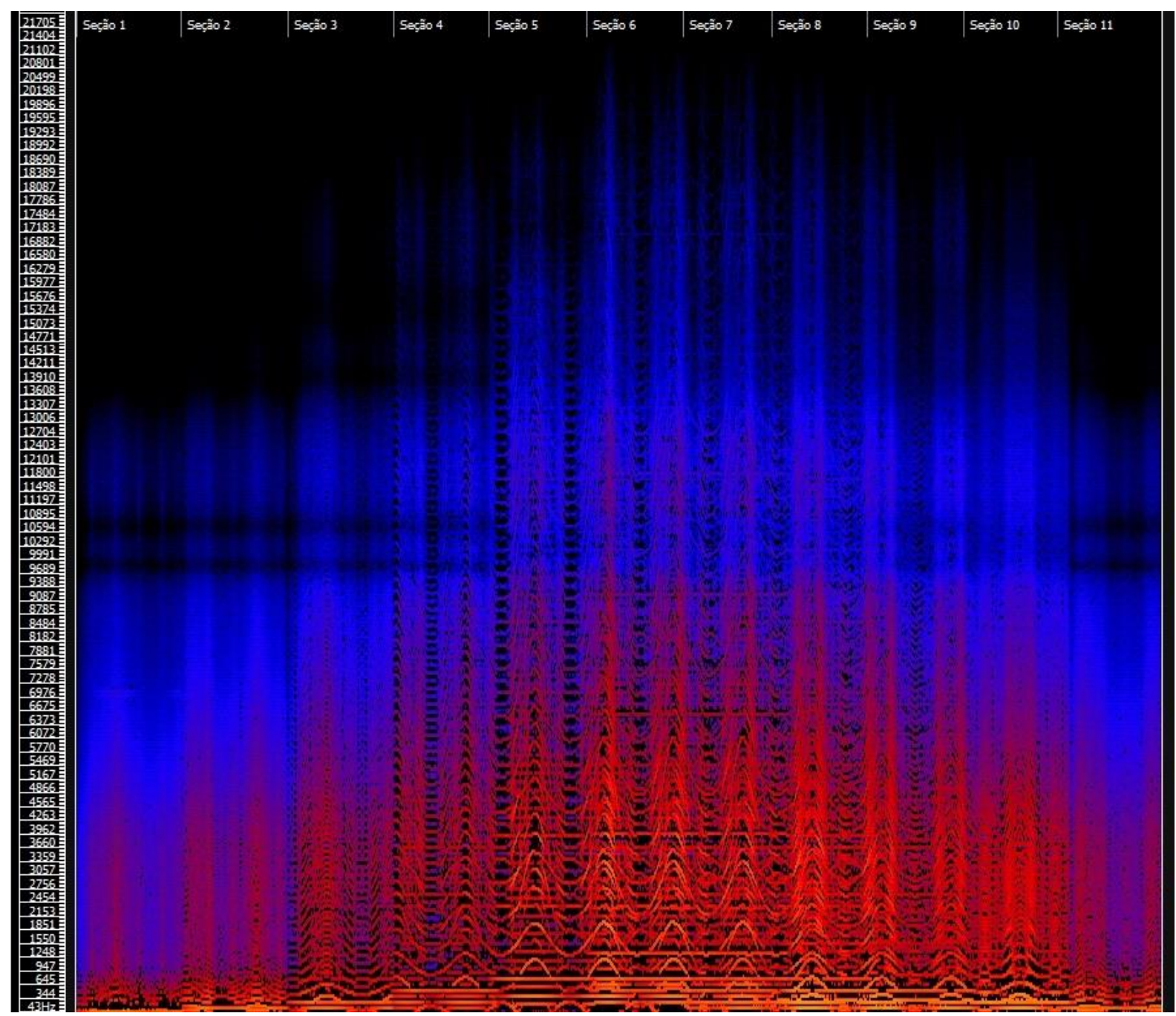

Figura 30- Espectrograma da peça Asperezas, dividindo-a em 11 seções, correspondentes às frequências da tabela 4.3 .

A partir da tabela 6 podemos observar que nas seções de 1 a 4 , temos uma única frequência de referência por seção: 65,4 Hz e suas oitavas. Nas seções 6 e 7, podemos notar frequências harmônicas sendo acrescentadas, e nas seções de 8 a 10, a exploração de relações inarmônicas, finalizando na seção 11 com a mesma frequência da seção 2. 


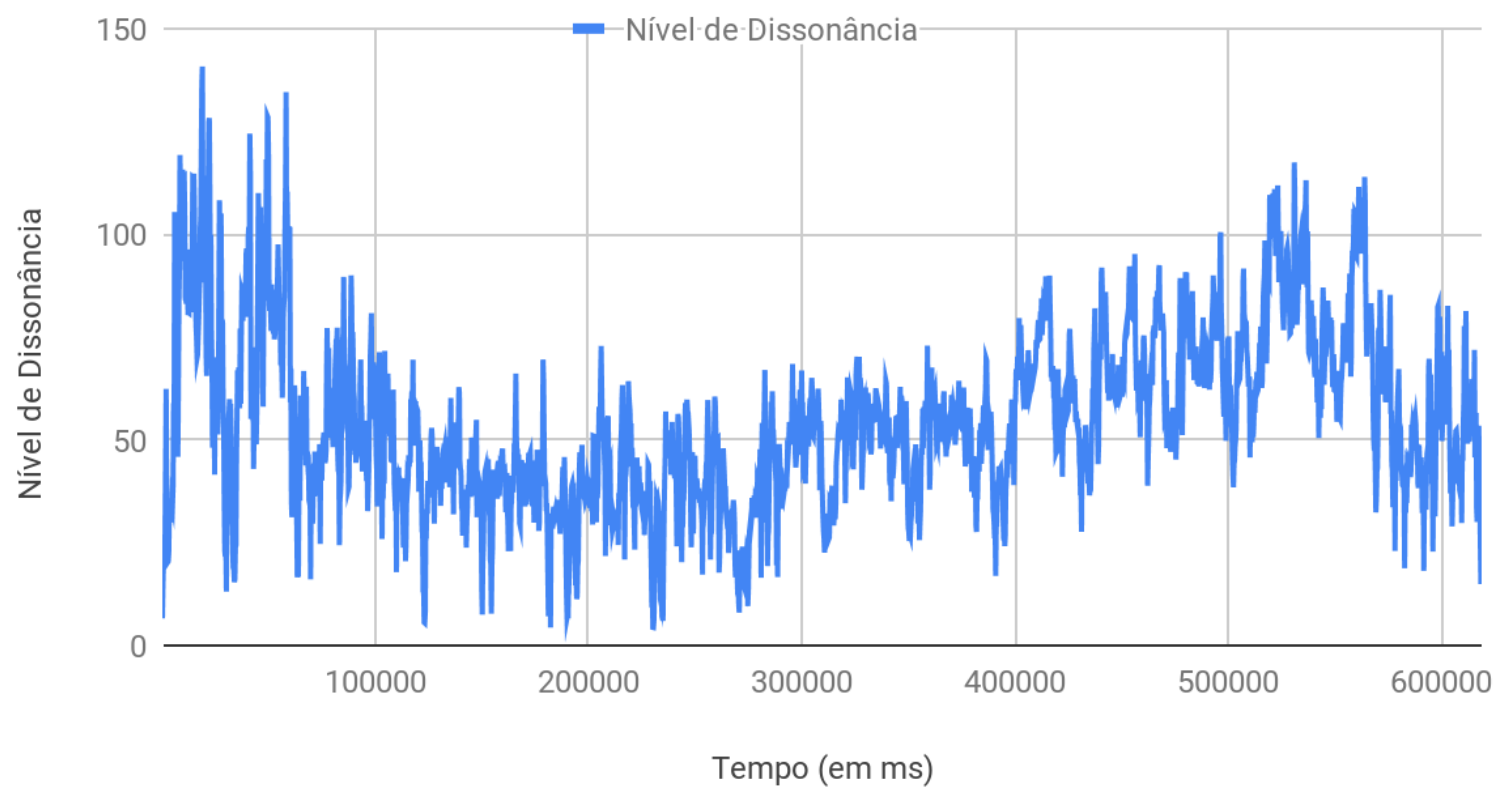

Gráfico 12- Curva de dissonância estimada para a peça Asperezas.

Com isso, resulta uma peça que oscila em níveis de dissonância a cada trecho, e essas "ondas" de dissonância-consonância vão exibindo gradativamente picos de dissonância cada vez maiores, até o ápice, quase ao final da peça. Os níveis de dissonância explorados na peça são determinados a partir dos modelos de dissonância de Vassilakis, e podem ser vistos no gráfico 12. 


\section{Conclusões}

Nesta seção, apresentamos as conclusões e discussões finais do trabalho, primeiramente com a análise dos testes subjetivos e suas conclusões, seguidos de discussões sobre as práticas artísticas, e finalizando com perspectivas para trabalhos futuros.

\subsection{Avaliação dos resultados dos testes subjetivos}

Apresentamos aqui, de forma separada, as análises dos testes 1 e 2, por conta das peculiaridades de cada teste, necessitando diferentes abordagens para análise de seus resultados.

Teste 1 (dissonância comparada entre díades da escala 8-tet para diferentes timbres)

Quando se trata da comparação de níveis de dissonância entre díades de timbres diferentes, verificamos que o modelo de dissonância de Vassilakis não forneceu uma boa estimativa para os valores experimentais obtidos. Isso pode ser inferido a partir dos seguintes dados apresentados no capítulo 3 e aqui recapitulados para fins de avaliação:

1- Não houve uma correlação significativa entre os resultados obtidos entre as populações de músicos e não-músicos, pois os coeficientes de correlação entre as indicações de músicos e não-músicos para as três respostas possíveis foram pouco significativos: para o timbre 8R tido como mais dissonante, $p=0,2703$; para o timbre $8 \mathrm{M}$ avaliado como mais dissonante, $p=0,3300$; e para o caso em que nenhum tenha sido avaliado como mais dissonante que o outro, $p=-0,2836$.

2- Não houve uma correlação significativa entre a avaliação de dissonância indicada pelas escolhas de cada população para o timbre 8R e a curva da diferença de dissonância esperada entre 8R e 8M. Para ambas populações este valor foi $p=-$ 0,3061; para os músicos, $p=0,1153$; e para não-músicos foi observada uma correlação negativa moderada de $p=-0,6722$.

Esses dados ressaltados acima revelam que não há um consenso entre as populações sobre o nível de dissonância dos timbres, o que leva a crer que não há um nível de diferença de dissonância significativa entre as variáveis independentes. 
Teste 2 (dissonância comparada de díades da escala 8-tet para o mesmo timbre)

Quando se trata da comparação de díades diferentes de uma escala com o mesmo timbre, o modelo de dissonância de Vassilakis (2001) estima parcialmente a sensação de dissonância.

Primeiramente, para termos uma visualização do comportamento das pontuações de dissonância com relação ao modelo de dissonância de Vassilakis, realizamos uma sobreposição da curva de resultados dos testes (experimental) com a curva derivada do modelo de Vassilakis (estimada). Para que uma confrontação das curvas fosse possível, normalizamos o modelo de Vassilakis pelo pico de dissonância da curva experimental, que no caso, ocorre na díade 0-1. Essa comparação é exibida nos gráficos 13 (para ambas as populações), 14 (para músicos), e 15 (para nãomúsicos).

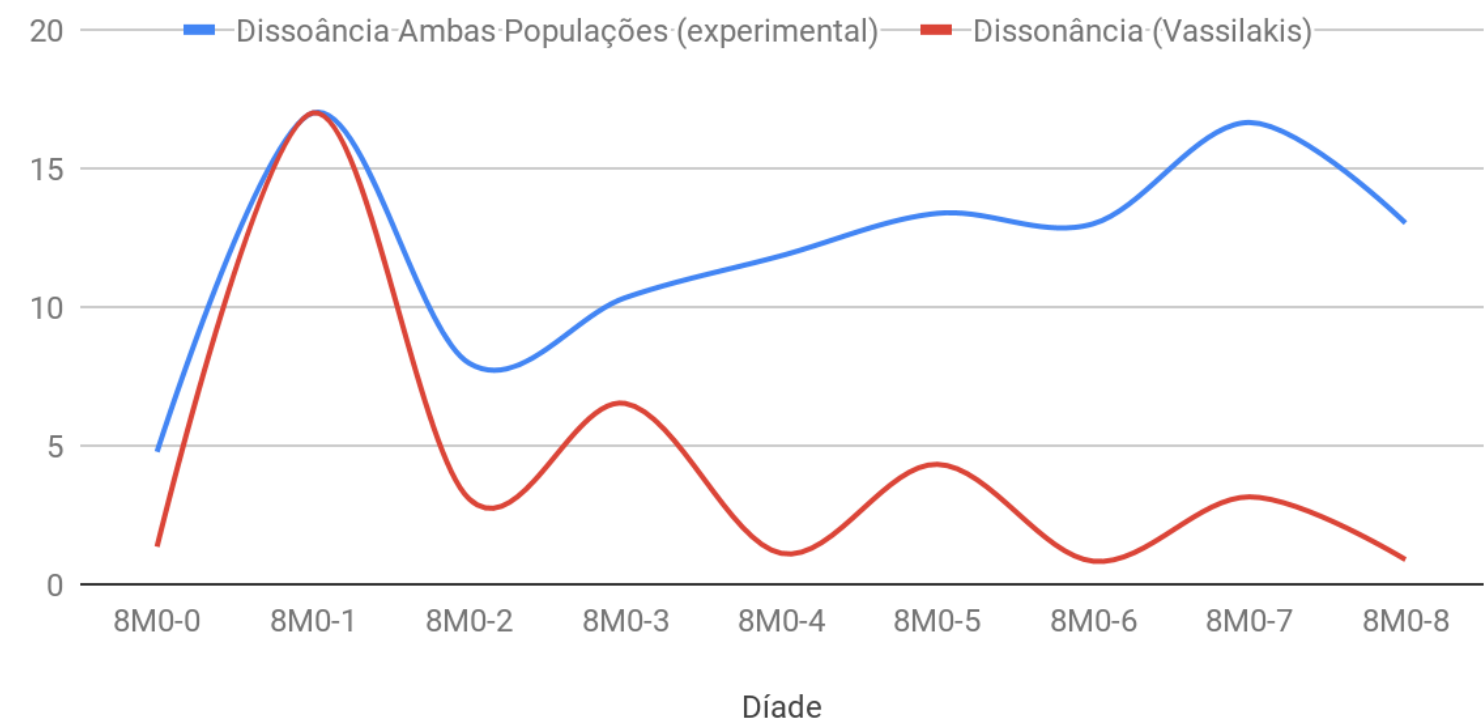

Gráfico 13- Comparação da pontuação de dissonância obtida no teste 2 para ambas as populações, curva experimental acima (em azul) versus a curva estimada segundo o modelo de Vassilakis, abaixo (em vermelho).

Ao observar estes gráficos, podemos notar que o perfil da curva experimental é sempre ascendente, se diferenciando da curva do modelo de Vassilakis. Embora isso ocorra, podemos notar que as curvas dos resultados do teste possuem em seu 
perfil alguma semelhança com a curva do modelo de Vassilakis, principalmente a da população de músicos, seguida de ambas as populações e finalmente a da população de não-músicos, que embora distante em valores, reserva alguma semelhança com o perfil da curva estimada de dissonância.

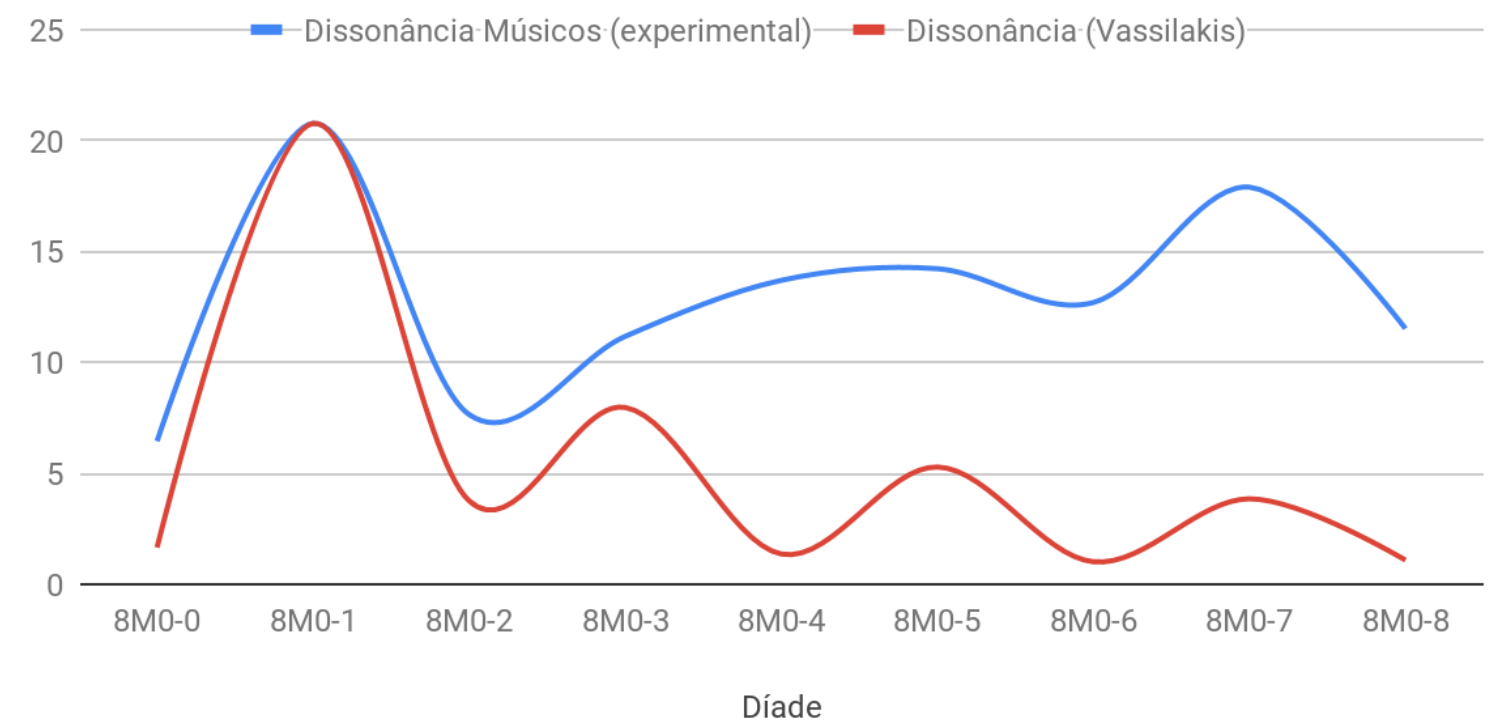

Gráfico 14- Comparação da pontuação de dissonância obtida no teste 2 para músicos, curva experimental acima (em azul) e curva estimada pelo modelo de Vassilakis, abaixo (em vermelho).
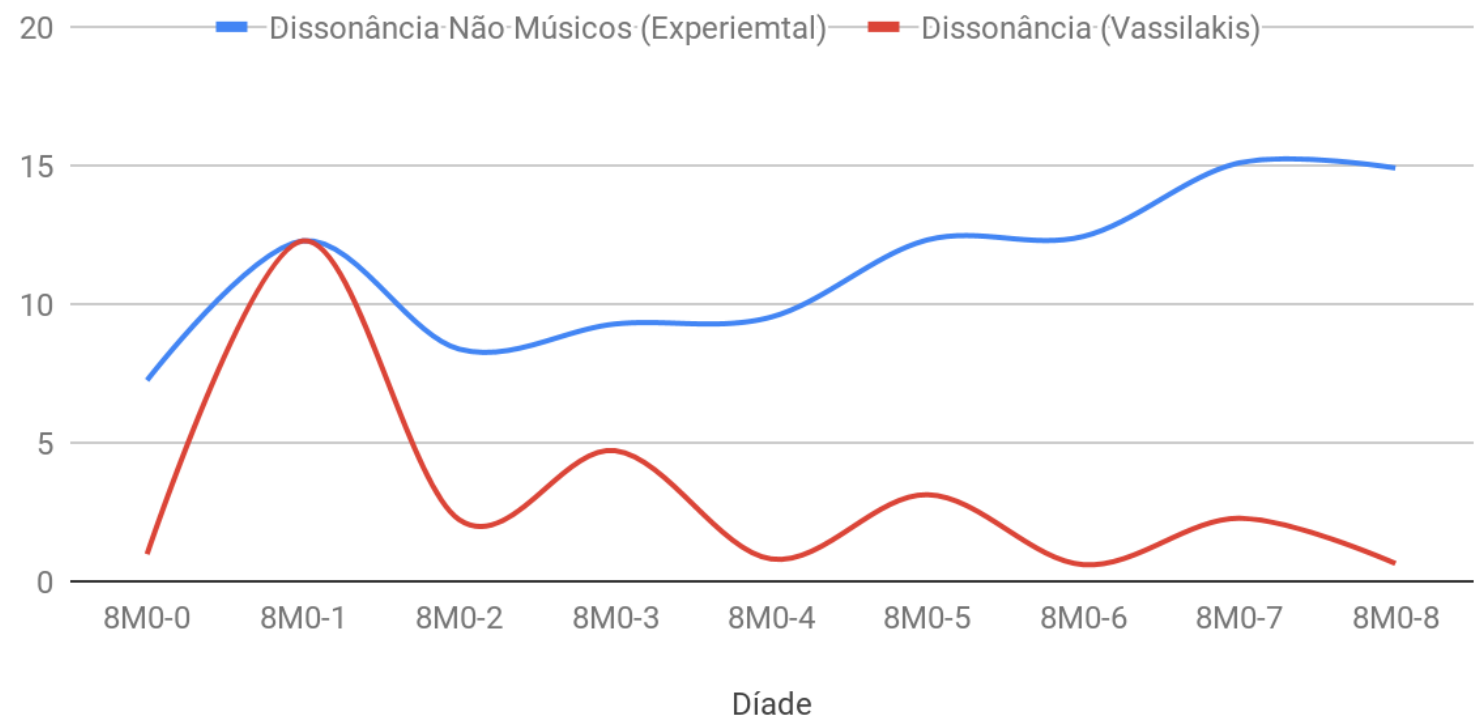

Gráfico 15- Comparação da pontuação de dissonância obtida no teste 2 para não-músicos, curva experimental acima (em azul) e curva do modelo de Vassilakis, abaixo (em vermelho).

Observando os resultados experimentais comparados aos resultados esperados pelo modelo de dissonância de Vassilakis, podemos observar que há uma 
maior correlação entre resultado esperado e resultado obtido até a díade 0-4. Para testar essa afirmação, calculamos o coeficiente de correlação entre os resultados do teste 2 e a curva de dissonância esperada, dividindo-os em 2 partes:

- Parte 1: Díades de 0-0 a 0-4

- Parte 2: Díades de 0-5 a 0-8

Com essa divisão, obtivemos os seguintes resultados:

\begin{tabular}{|l|r|l|r|}
\hline & Ambas as populações & Músicos & Não-músicos \\
\hline Correlação Parte 1: & 0,8179444972 & 0,8358642918 & 0,8874621508 \\
\hline Correlação Parte 2: & 0,4180122565 & 0,6381563364 & $-0,1864968937$ \\
\hline
\end{tabular}

Tabela 7- Correlação entre as curvas de dissonância obtida experimentalmente e a estimada pelo modelo de Vassilakis avaliadas em 2 segmentos (parte 1 e parte 2).

Da tabela 7 pode-se constatar que a correlação entre os valores de dissonância obtidos e esperados para as díades da primeira parte (de 0-0 a 0-4) apresentam uma correlação alta. Já para as díades da segunda parte, não constatamos correlação significante entre as curvas obtida e esperada.

\subsection{Ferramentas, instrumentos e práticas criativas realizadas}

Como uma contribuição significativa deste trabalho em práticas criativas, destacamos o algoritmo gerador de timbres modelados em dissonância para escalas do temperamento por igual. Esse algoritmo tem o mérito de formalizar práticas pioneiras iniciadas por Pierce e Sethares, e permite uma expansão dessa formalização para acoplar novos desdobramentos em modelagem de dissonância, bem como para ser aplicado em outros processos de síntese sonora. Esse algoritmo também se mostrou muito potente para gerar material sonoro para a prática composicional.

No âmbito das práticas composicionais, podemos notar que na composição da peça Kalimba Super Consonante explorou-se um diálogo consistente entre modelos psicoacústicos de dissonância e luteria digital, que foram os fundamentos das explorações sonoras que definiram as práticas composicionais. Os modelos psicoacústicos de dissonância foram explorados via síntese aditiva, a partir do algoritmo gerador de espectros. A luteria digital ficou a cargo do processo de construção dos timbres utilizando ferramentas digitais, e pelo mapeamento das 
escalas via teclado MIDI, que permitiu a manipulação do material sonoro para as improvisações que fazem parte do procedimento composicional. Isso permitiu a criação de uma peça musical que tem como material uma escala pouco utilizada no repertório convencional (8-tet) e em um novo contexto de escuta, onde as escolhas das sonoridades são mediadas pela psicoacústica.

Neste ambiente de diálogo entre estas ferramentas, este processo de composição se revelou capaz de gerar uma gama de diversidade sonora. Primeiramente, pela versatilidade proporcionada pelo uso de uma escala com alturas fixas. Isso permite utilizá-la, ora como melodias, o que permite a criação de linhas e contrapontos; ora como acordes, explorando suas riquezas de movimentos harmônicos proporcionados pela relação de consonância e dissonância; e por fim, a partir de sonoridades com clusters ou grandes conglomerados de alturas, que viabiliza trata-la como um objeto sonoro a ser transformado durante o processo composicional.

Além disso, explorou-se como proposta criativa na peça Asperezas a ideia de tratar a dissonância como protagonista e geradora da forma musical, tratando-a como assunto primordial da peça. Isso proporciona a possibilidade de escutar a dissonância fora do contexto tonal de tensão e resolução e fora de um contexto de música descritiva, que utiliza a dissonância para fins narrativos. Portanto, a partir da ideia de eleger fenômenos perceptivos como protagonistas da composição, temos mais uma contribuição para uma escola de composição musical que tem na percepção do som o seu discurso, como já acontece na música espectral de Gérard Grisey e na micropolifonia de György Ligeti.

\subsection{Discussões finais e trabalhos futuros}

Os resultados experimentais do presente estudo não demonstraram a eficácia ou precisão dos modelos preditivos que abordamos em estimar a dissonância em escalas temperadas 8-tet, particularmente para os timbres inarmônicos aqui explorados. Além disso, sugerem que resultados diferentes obtidos entre músicos e não-músicos sejam devido a fatores além da base fisiológica comum do aparelho auditivo, compartilhada por estas populações.

Embora acredite-se que a estimativa cumulativa da dissonância obtida a partir da somatória da dissonância calculada entre parciais seja mais complexa na medida 
em que o número de parciais aumentam bem como sua distribuição inarmônica, as discrepâncias observadas, todavia, não permitem extrair conclusões definitivas que as expliquem, embora apontem para a necessidade de novos métodos preditivos, que considerem novas variáveis e cubram as lacunas observadas nos atuais.

Partindo dos resultados obtidos nos testes, enumeramos aqui duas possíveis leituras, que podem ser exploradas em trabalhos futuros:

1. Os modelos de dissonância vistos não preveem um limiar diferencial de dissonância, isto é, uma diferença mínima perceptível de dissonância. Os modelos psicoacústicos como sensação de altura, loudness, mascaramento, entre outros, preveem um modelo de limiar, aferidos em testes subjetivos. Esse não é o caso dos modelos de dissonância abordados. Por isso, ao comparar um timbre com outro, não podemos estabelecer uma medida exata de qual será o mínimo de diferença de dissonância a ser percebida. Partindo dessa afirmação, um futuro estudo sobre dissonância pode se debruçar em testes que avaliem esses limiares.

2. Os trabalhos de dissonância aqui estudados têm lido os modelos de dissonância de maneira isolada, não dialogando com outros modelos psicoacústicos. Por exemplo, as especulações sobre sons inarmônicos não se atentam ao fenômeno chamado de Tonalness ou Tonality. Tonalness é uma medida da clareza de percepção de altura, ou seja, a ideia de que uma única altura é percebida (Porres, 2012). Zwicker and Falst (1999, p. 244) argumentam que a agradabilidade de um som é diretamente proporcional ao tonalness deste som. Este fenômeno pode ser estudado à luz do modelo de altura virtual de Terhardt (1974).

Esse fenômeno está intimamente ligado aos sons harmônicos, sons estes que foram explorados em testes experimentais de Kameoka e Kuriygawa (1969), Vassilakis (2001) e Porres (2012), e que colaboram com a afirmação de modelos de dissonância como o de Vassilakis (2001). No entanto, ao sintetizar espectros inarmônicos para minimizar a dissonância, ao mesmo tempo manipulamos o tonalness, que é um fenômeno psicoacústico que não está previsto nos modelos de dissonância propostos na literatura.

Tendo isso em perspectiva, futuros trabalhos de dissonância com sons inarmônicos podem especular sobre modelos de dissonância que sejam mais multidimensionais, dialogando de maneira mais precisa com a percepção sonora. 
É notável a diversidade em métricas e metodologias adotadas para os diversos experimentos psicoacústicos mapeados desde 1965, destacando-se pontos fortes, como a seleção de participantes com treinamento musical propiciando a confirmação de hipóteses e correlações esperadas, o que colaborou para expandir o entendimento do mecanismo funcional da dissonância; mas também destacando pontos frágeis, como a falta de padronização nos procedimentos experimentais entre os trabalhos, a aplicação de ajustes paramétricos com escalamento linear a fenômenos sensoriais, ou o número reduzido de participantes e critérios de inclusão e exclusão pouco esclarecidos. Sendo assim, futuros trabalhos dedicados à quantificação da dissonância terão de se aprofundar no estudo de metodologias para avaliação subjetivas de parâmetros psicoacústicos.

Propomos ainda caminhos para novas explorações do algoritmo gerador de espectros reduzidos em dissonância, por demonstrar-se de grande utilidade em práticas criativas e experimentais, e pela possibilidade de ser expandido para acoplar novas funcionalidades. Por exemplo, uma das limitações no algoritmo apresentado é a impossibilidade de minimizar a dissonância em graus que estejam dentro da mesma banda crítica. Por isso, prevemos para uma implementação futura a concepção de uma métrica para mapear um "nível de eficácia", que estimará o quanto a escala ntet e seus graus escolhidos contribuem efetivamente para a redução da dissonância.

Outra limitação do método que pode ser abordada em aprofundamentos futuros é o fato de a riqueza espectral estar ligada à quantidade de graus da escala n-tet escolhidos. Neste aspecto, o nível de eficácia também poderia atuar como um mecanismo de compensação onde possa haver uma escolha por uma menor redução de dissonância em detrimento de mais riqueza espectral, e vice versa. E, por fim, considera-se que o presente trabalho abra caminho para que esse algoritmo seja extrapolado em direção ao uso de técnicas de síntese além da aditiva. 


\section{Referências bibliográficas}

ASSELIN, Pierre Y. Musique et tempérament. Éditions Costallat, 1984.

ASSOCIAÇÃO BRASILEIRA DE NORMAS TÉCNICAS. NBR 13088: Teste de comparação pareada em análise sensorial dos alimentos e bebidas. Rio de Janeiro, 1994.

BAILHACHE, Patrice. Une histoire de l'acoustique musicale. CNRS, 2001.

BARBOUR, J. Murray. A geometrical approximation to the roots of numbers. American Mathematical Monthly, p. 1-9, 1957. $\overline{555,1948}$

Music and ternary continued fractions. American Mathematical Monthly, p. 545-

Tuning and Temperament a Historical Survey, Michigan State College Press, E. Lansing, 1951. 2004.

BARLOW, Clarence. Bus Journey to Parametron:(all about Çogluotobüsişletmesi). Feedback-Studio-Verl, 1980.

BLACKWOOD, Easley. Modes and Chord Progressions in Equal Tunings. Perspectives of New Music, p. 166-200, 1991

The structure of recognizable diatonic tunings. Princeton University Press, 2014.

BALZANO, Gerald J. The group-theoretic description of 12 -fold and microtonal pitch systems. Computer music journal, p. 66-84, 1980.

ERLICH, Paul. Tuning, tonality, and twenty-two-tone temperament. Xenharmonikon, v. 17, p. 12-40, 1998.

FARIA, Regis R. A. The tempered space on the design of spatial musical instruments. In: Proceedings of the $18^{\text {th }}$ International Congress on Sound \& Vibration (ICSV18), Rio de Janeiro, 2011. 8p.

FLETCHER, Harvey; MUNSON, Wilden A. Loudness, its definition, measurement and calculation. Bell Labs Technical Journal, v. 12, n. 4, p. 377-430, 1933.

FULLER, Ramon. A study of microtonal equal temperaments. Journal of Music Theory, v. 35, n. 1/2, p. 211-237, 1991.

G. R. Morrison, “88 cent equal temperament,” Xenharmonikon, v. 15 (1993).

HELMHOLTZ, Hermann LF; ELLIS, Alexander J. The sensations of tone: As a physiological basis for the theory of music. 1875.

HUTCHINSON, William; KNOPOFF, Leon. The acoustic component of Western consonance. Journal of New Music Research, v. 7, n. 1, p. 1-29, 1978.

INTERNATIONAL ORGANIZATION FOR STANDARDIZATION. ISO 5495: Sensory Analysis- Methodology: Paired Comparison Test. Genebra, 2005

INTERNATIONAL TELECOMMUNICATIONS UNION. Recommendation BS. 1116-1: Methods for the subjective assessment of small impairments in audio systems including multichannel sound systems. Genebra, 1997. 
KEISLAR, Douglas et al. Six American composers on nonstandard tunings. Perspectives of New Music, p. 176-211, 1991

KLERK, Dirk de. Equal temperament. Acta Musicologica, p. 140-150, 1979.

KRANTZ, Richard J.; DOUTHETT, Jack. A measure of the reasonableness of equal tempered musical scales. The Journal of the Acoustical Society of America, v. 95, n. 6, p. 36423650,1994

Construction and interpretation of equal-tempered scales using frequency ratios, maximally even sets, and P-cycles. The Journal of the Acoustical Society of America, v. 107 , n. 5, p. 2725-2734, 2000.

MARINS, Paulo. Beyond Basic Audio Quality: Characterizing the Perceptual Effects Introduced by Low Bit Rate Spatial Audio Codecs. 2009. Tese de Doutorado. University of Surrey.

MARSHALL, Mark T. Physical interface design for digital musical instruments. 2008. Tese de Doutorado. McGill University.

MATHEWS, Max V. et al. Theoretical and experimental explorations of the Bohlen-Pierce scale. The journal of the Acoustical Society of America, v. 84, n. 4, p. 1214-1222, 1988

MIRANDA, Eduardo Reck; WANDERLEY, Marcelo M. New digital musical instruments: control and interaction beyond the keyboard. AR Editions, Inc., 2006.

MORENO, Enrique Ignacio. Embedding Equal Pitch Spaces and the Question of Expanded Chromas: An Experimental Approach. CCRMA, Department of Music, Stanford University, 1995.

Expanded chromas and the new frontiers of tonality: An introduction. Journal of New Music Research, v. 23, n. 3, p. 235-244, 1994.

NASSAR, Antonio. A New Keyboard for the Bohlen-Pierce Scale. arXiv preprint arXiv:1111.0542, 2011.

O'MODHRAIN, Sile. A framework for the evaluation of digital musical instruments. Computer Music Journal, v. 35, n. 1, p. 28-42, 2011

PARNCUTT, Richard. Harmony: A psychoacoustical approach. Springer Science \& Business Media, 2012.

PAUL, Nasca O. ZynAddSubFX. Version 2. [S.I.: s.n.], 2005. Disponível em: <http://zynaddsubfx.sourceforge.net/>. Acesso em: 18 out. 2018.

PLOMP, Reinier; LEVELT, Willem JM. Tonal consonance and critical bandwidth. The journal of the Acoustical Society of America, v. 38, n. 4, p. 548-560, 1965.

PIERCE, John R. Attaining consonance in arbitrary scales. The Journal of the Acoustical Society of America, v. 40, n. 1, p. 249-249, 1966.

PORRES, Alexandre Torres. Modelos psicoacústicos de dissonância para eletrônica ao vivo. 2012. Tese de Doutorado. Universidade de São Paulo.

Processos de Composição Microtonal por meio do Modelo de Dissonância Sensorial. 2007. Dissertação (Mestrado) - Instituto de Artes, Universidade Estadual de Campinas, Campinas 
PORRES, Alexandre Torres; MANZOLLI, Jônatas. Sistemas de afinação: um apanhado histórico. In: Proceedings of the 2. II Seminário de Música, Ciência e Tecnologia. 2005.

PORRES, Alexandre Torres; PIRES, André Salim. Um external de aspereza para puredata \& MAX/MSP. In: Proceedings of the 12th Brazilian Symposium on Computer Music 2009. 2009.

PORRES, T. A.; MANZOLLI, J.; FURLANETE, Fábio. Análise de dissonância sensorial de espectros sonoros. In: Congresso da ANPPOM. 2006.

RAMEAU, Jean-Philippe. Traité de I'harmonie réduite à ses principes naturels.. Imp. de J.-B.-C. Ballard, 1722

RIEMANN, Hugo. Harmony simplified, or The theory of the tonal functions of chords. 1903.

SETHARES, William A. Adaptive tunings for musical scales. The Journal of the Acoustical Society of America, v. 96, n. 1, p. 10-18, 1994.

Local consonance and the relationship between timbre and scale. The Journal of the Acoustical Society of America, v. 94, n. 3, p. 1218-1228, 1993.

Tuning, timbre, spectrum, scale. Springer Science \& Business Media, 1998.

STRAUS, Joseph N. Introdução à teoria pós-tonal. Tradução Ricardo Mazzini Bordini, Editora Prentice-Hall do Brasil, Ltda., Rio de Janeiro, 2000.

SCHOENBERG, Arnold. Theory of Harmony. 1949

TENNEY, James. A history of 'consonance' and 'dissonance'. 1988.

TERHARDT, Ernst. Pitch, consonance, and harmony. The Journal of the Acoustical Society of America, v. 55, n. 5, p. 1061-1069, 1974

TRAUNMÜLLER, Hartmut. Analytical expressions for the tonotopic sensory scale. The Journal of the Acoustical Society of America, v. 88, n. 1, p. 97-100, 1990.

TYTEL, Matt. Helm. Version 0.8.6. [S.I.: s.n.], [2016?]. Disponível em: $<$ https://tytel.org/helm/>. Acesso em: 18 set. 2018.

VASSILAKIS, Panteleimon Nestor. Perceptual and physical properties of amplitude fluctuation and their musical significance. 2001. Tese de Doutorado. UNIVERSITY OF CALIFORNIA Los Angeles.

VASSILAKIS, Pantelis N.; FITZ, Kelly. SRA: Spectral and Roughness Analysis. Version 2.0. [S.I.: $\quad$ S.n.], 2007. Disponível em: <http://musicalgorithms.ewu.edu/algorithms/roughness.html>. Acesso em: 18 out. 2018.

ZUBEN, Paulo. Ouvir o som. Atelie Editorial, 2005.

ZWICKER, Eberhard. Subdivision of the audible frequency range into critical bands (Frequenzgruppen). The Journal of the Acoustical Society of America, v. 33, n. 2, p. 248248, 1961.

ZWICKER, Eberhard; FASTL, Hugo. Psychoacoustics: Facts and models. Springer Science \& Business Media, 2013

ZWICKER, E; Flottorp, G. and Stevens, S.S. Critical Band Width in Loudness Summation. Journal of Acoust. Soc. Am. 29, 548-557, 1957. 


\section{Apêndice I: Dados dos Testes Subjetivos}

Apresentamos nesse apêndice os dados obtidos e uma compilação dos resultados dos testes subjetivos realizados nessa pesquisa, com o objetivo de disponibiliza-los para consulta.

Primeiramente apresentamos os resultados do Teste 1, em porcentagens, para ambas populações (tabela 8), músicos (tabela 9) e não-músicos (tabela 10).

\begin{tabular}{|l|l|l|l|}
\hline \multicolumn{5}{|c|}{ Ambas Populações - Teste 1 } \\
\hline AXB & $\begin{array}{l}\text { Espectro M (\% de } \\
\text { votos) }\end{array}$ & $\begin{array}{l}\text { Espectro R (\% de } \\
\text { votos) }\end{array}$ & $\begin{array}{l}\text { Não Sei (\% de } \\
\text { votos) }\end{array}$ \\
\hline 8M0-0/8R0-0 & 22,22222222 & 61,11111111 & 16,66666667 \\
\hline 8M0-1/8R0-1 & 61,11111111 & 22,22222222 & 16,66666667 \\
\hline 8M0-2/8R0-2 & 42,59259259 & 42,59259259 & 14,81481481 \\
\hline 8M0-3/8R0-3 & 38,88888889 & 39,81481481 & 21,2962963 \\
\hline 8M0-4/8R0-4 & 37,03703704 & 47,22222222 & 15,74074074 \\
\hline 8M0-5/8R0-5 & 61,11111111 & 23,14814815 & 15,74074074 \\
\hline 8M0-6/8R0-6 & 57,40740741 & 25,92592593 & 16,66666667 \\
\hline 8M0-7/8R0-7 & 66,66666667 & 18,51851852 & 14,81481481 \\
\hline 8M0-8/8R0-8 & 44,44444444 & 31,48148148 & 24,07407407 \\
\hline
\end{tabular}

Tabela 8- Resutados, em porcentagens, para o teste 1, para ambas populações.

\begin{tabular}{|l|l|l|l|}
\hline \multicolumn{5}{|c|}{ Músicos - Teste 1 } \\
\hline AXB & $\begin{array}{l}\text { Espectro M (\% de } \\
\text { votos) }\end{array}$ & $\begin{array}{l}\text { Espectro R (\% de } \\
\text { votos) }\end{array}$ & $\begin{array}{l}\text { Não Sei (\% de } \\
\text { votos) }\end{array}$ \\
\hline 8M0-0/8R0-0 & 17,46031746 & 60,31746032 & 22,22222222 \\
\hline 8M0-1/8R0-1 & 63,49206349 & 14,28571429 & 22,22222222 \\
\hline 8M0-2/8R0-2 & 19,04761905 & 61,9047619 & 19,04761905 \\
\hline 8M0-3/8R0-3 & 39,68253968 & 44,44444444 & 15,87301587 \\
\hline 8M0-4/8R0-4 & 26,98412698 & 57,14285714 & 15,87301587 \\
\hline 8M0-5/8R0-5 & 55,55555556 & 26,98412698 & 17,46031746 \\
\hline
\end{tabular}




\begin{tabular}{|l|l|l|l|}
\hline 8M0-6/8R0-6 & 47,61904762 & 31,74603175 & 20,63492063 \\
\hline 8M0-7/8R0-7 & 71,42857143 & 15,87301587 & 12,6984127 \\
\hline 8M0-8/8R0-8 & 47,61904762 & 28,57142857 & 23,80952381 \\
\hline
\end{tabular}

Tabela 9- Resutados, em porcentagens, para o teste 1, para músicos.

\begin{tabular}{|l|l|l|l|}
\hline \multicolumn{4}{|c|}{ Não-músicos - Teste 1 } \\
\hline AXB & $\begin{array}{l}\text { Espectro M (\% de } \\
\text { votos) }\end{array}$ & $\begin{array}{l}\text { Espectro R (\% de } \\
\text { votos) }\end{array}$ & $\begin{array}{l}\text { Não Sei (\% de } \\
\text { votos) }\end{array}$ \\
\hline 8M0-0/8R0-0 & 28,88888889 & 62,22222222 & 8,888888889 \\
\hline 8M0-1/8R0-1 & 57,77777778 & 33,33333333 & 8,888888889 \\
\hline 8M0-2/8R0-2 & 75,55555556 & 15,55555556 & 8,888888889 \\
\hline 8M0-3/8R0-3 & 37,77777778 & 33,33333333 & 28,88888889 \\
\hline 8M0-4/8R0-4 & 51,11111111 & 33,33333333 & 15,55555556 \\
\hline 8M0-5/8R0-5 & 68,88888889 & 17,77777778 & 13,33333333 \\
\hline 8M0-6/8R0-6 & 71,11111111 & 17,77777778 & 11,11111111 \\
\hline 8M0-7/8R0-7 & 60 & 22,22222222 & 17,77777778 \\
\hline 8M0-8/8R0-8 & 40 & 35,55555556 & 24,44444444 \\
\hline
\end{tabular}

Tabela 10- Resutados, em porcentagens, para o teste 1, para não-músicos.

Abaixo, exibimos os resultados do Teste 2, em porcentagens, para ambas populações (tabela 11), músicos (tabela 12) e não-músicos (tabela 13).

\begin{tabular}{|l|l|l|l|}
\hline \multicolumn{4}{|c|}{ Ambas Populações - Teste 2 } \\
\hline AXB & $\begin{array}{l}\text { Som A (\% de } \\
\text { votos) }\end{array}$ & $\begin{array}{l}\text { Som B (\% de } \\
\text { votos) }\end{array}$ & $\begin{array}{l}\text { Não Sei (\% de } \\
\text { votos) }\end{array}$ \\
\hline 8M0-0X8M0-1 & 15,74074074 & 83,33333333 & 0,925925926 \\
\hline 8M0-2X8M0-0 & 66,66666667 & 15,74074074 & 17,59259259 \\
\hline 8M0-0X8M0-3 & 15,74074074 & 69,44444444 & 14,81481481 \\
\hline 8M0-4X8M0-0 & 70,37037037 & 18,51851852 & 11,11111111 \\
\hline 8M0-0X8M0-5 & 13,88888889 & 73,14814815 & 12,96296296 \\
\hline 8M0-6X8M0-0 & 77,77777778 & 12,03703704 & 10,18518519 \\
\hline
\end{tabular}




\begin{tabular}{|c|c|c|c|}
\hline 8M0-0X8M0-7 & 7,407407407 & 87,03703704 & 5,555555556 \\
\hline 8M0-8X8M0-0 & 69,44444444 & 16,66666667 & 13,88888889 \\
\hline $8 \mathrm{MO}-1 \mathrm{X} 8 \mathrm{MO}-2$ & 77,77777778 & 12,96296296 & 9,259259259 \\
\hline $8 \mathrm{M0} 0-3 \times 8 \mathrm{MO}-1$ & 20,37037037 & 75 & 4,62962963 \\
\hline $8 \mathrm{MO}-1 \mathrm{X} 8 \mathrm{MO}-4$ & 54,62962963 & 35,18518519 & 10,18518519 \\
\hline $8 \mathrm{M0}-5 \times 8 \mathrm{MO}-1$ & 23,14814815 & 73,14814815 & 3,703703704 \\
\hline $8 \mathrm{M0-1X8M0-6}$ & 61,11111111 & 34,25925926 & 4,62962963 \\
\hline $8 \mathrm{MO}-7 \mathrm{X} 8 \mathrm{M0-1}$ & 36,11111111 & 58,33333333 & 5,555555556 \\
\hline $8 \mathrm{M0-1X8M0-8}$ & 60,18518519 & 32,40740741 & 7,407407407 \\
\hline $8 \mathrm{MO}-2 \times 8 \mathrm{MO}-3$ & 25,92592593 & 55,55555556 & 18,51851852 \\
\hline $8 \mathrm{MO-4X8M0-2}$ & 63,88888889 & 23,14814815 & 12,96296296 \\
\hline $8 \mathrm{MO}-2 \times 8 \mathrm{MO}-5$ & 15,74074074 & 68,51851852 & 15,74074074 \\
\hline 8M0-6X8M0-2 & 59,25925926 & 25 & 15,74074074 \\
\hline $8 \mathrm{MO} 0-2 \times 8 \mathrm{MO}-7$ & 16,66666667 & 73,14814815 & 10,18518519 \\
\hline $8 \mathrm{M0-8X8M0-2}$ & 62,96296296 & 22,22222222 & 14,81481481 \\
\hline $8 \mathrm{MO}-3 \times 8 \mathrm{MO}-4$ & 25,92592593 & 57,40740741 & 16,66666667 \\
\hline $8 \mathrm{M0-5X8M0-3}$ & 49,07407407 & 32,40740741 & 18,51851852 \\
\hline $8 \mathrm{MO}-3 \times 8 \mathrm{MO}-6$ & 27,77777778 & 61,11111111 & 11,11111111 \\
\hline 8M0-7X8M0-3 & 64,81481481 & 22,22222222 & 12,96296296 \\
\hline $8 \mathrm{M0}-3 \times 8 \mathrm{M0}-8$ & 39,81481481 & 50 & 10,18518519 \\
\hline $8 \mathrm{M0-4X8M0-5}$ & 22,22222222 & 66,66666667 & 11,11111111 \\
\hline 8M0-6X8M0-4 & 47,22222222 & 37,96296296 & 14,81481481 \\
\hline $8 \mathrm{MO}-4 \mathrm{X} 8 \mathrm{MO}-7$ & 15,74074074 & 76,85185185 & 7,407407407 \\
\hline $8 \mathrm{M0} 0-8 \times 8 \mathrm{M0}-4$ & 47,22222222 & 42,59259259 & 10,18518519 \\
\hline 8M0-5X8M0-6 & 33,33333333 & 49,07407407 & 17,59259259 \\
\hline 8M0-7X8M0-5 & 48,14814815 & 29,62962963 & 22,22222222 \\
\hline 8M0-5X8M0-8 & 45,37037037 & 42,59259259 & 12,03703704 \\
\hline 8M0-6Х8M0-7 & 15,74074074 & 75 & 9,259259259 \\
\hline 8M0-8X8M0-6 & 47,22222222 & 41,66666667 & 11,11111111 \\
\hline
\end{tabular}




\begin{tabular}{|l|l|l|l|}
\hline 8M0-7X8M0-8 & 51,85185185 & 37,03703704 & 11,11111111 \\
\hline
\end{tabular}

Tabela 11- Resultados, em porcentagens, para o teste 2, para ambas populações.

\begin{tabular}{|c|c|c|c|}
\hline \multicolumn{4}{|c|}{ Músicos - Teste 2} \\
\hline AXB & Som A (\%) & Som B (\%) & Não Sei (\%) \\
\hline 8M0-0X8M0-1 & 0 & 100 & 0 \\
\hline $8 \mathrm{MO}-2 \times 8 \mathrm{M0}-0$ & 68,25396825 & 6,349206349 & 25,3968254 \\
\hline 8M0-0X8M0-3 & 9,523809524 & 73,01587302 & 17,46031746 \\
\hline $8 \mathrm{MO}-4 X 8 \mathrm{M0}-0$ & 76,19047619 & 9,523809524 & 14,28571429 \\
\hline 8M0-0X8M0-5 & 9,523809524 & 74,6031746 & 15,87301587 \\
\hline 8M0-6X8M0-0 & 80,95238095 & 4,761904762 & 14,28571429 \\
\hline 8M0-0X8M0-7 & 0 & 90,47619048 & 9,523809524 \\
\hline 8M0-8X8M0-0 & 74,6031746 & 7,936507937 & 17,46031746 \\
\hline $8 \mathrm{MO}-1 \mathrm{X} 8 \mathrm{M0}-2$ & 85,71428571 & 6,349206349 & 7,936507937 \\
\hline $8 \mathrm{MO}-3 \times 8 \mathrm{M0}-1$ & 7,936507937 & 87,3015873 & 4,761904762 \\
\hline $8 \mathrm{M0}-1 \mathrm{XMM}-4$ & 60,31746032 & 33,33333333 & 6,349206349 \\
\hline $8 \mathrm{M0-5X8M0-1}$ & 11,11111111 & 84,12698413 & 4,761904762 \\
\hline $8 \mathrm{MO} 0-1 \mathrm{XMM0-6}$ & 74,6031746 & 19,04761905 & 6,349206349 \\
\hline 8M0-7X8M0-1 & 23,80952381 & 69,84126984 & 6,349206349 \\
\hline $8 \mathrm{M0-1X8M0-8}$ & 74,6031746 & 15,87301587 & 9,523809524 \\
\hline $8 \mathrm{MO-2X8M0-3}$ & 19,04761905 & 61,9047619 & 19,04761905 \\
\hline $8 \mathrm{MO}-4 X 8 \mathrm{M0-2}$ & 66,66666667 & 15,87301587 & 17,46031746 \\
\hline $8 \mathrm{MO}-2 \times 8 \mathrm{M0}-5$ & 11,11111111 & 69,84126984 & 19,04761905 \\
\hline $8 \mathrm{M0-6X8M0-2}$ & 61,9047619 & 15,87301587 & 22,22222222 \\
\hline $8 \mathrm{M0-2X8M0-7}$ & 9,523809524 & 76,19047619 & 14,28571429 \\
\hline 8M0-8X8M0-2 & 55,55555556 & 23,80952381 & 20,63492063 \\
\hline $8 \mathrm{MO}-3 \times 8 \mathrm{MO}-4$ & 22,22222222 & 61,9047619 & 15,87301587 \\
\hline 8M0-5X8M0-3 & 42,85714286 & 34,92063492 & 22,22222222 \\
\hline $8 \mathrm{M} 0-3 \times 8 \mathrm{M0-6}$ & 25,3968254 & 58,73015873 & 15,87301587 \\
\hline
\end{tabular}




\begin{tabular}{|l|l|l|l|}
\hline 8M0-7X8M0-3 & 61,9047619 & 20,63492063 & 17,46031746 \\
\hline 8M0-3X8M0-8 & 46,03174603 & 39,68253968 & 14,28571429 \\
\hline 8M0-4X8M0-5 & 26,98412698 & 63,49206349 & 9,523809524 \\
\hline 8M0-6X8M0-4 & 41,26984127 & 42,85714286 & 15,87301587 \\
\hline 8M0-4X8M0-7 & 12,6984127 & 77,77777778 & 9,523809524 \\
\hline 8M0-8X8M0-4 & 25,3968254 & 57,14285714 & 17,46031746 \\
\hline 8M0-5X8M0-6 & 39,68253968 & 41,26984127 & 19,04761905 \\
\hline 8M0-7X8M0-5 & 41,26984127 & 30,15873016 & 28,57142857 \\
\hline 8M0-5X8M0-8 & 50,79365079 & 30,15873016 & 19,04761905 \\
\hline 8M0-6X8M0-7 & 11,11111111 & 82,53968254 & 6,349206349 \\
\hline 8M0-8X8M0-6 & 36,50793651 & 49,20634921 & 14,28571429 \\
\hline 8M0-7X8M0-8 & 61,9047619 & 25,3968254 & 12,6984127 \\
\hline
\end{tabular}

Tabela 12- Resutados, em porcentagens, para o teste 2 , para músicos.

\begin{tabular}{|l|l|l|l|}
\hline \multicolumn{5}{|c|}{ Não-músicos - Teste 2 } \\
\hline AXB & Som A (\%) & Som B (\%) & Não Sei (\%) \\
\hline 8M0-0X8M0-1 & 37,77777778 & 60 & 2,222222222 \\
\hline 8M0-2X8M0-0 & 64,44444444 & 28,88888889 & 6,666666667 \\
\hline 8M0-0X8M0-3 & 24,44444444 & 64,44444444 & 11,11111111 \\
\hline 8M0-4X8M0-0 & 62,22222222 & 31,11111111 & 6,666666667 \\
\hline 8M0-0X8M0-5 & 20 & 71,11111111 & 8,888888889 \\
\hline 8M0-6X8M0-0 & 73,33333333 & 22,22222222 & 4,444444444 \\
\hline 8M0-0X8M0-7 & 17,77777778 & 82,22222222 & 0 \\
\hline 8M0-8X8M0-0 & 62,22222222 & 28,88888889 & 8,888888889 \\
\hline 8M0-1X8M0-2 & 66,66666667 & 22,22222222 & 11,11111111 \\
\hline 8M0-3X8M0-1 & 37,77777778 & 57,77777778 & 4,444444444 \\
\hline 8M0-1X8M0-4 & 46,66666667 & 37,77777778 & 15,55555556 \\
\hline 8M0-5X8M0-1 & 40 & 57,77777778 & 2,222222222 \\
\hline 8M0-1X8M0-6 & 42,22222222 & 55,55555556 & 2,222222222 \\
\hline
\end{tabular}




\begin{tabular}{|c|c|c|c|}
\hline $8 \mathrm{M0-7X8M0-1}$ & 53,33333333 & 42,22222222 & 4,444444444 \\
\hline $8 \mathrm{M0-1X8M0-8}$ & 40 & 55,55555556 & 4,444444444 \\
\hline $8 \mathrm{MO} 0-2 \times 8 \mathrm{MO}-3$ & 35,55555556 & 46,66666667 & 17,77777778 \\
\hline $8 \mathrm{M0-4X8M0-2}$ & 60 & 33,33333333 & 6,666666667 \\
\hline 8M0-2X8M0-5 & 22,22222222 & 66,66666667 & 11,11111111 \\
\hline 8M0-6X8M0-2 & 55,55555556 & 37,77777778 & 6,666666667 \\
\hline 8M0-2Х8M0-7 & 26,66666667 & 68,88888889 & 4,444444444 \\
\hline 8M0-8X8M0-2 & 73,33333333 & 20 & 6,666666667 \\
\hline $8 \mathrm{MO}-3 \times 8 \mathrm{MO}-4$ & 31,11111111 & 51,11111111 & 17,77777778 \\
\hline $8 \mathrm{MO}-5 \times 8 \mathrm{MO}-3$ & 57,77777778 & 28,88888889 & 13,33333333 \\
\hline 8M0-3X8M0-6 & 31,11111111 & 64,44444444 & 4,444444444 \\
\hline 8M0-7X8M0-3 & 68,88888889 & 24,44444444 & 6,666666667 \\
\hline 8M0-3X8M0-8 & 31,11111111 & 64,44444444 & 4,444444444 \\
\hline 8M0-4X8M0-5 & 15,55555556 & 71,11111111 & 13,33333333 \\
\hline 8M0-6X8M0-4 & 55,55555556 & 31,11111111 & 13,33333333 \\
\hline 8M0-4X8M0-7 & 20 & 75,55555556 & 4,444444444 \\
\hline
\end{tabular}

Tabela 13- Resutados, em porcentagens, para o teste 2, para não-músicos.

A seguir, revelamos as pontuações (scores) do Teste 2, em porcentagens, para ambas populações (tabela 14), músicos (tabela 15) e não-músicos (tabela 16).

\begin{tabular}{|l|l|}
\hline \multicolumn{2}{|c|}{ Pontuação (Score) Ambas Populações } \\
\hline Díade & Score \\
\hline $8 \mathrm{M0}-0$ & 172 \\
\hline $8 \mathrm{M0}-1$ & 612 \\
\hline $8 \mathrm{M0}-2$ & 287 \\
\hline $8 \mathrm{M0}-3$ & 372 \\
\hline $8 \mathrm{M0}-4$ & 426,5 \\
\hline $8 \mathrm{M0}-5$ & 481,5 \\
\hline $8 \mathrm{M0}-6$ & 468 \\
\hline
\end{tabular}




\begin{tabular}{|l|l|}
\hline 8M0-7 & 599,5 \\
\hline 8M0-8 & 469 \\
\hline
\end{tabular}

Tabela 14- Pontuação (Scores) de dissonância do Teste 2 para ambas populações.

\begin{tabular}{|l|l|}
\hline \multicolumn{2}{|c|}{ Pontuação (Score) Músicos } \\
\hline Som & Score \\
\hline $8 \mathrm{M0}-0$ & 129 \\
\hline $8 \mathrm{M0}-1$ & 415,5 \\
\hline $8 \mathrm{M0}-2$ & 153 \\
\hline $8 \mathrm{M0}-3$ & 223,5 \\
\hline $8 \mathrm{M0}-4$ & 274 \\
\hline $8 \mathrm{M0}-5$ & 284,5 \\
\hline $8 \mathrm{M0}-6$ & 254 \\
\hline $8 \mathrm{M0}-7$ & 358 \\
\hline $8 \mathrm{M} 0-8$ & 230,5 \\
\hline
\end{tabular}

Tabela 15- Pontuação (Scores) de dissonância do Teste 2 para população músicos.

\begin{tabular}{|c|c|}
\hline \multicolumn{2}{|c|}{ Pontuação (Score) Não-músicos } \\
\hline Som & Score \\
\hline $8 \mathrm{MO}-0$ & 116 \\
\hline $8 \mathrm{MO}-1$ & 196,5 \\
\hline $8 \mathrm{MO}-2$ & 134 \\
\hline $8 \mathrm{MO}-3$ & 148,5 \\
\hline $8 \mathrm{MO}-4$ & 152,5 \\
\hline $8 \mathrm{MO}-5$ & 197 \\
\hline $8 \mathrm{M0}-6$ & 199 \\
\hline $8 \mathrm{MO}-7$ & 241,5 \\
\hline $8 \mathrm{MO}-8$ & 238,5 \\
\hline
\end{tabular}

Tabela 16- Pontuação (Scores) de dissonância do Teste 2 para população não-músicos. 
Por fim, exibimos na tabela 17 as médias de pontuações comparadas para ambas populações, músicos e não-músicos.

\begin{tabular}{|l|l|l|l|}
\hline \multicolumn{5}{|c|}{ Média dos Scores } \\
\hline Som & Ambas Populações & Músicos & Não-músicos \\
\hline $\mathbf{8 M 0 - 0}$ & 4,777777778 & 6,45 & 7,25 \\
\hline $\mathbf{8 M 0 - 1}$ & 17 & 20,775 & 12,28125 \\
\hline $\mathbf{8 M 0 - 2}$ & 7,972222222 & 7,65 & 8,375 \\
\hline $\mathbf{8 M 0 - 3}$ & 10,33333333 & 11,175 & 9,28125 \\
\hline $\mathbf{8 M 0 - 4}$ & 11,84722222 & 13,7 & 9,53125 \\
\hline $\mathbf{8 M 0 - 5}$ & 13,375 & 14,225 & 12,3125 \\
\hline $\mathbf{8 M 0} 0-6$ & 13 & 12,7 & 12,4375 \\
\hline $\mathbf{8 M 0 - 7}$ & 16,65277778 & 17,9 & 15,09375 \\
\hline $\mathbf{8 M 0} 0-8$ & 13,02777778 & 11,525 & 14,90625 \\
\hline
\end{tabular}

Tabela 17- Médias das pontuações (scores) para ambas populações, músicos e não-músicos. 